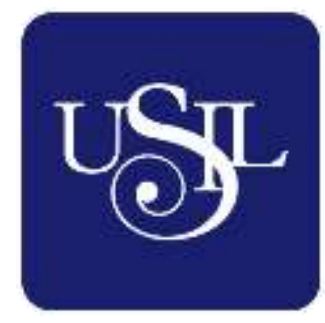

UNIVERSIDAD

SAN IGNACIO

DE LOYOLA

ESCUELA DE POSTGRADO

Maestría en Educación con Mención en Gestión de la Educación

\title{
ESTRATEGIA DIDÁCTICA PARA MEJORAR EL ESTILO DE APRENDIZAJE EN ESTUDIANTES DE LA CARRERA DE COSMÉTICA DERMATOLÓGICA EN UN INSTITUTO PUBLICO DE LIMA
}

Tesis para optar el grado de Maestro en Educación con Mención en Gestión de la Educación

\section{NALDA LLACTAHUAMAN CHAVELON}

Asesor:

Hernán Gerardo Flores Valdiviezo

Lima - Perú

2021 


\section{Dedicatoria}

A mis padres por su apoyo y comprensión, a mi hijo Wilfredo Junior por su compañía en todo este año de preparación de estudios 


\section{Agradecimiento}

A mis maestros de la universidad, por su motivación constante para concluir los estudios y la tesis de manera muy especial a mi asesor Mg Hernán Flores Valdiviezo por su apoyo constante, sus enseñanzas y paciencia para concluir y sustentar mi tesis. 


\section{Índice}

Dedicatoria

Agradecimiento

Indicé de tablas

Índice de figuras

Resumen

Abstract

Introducción 1

$\begin{array}{ll}\text { Planteamiento del problema } & 1\end{array}$

Formulación del problema 2

Problema científico 2

Preguntas científicas específicas

Objetivos de la investigación 3

Objetivo general 3

Objetivos específicos o tareas científicas 3

Categorías y subcategorías $\quad 4$

Categoría apriorística y subcategorías de investigación 4

Población, muestra, muestreo y unidad de análisis $\quad 6$

$\begin{array}{ll}\text { Población } & 6\end{array}$

$\begin{array}{ll}\text { Muestra } & 7\end{array}$

$\begin{array}{ll}\text { Muestreo } & 7\end{array}$

$\begin{array}{ll}\text { Unidad de análisis } & 7\end{array}$

$\begin{array}{ll}\text { Justificación de la investigación } & 7\end{array}$

$\begin{array}{lr}\text { Justificación teórica } & 8\end{array}$

Justificación práctica 
Histórico - lógico

Análisis - síntesis

Inductivo - deductivo

Modelación

Técnicas e instrumentos 12

$\begin{array}{ll}\text { Observación a clases } & 13\end{array}$

$\begin{array}{ll}\text { Encuesta } & 13\end{array}$

$\begin{array}{ll}\text { Entrevista } & 13\end{array}$

$\begin{array}{ll}\text { Criterio de expertos } & 14\end{array}$

Métodos estadísticos matemáticos 14

$\begin{array}{ll}\text { Perspectiva del investigador en el análisis de los datos } & 14\end{array}$

$\begin{array}{ll}\text { Fundamentación teórica } & 15\end{array}$

$\begin{array}{ll}\text { Capítulo I - Marco Teórico } & 15\end{array}$

$\begin{array}{ll}\text { Fundamentación teórica de la investigación } & 15\end{array}$

$\begin{array}{ll}\text { Antecedentes de la investigación } & 15\end{array}$

$\begin{array}{ll}\text { Antecedentes internacionales } & 15\end{array}$

$\begin{array}{ll}\text { Antecedentes nacionales } & 17\end{array}$

$\begin{array}{ll}\text { Fundamentos teóricos } & 20\end{array}$

Bases teóricas y conceptuales sobre estilos de aprendizaje 20

$\begin{array}{ll}\text { Aprendizaje } & 21\end{array}$ 
Estilos de aprendizaje

Estilo de aprendizaje convergente 28

$\begin{array}{ll}\text { Estilo de aprendizaje divergente } & 29\end{array}$

Estilos de aprendizaje asimilador 31

Estilo de aprendizaje acomodador 32

$\begin{array}{ll}\text { Estrategias } & 34\end{array}$

$\begin{array}{ll}\text { Estrategias didácticas } & 35\end{array}$

$\begin{array}{ll}\text { Secuencia didáctica } & 36\end{array}$

Creación de espacio para favorecer la atención de los estudiantes $\quad 40$

Espacios académicos para generar la personalización de la información 41

Espacio pedagógico para alcanzar la adquisición de la información $\quad 42$

Construcción lógica del conocimiento 44

Diagnóstico o trabajo de campo 45

Capítulo II - Diagnóstico o trabajo de campo 45

Análisis e interpretación de los hallazgos por técnicas e instrumentos 45

$\begin{array}{ll}\text { Validación de instrumentos } & 46\end{array}$

Presentación de resultados por técnicas e instrumentos de investigación 47

$\begin{array}{ll}\text { Cuestionario realizado a los estudiantes } & 47\end{array}$

$\begin{array}{ll}\text { Conclusión } & 54\end{array}$

$\begin{array}{ll}\text { Entrevista semi estructurada a docentes } & 54\end{array}$

$\begin{array}{ll}\text { Observación a docentes } & 56\end{array}$

Análisis e interpretación de categorías emergentes y apriorísticas $\quad 58$

Creación de espacios para favorecer la atención de los estudiantes $\quad 61$

Espacios académicos para motivar la personalización de la información 62

Espacio pedagógico para alcanzar la adquisición de la información 63 
Construcción lógica del conocimiento $\quad 64$

$\begin{array}{ll}\text { Estilo de aprendizaje divergente } & 65\end{array}$

Estilo de aprendizaje acomodador $\quad 66$

$\begin{array}{ll}\text { Estilo de aprendizaje convergente } & 67\end{array}$

$\begin{array}{ll}\text { Estilo de aprendizaje asimilador } & 68\end{array}$

$\begin{array}{ll}\text { Gestión e implementación pedagógica } & 70\end{array}$

$\begin{array}{ll}\text { Seguimiento y evaluación docente } & 71\end{array}$

$\begin{array}{ll}\text { Conclusiones del estudio de campo } & 73\end{array}$

Capítulo III - Modelación de la propuesta $\quad 77$

$\begin{array}{ll}\text { Propósito de la propuesta } & 77\end{array}$

$\begin{array}{ll}\text { Fundamentos científicos } & 77\end{array}$

$\begin{array}{ll}\text { Fundamentos socioeducativos } & 77\end{array}$

$\begin{array}{ll}\text { Fundamentos psicológicos } & 78\end{array}$

$\begin{array}{ll}\text { Fundamentos neuroeducacionales } & 79\end{array}$

$\begin{array}{ll}\text { Fundamentos pedagógicos } & 81\end{array}$

$\begin{array}{ll}\text { Fundamentos curriculares } & 82\end{array}$

$\begin{array}{lc}\text { Diseño de la propuesta } & 83\end{array}$

$\begin{array}{ll}\text { Desarrollo de la propuesta } & 85\end{array}$

$\begin{array}{ll}\text { Fases y actividades de la propuesta } & 85\end{array}$

Fases de apertura $\quad 86$

$\begin{array}{ll}\text { Acciones a realizar } & 86\end{array}$

$\begin{array}{ll}\text { Fases de desarrollo } & 87\end{array}$

Taller 01: Proyecto formativo estratégico institucional 89

Taller 02: Estrategia didáctica a través del trabajo colaborativo y el

Estilo de aprendizaje $\quad 91$

Taller 03: Evaluación constructivista considerando el estilo de 
$\begin{array}{ll}\text { Fase de resultados } & 96\end{array}$

$\begin{array}{ll}\text { Validación de la propuesta } & 98\end{array}$

$\begin{array}{ll}\text { Conclusiones } & 104\end{array}$

$\begin{array}{ll}\text { Recomendaciones } & 106\end{array}$

$\begin{array}{ll}\text { Referencias } & 107\end{array}$

\section{ANEXOS}

Anexo 1: Matriz de categorización

Anexo 2: Entrevista abierta semi estructurada a los docentes

Anexo 3: Cuestionario a los docentes

Anexo 4: Guía de observación de clases

Anexo 5: Validación por juicio de expertos de instrumentos de recojo de información Anexo 6: Validación de la propuesta. 


\section{Índice de tablas}

Tabla 1 Categorías y subcategorías apriorísticas $\quad 4$

Tabla 2 Descripción de categorías y sub categorías apriorísticas 5

Tabla 3 Expertos seleccionados para validar los instrumentos $\quad 46$

Tabla 4 Fase I Apertura $\quad 86$

Tabla 5 Fase II de desarrollo $\quad 88$

Tabla 6 Taller: Proyecto formativo estratégico institucional 90

Tabla 7 Taller: Estrategia didáctica tomando en cuenta el estilo de aprendizaje $\quad 92$

a través del trabajo colaborativo

$\begin{array}{llllll}\text { Tabla } 8 & \text { Taller: Seguimiento y tipos de evaluación constructivista } & 94\end{array}$ considerando el estilo de aprendizaje

$\begin{array}{ll}\text { Tabla } 9 \text { Fase III De resultados } & 97\end{array}$

Tabla 10 Expertos seleccionados para validar los instrumentos $\quad 98$

$\begin{array}{ll}\text { Tabla } 11 \text { Tabla de valoración } & 99\end{array}$

Tabla 12 Criterios de evaluación interna de la propuesta 99

$\begin{array}{ll}\text { Tabla } 13 \text { Valoracion interna por criterios de expertos } & 100\end{array}$

Tabla 14 Criterios de validacion externa de la propuesta $\quad 101$

$\begin{array}{ll}\text { Tabla } 15 \text { Valoracion externa por criterios de expertos } & 102\end{array}$

Tabla 16 Expertos seleccionados para validar los instrumentos 102

$\begin{array}{ll}\text { Tabla } 17 \text { Escala de valoración } & 102\end{array}$

$\begin{array}{ll}\text { Tabla } 18 \text { Resultado de valoración interna y externa } & 103\end{array}$ 


\section{Índice de figuras}

Figura 1 Ciclo del aprendizaje según David Kolb 27

Figura 2 La estrategia didáctica, su clasificación 36

$\begin{array}{ll}\text { Figura } 3 \text { Secuencia didactica } & 38\end{array}$

Figura 4 Resultados del diagnóstico de campo $\quad 59$

$\begin{array}{ll}\text { Figura 5 Categorías sustantivas } & 60\end{array}$

Figura 6 Creación de espacios para favorecer la atención de los alumnos $\quad 61$

Figura 7 Espacios académicos para motivar la personalización de la información $\quad 62$

Figura 8 Espacios pedagogicos en la sesion de clases para alcanzar la adquisicion $\quad 63$ de la informacion

Figura 9 Construcción lógica del conocimiento 65

Figura 10 Estilo de aprendizaje divergente $\quad 66$

$\begin{array}{ll}\text { Figura } 11 \text { Estilo de aprendizaje acomodador } & 67\end{array}$

$\begin{array}{lr}\text { Figura } 12 \text { Estilo de aprendizaje convergente } & 68\end{array}$

$\begin{array}{lr}\text { Figura } 13 \text { Estilo de aprendizaje asimilador } & 69\end{array}$

Figura 14 Gestión e implementación pedagógica $\quad 71$

$\begin{array}{ll}\text { Figura } 15 \text { Seguimiento y evaluación docente } & 73\end{array}$

Figura 16 Periodos de atención de una clase de 40 minutos $\quad 80$

Figura 17 Esquema grafico funcional de la modelación de la propuesta $\quad 84$ 


\section{Resumen}

El objetivo general de la investigación es diseñar una estrategia didáctica para mejorar el estilo de aprendizaje en estudiantes del I Ciclo de la Carrera Cosmética Dermatológica del instituto superior tecnológico público de Lima. Tiene un paradigma socio crítico interpretativo y un enfoque cualitativo aplicada educacional, dada la existencia de una relación lógica entre el objeto y el sujeto. Con el fin de dar una respuesta al estudio, se aplicó métodos cualitativos y cuantitativos para buscar la objetividad del problema para su posterior análisis y la transformación de la realidad educativa. El objeto de estudio está fundamentado a nivel científico en relación a las categorías apriorísticas, estrategias didácticas y estilo de aprendizaje, la muestra de estudio que se seleccionó a través del muestreo no probabilístico, consta de dos docentes que desarrollan unidades didácticas del primer ciclo y 15 estudiantes del turno diurno y nocturno. Para el diagnóstico de campo se empleó instrumentos y técnicas, una guía de observación de clases, un cuestionario a los estudiantes y una entrevista que se aplicó a los docentes. El resultado aporta información valiosa y específica sobre las carencias y fortalezas con respecto a los problemas que se identificaron a partir de las categorías emergentes, la propuesta de la investigación es el diseño de tres sesiones de clases, que serán usadas como estrategia didáctica, cuya base científica se encuentra en el marco teórico de la investigación.

Palabras claves: Estilo de aprendizaje, estrategia didáctica. 


\begin{abstract}
The general objective of the research is to design a didactic strategy to improve the learning style in students of the I Cycle of the Dermatological Cosmetic Career of the public higher technological institute of Lima. It has an interpretive socio-critical paradigm and an applied educational qualitative approach, given the existence of a logical relationship between the object and the subject. In order to give an answer to the study, qualitative and quantitative methods were applied to seek the objectivity of the problem for its subsequent analysis and transformation of the educational reality. The object of study is scientifically based in relation to a priori categories, didactic strategies and learning style, the study sample that was selected through non-probability sampling, consists of two teachers who develop didactic units of the first cycle and 15 students of the day and night shift. Instruments and techniques, a class observation guide, a questionnaire for the students and an interview that was applied to the teachers were used for the field diagnosis. The result provides valuable and specific information on the weaknesses and strengths with respect to the problems that were identified from the emerging categories, the research proposal is the design of three class sessions, which will be used as a didactic strategy, whose base scientific research is in the theoretical framework of the research.
\end{abstract}

Keywords: Learning style, didactic strategy. 


\section{Introduccion}

\section{Planteamiento del problema}

Es importante comprender que los seres humanos, tenemos diferentes modos y maneras de percibir, sentir, actuar, estilos, técnicas y formas de aprender. En tal sentido es importante tener en cuenta la individualidad y complejidad de cada individuo, por lo cual es necesario evidenciar cada una de sus características propias e inherentes. Por lo tanto, hay que recordar que el proceso de enseñanza-aprendizaje es un conjunto de técnicas muy complejas en la que hay tener en cuenta diversos aspectos, como es su entorno en el que se desenvuelve, como percibe ese entorno, sus capacidades más sobresalientes, tomando en cuenta diferentes aspectos, permitirá el uso de diversas estrategias, técnicas e instrumentos en el proceso educativo.

Definitivamente, la experiencia como docente nos indica que tenemos diferentes estilos de aprender, por lo tanto es sumamente importante reconocer la preferencia de cómo nos gusta recibir la información, esto nos permitirá determinar diferentes características del estudiante en relación a su estilo de aprendizaje inherente.

Para Quiroga y Rodríguez (2002 p.2) sostiene que los estilos cognitivos reflejan diferencias cualitativas y cuantitativas individuales en la forma mental fruto de la integración de los aspectos cognitivos y afectivo-motivacionales del funcionamiento individual y por lo tanto, determinan la forma en que el aprendiz percibe, atiende, recuerda y/o piensa, como en general se hacen las cosas.

Para Toffler (1991) el estilo de aprendizaje viene hacer la forma muy variada de como la mente procesa la información y cómo influye esta misma de acuerdo a la percepción de cada individuo para luego convertirla en conocimiento propio, su teoría hace referencia que el poder depende del conocimiento en este sentido afirma que es necesario una reestructuración 
profunda de los esquemas en el desarrollo del proceso de aprendizaje, considerando las actitudes y aptitudes del estudiante. (p.491).

La educación como proceso social tiene por objetivo contribuir a la formación integral de los estudiantes para la vida en sociedad. Son responsables de su desarrollo la familia y la escuela, en particular Desde los fundamentos científicos deben orientar en el proceso de enseñanza aprendizaje para estimular el pensamiento científico y la esfera afectiva emocional de los educandos para que sean conscientes de lo que aprenden y de cómo el conocimiento científico le permite resolver problemas de la realidad como enfatizan González (2003), Castellanos (2007), y Mora (2014).

Hacia la descripción teórica y abstracta del contenido sin relacionarlo con las situaciones del contexto, no se aplican los métodos que les permiten a los estudiantes explorar, observar, analizar, plantearse preguntas, criticar, reflexionar, problematizar el contenido para que sean conscientes de lo que aprenden y puedan solucionar problemas.

Por todo lo anteriormente expuesto se plantea el siguiente problema científico.

\section{Formulación del problema}

\section{Problema científico.}

¿Cómo contribuir al desarrollo de un estilo de aprendizaje en los estudiantes del I ciclo de la carrera de Cosmética Dermatológica en un instituto público de Lima?.

\section{Preguntas científicas específicas.}

¿Cuál es el estado actual del estilo de aprendizaje en estudiantes del I ciclo de la carrera de Cosmética Dermatológica en un instituto público?.

¿Cuáles son los fundamentos teóricos de una estrategia didáctica para contribuir al desarrollo del estilo de aprendizaje en estudiantes del I ciclo de la carrera de Cosmética Dermatológica de un instituto público?. 
¿Qué criterios se tendrán en cuenta en la modelación de la propuesta de una estrategia didáctica para contribuir al desarrollo del estilo de aprendizaje en estudiantes del I ciclo de la carrera de Cosmética Dermatológica de un instituto público?.

¿Cuáles son las potencialidades de validez curriculares para contribuir al desarrollo del estilo de aprendizaje en estudiantes del I ciclo de la carrera de Cosmética Dermatológica de un instituto público?.

Para generar respuestas científicas a las preguntas, se formularon los siguientes objetivos.

\section{Objetivos de la investigación}

\section{Objetivo general}

Proponer una estrategia didáctica para desarrollar el estilo de aprendizaje en los estudiantes del I Ciclo de la Carrera de Cosmética Dermatológica de un Instituto público de Lima.

\section{Objetivos específicos y tareas científicas}

Diagnosticar el estado actual del estilo de aprendizaje en los estudiantes del I ciclo de la carrera de Cosmética Dermatológica de un instituto público.

Sistematizar los fundamentos teóricos de una estrategia didáctica para contribuir al desarrollo del estilo de aprendizaje en los estudiantes del I ciclo de la carrera de Cosmética Dermatológica en un instituto público.

Determinar los criterios que se tendrán en cuenta para la modelación de la propuesta de una estrategia didáctica para contribuir al desarrollo de un estilo de aprendizaje en los estudiantes del I ciclo de la carrera de Cosmética Dermatológica de un instituto público.

Identificar las potencialidades de validez curricular para contribuir al desarrollo del estilo de aprendizaje en los estudiantes del I ciclo de la carrera de Cosmética Dermatológica de un instituto público. 


\section{Categorías y subcategorías}

Al respecto Cisterna (2005) enfatiza en que son frases o palabras construidas desde un aspecto teórico y científico en relación a las categorías, en referencia a las sub categorías son condiciones extraídas de dicha construcción principal, en aspectos desglosados y desmembrados para facilitar su estudio, por lo tanto considera que las categorías son desencadenantes del proceso de indagación y sistematización de la información, antes del trabajo del proceso y diagnóstico de campo; a diferencia de las categorías emergentes que surgen de la indagación y exploración a través de la aplicación de instrumentos.

\section{Categorías apriorísticas y subcategorías de investigación.}

La presente investigación tendrá en cuenta el análisis de los datos de dos categorías.

\section{Tabla 1}

Categorías y sub categorías apriorísticas:

\begin{tabular}{|c|c|}
\hline Categorías apriorísticas & Sub categorías apriorísticas \\
\hline \multirow{4}{*}{ Estilo de aprendizaje. } & Estilo de aprendizaje divergente. \\
\hline & Estilo de aprendizaje acomodador. \\
\hline & Estilo de aprendizaje convergente. \\
\hline & Estilo de aprendizaje asimilador. \\
\hline \multirow{4}{*}{ Estrategia didáctica. } & $\begin{array}{l}\text { Creación de espacio para favorecer la atención de los } \\
\text { estudiantes. }\end{array}$ \\
\hline & $\begin{array}{l}\text { Espacios académicos para generar la personalización de la } \\
\text { información. }\end{array}$ \\
\hline & $\begin{array}{l}\text { Espacio pedagógico en la sesión de clases para alcanzar la } \\
\text { adquisición de la información. }\end{array}$ \\
\hline & Construcción lógica del conocimiento. \\
\hline
\end{tabular}

Fuente: Elaboración propia 2020. 


\section{Tabla 2}

Descripción de categorías y sub categorías apriorísticas:

\begin{tabular}{|c|c|}
\hline Apriorística & Subcategoría \\
\hline \multirow{4}{*}{$\begin{array}{l}\text { Estilos de aprendizaje: } \\
\text { Es el reconocimiento de } \\
\text { las características en los } \\
\text { estudiantes, en relación al } \\
\text { estilo de aprendizaje, la } \\
\text { preferencia e inclinación } \\
\text { por desempeñar su } \\
\text { proceso de aprendizaje } \\
\text { con el uso adecuado de } \\
\text { materiales y técnicas } \\
\text { pedagógicas. (Kolb }\end{array}$} & $\begin{array}{l}\text { Estilo de aprendizaje divergente. } \\
\text { Estudiantes con una habilidad en recabar información y por lo tanto } \\
\text { desarrollan con facilidad ideas con contenidos innovadores y } \\
\text { originales, tienen una capacidad de observar lo que sucede antes de } \\
\text { actuar. (Dunn, 2010). }\end{array}$ \\
\hline & $\begin{array}{l}\text { Estilo de aprendizaje acomodador. } \\
\text { En este estilo se desarrollan las capacidades pragmáticas y } \\
\text { experimentales, cuentan con mucho facilidad para establecerse } \\
\text { objetivos y trabajar en el campo asi como para el ejercicio de roles. } \\
\text { (Alonso, 2010). }\end{array}$ \\
\hline & $\begin{array}{l}\text { Estilo de aprendizaje convergente. } \\
\text { Desarrollan actividades y tareas prácticas basadas a las teorías } \\
\text { científicas, aplican con mucha facilidad sus conocimientos en } \\
\text { resolución de problemas lo que les permite tomar decisiones. (Dunn, } \\
2010 \text { ). }\end{array}$ \\
\hline & $\begin{array}{l}\text { Estilo de aprendizaje asimilador. } \\
\text { Exteriorizan enfoques sucintos, lógicos y exactos, organizan la } \\
\text { información para tener una óptima comprensión facilitándoles } \\
\text { conceptos, teorías más claras, tienen en cuenta la experiencia de lo } \\
\text { aprendido buscando integrarlas a situaciones de contenido abstracto, } \\
\text { se inclinan por descripciones oportunas y claras. (Alonso, 2010). }\end{array}$ \\
\hline $\begin{array}{l}\text { Estrategia didáctica: } \\
\text { Se consideran como una } \\
\text { construcción lógica, } \\
\text { pensada para orientar el } \\
\text { proceso de enseñanza- } \\
\text { aprendizaje de las } \\
\text { competencias en los }\end{array}$ & $\begin{array}{l}\text { Creación de espacio para favorecer la atención de los } \\
\text { estudiantes. } \\
\text { E rol del docente es aplicar diferentes estrategias para despertar la } \\
\text { concentración y atención del estudiante, la participación de los } \\
\text { mismos es indispensable para formular las competencias, siendo } \\
\text { necesario planificar un proceso consiente. (Díaz y Hernández, } \\
\text { 1999). }\end{array}$ \\
\hline $\begin{array}{l}\text { diversos niveles } \\
\text { educativos, basados en }\end{array}$ & $\begin{array}{l}\text { Espacios académicos para generar la personalización de la } \\
\text { información. }\end{array}$ \\
\hline
\end{tabular}




\begin{tabular}{|c|c|}
\hline $\begin{array}{l}\text { procedimientos } \\
\text { compuestos por un } \\
\text { conjunto de etapas que } \\
\text { facilita el aprendizaje de }\end{array}$ & $\begin{array}{l}\text { Son procesos ejecutados por el docente, de manera sistemática con } \\
\text { la finalidad de que los estudiantes tomen la formulación de la } \\
\text { competencia desde un punto de vista personal, tomando en cuenta su } \\
\text { proyecto de vida de manera pro activa (Cooper, 1990). }\end{array}$ \\
\hline $\begin{array}{l}\text { los estudiantes. (Tobón, } \\
\text { 2009). }\end{array}$ & $\begin{array}{l}\text { Espacio pedagógico en la sesión de clases para alcanzar la } \\
\text { adquisición de la información. }\end{array}$ \\
\hline & $\begin{array}{l}\text { El docente tienen que crear las estrategias que permitan originar la } \\
\text { aceleración de los aprendizajes tomando en cuenta los saberes en la } \\
\text { memoria a largo plazo así como los aprendizajes anteriores y la } \\
\text { información reciente con un contenido coherente, metódico y } \\
\text { lógico. (Mayor, 1993). }\end{array}$ \\
\hline & Construcción lógica del conocimiento. \\
\hline & $\begin{array}{l}\text { Es importante determinar la relevancia de los saberes previos en la } \\
\text { construcción del conocimiento, para lo cual este contenido debe ser } \\
\text { sencillo y simple, para facilitar el entendimiento, la interpretación } \\
\text { así como la asimilación de la información, de esta manera se } \\
\text { reestructura y transforma en nuevas posibilidades.( Miras, 1993). }\end{array}$ \\
\hline
\end{tabular}

Fuente: Elaboración propia 2020.

\section{Población, muestra, muestreo y unidad de análisis}

\section{Población.}

Para Hernández, Fernández y Baptista (2014) plantea que en el proceso de la investigación cualitativa la población que se va estudiar puede darse por un grupo de personas o comunidades en las cuales se recogerán datos valiosos, en la cual se seleccionara una muestra representativa o no necesariamente.

La población la forman seiscientos alumnos de la carrera de cosmética dermatológica del instituto público de Lima seleccionada en el cual se realizó el diagnostico de campo en los turnos diurno y nocturno. 


\section{Muestra.}

La muestra lo integran tres docentes y quince estudiantes que cursan el primer ciclo tanto del turno diurno como el nocturno, a quienes se observó durante el desarrollo de clases y se les aplicará una entrevista y también un cuestionario estructurado para determinar a qué estilo de aprendizaje se adaptan.

Para Cisterna (2007) la investigación tiene que ser transparente, porque estará expuesta a crítica y réplica, por lo cual el investigador delimita con claridad la población que se va estudiar y hacer explícito el proceso de selección de su muestra, además indica que este subgrupo de la población o universo permite definir la unidad de muestreo y de análisis.

\section{Muestreo.}

El muestro no probabilístico por conveniencia está integrada por dos docentes y 15 estudiantes del primer ciclo del turno diurno y nocturno. En la investigación cualitativa Cisterna (2007), señala que en el muestreo cualitativo es no probabilístico, por lo cual selecciona casos con uno o varios propósitos, además indica que los casos pueden ser o no representativos.

\section{Unidades de análisis.}

El objeto de estudio serán tres docentes y quince del primer ciclo de ambos turnos diurno y nocturno de un instituto superior tecnologico publico del distrito de Pueblo Libre en Lima.

Para Cisterna define que la unidad de muestreo es la misma que la unidad de análisis, aunque para otros autores Thompson (2012) y Lepkowski (2008) indican que es distinta.

\section{Justificación de la investigación}

Teniendo en cuenta la importancia de los estilos de aprendizaje en los estudiantes y aplicación de diversas estrategias pedagógicas a la sesión de clases, siendo la propuesta una estrategia didáctica que contribuirá a mejorar el proceso de enseñanza aprendizaje y por ende la calidad educativa, además del cumplimiento de los objetivos y de las preguntas de 
investigación, es necesario justificar el estudio mediante la exposición de los siguientes aspectos.

\section{Justificación teórica.}

Teniendo en cuenta desde el punto de vista teórico, se realizó la revisión y sistematización de los antecedentes teóricos sobre el tema de investigación a nivel nacional e internacional, para lo cual se tomaron en cuenta los enfoques, teorías y las tendencias los cuales nos permitirán lograr los objetivos propuestos. La implicancia teórica que se toma en cuenta en el trabajo, va garantizar los fundamentos metodológicos, prácticos, así como teóricos aplicados en la educación, los cuales se verán reflejados en el marco conceptual propuesto en la investigación.

Para el desarrollo de la justificación teórica se consideró la revisión de los antecedentes, los fundamentos teóricos conceptuales, que cimientan los aportes científicos sobre los estilos de aprendizaje que hay que tener en cuenta en el proceso de enseñanza-aprendizaje; asimismo, se tomó en cuenta las subcategorías señaladas por Kolb (1984), en segundo término, se analizó las estrategias didácticas según Díaz y Hernández (2002) que actualmente se desarrollan con los estudiantes del primer ciclo de un instituto público.

El rol del docente tiene una función esencial para activar y desarrollar las diferentes habilidades del estudiante; esto exige una labor docente con formación permanente, integral de contenidos pedagógicos y científicos, acorde al avance de la tecnología educativa, a su vez contar con docentes que se desempeñan de manera ética y competente así lo destaca, el Proyecto Educativo Nacional al 2021 declara en el Objetivo 3 Maestros bien preparados que ejercen profesionalmente la Docencia. La mejora en los sistemas de formación de los profesionales de educación, garantizara estándares de calidad y ética. (PEN, p. 83). 


\section{Justificación práctica.}

Tomando en cuenta la complejidad del proceso de enseñanza-aprendizaje en el aspecto práctico, esta investigación será de mucha utilidad para los directivos y los docentes, así como muy beneficioso para los estudiantes de las instituciones educativas, por tal motivo esta investigación busca diagnosticar los estilos de aprendizaje que caracterizan o exteriorizan cada estudiante, así como analizar las técnicas pedagógicas del docente y si estos están acorde con las necesidades de los estudiantes, así de esta manera se propondrá una estrategia didáctica que permita mejorar el estilo de aprendizaje en los estudiantes de una institución de Lima.

En este sentido, en el Marco del Buen desempeño docente en la Competencia 4 desempeño 22 existen lineamientos para el uso de diversas técnicas, estrategias y recursos que permitan al estudiante desarrollar capacidades, el docente desarrolla estrategias pedagógicas y actividades de aprendizaje que promuevan el desempeño, en su aspecto creativo y los motiva a aprender (Ministerio de Educación del Perú, 2012, p. 41).

\section{Justificación metodológica.}

En el aspecto metodológico, las conclusiones del trabajo de investigación además de los resultados serán tomados en cuenta y sistematizados como una herramienta de estrategia metodológica y como material científico de contenido científico y práctico de uso pedagógico para el docente, permitiendo consolidar conocimientos, desenvolverse en actividades de construcción lógica de diversos procedimientos, esto contribuirá en el proceso de enseñanza aprendizaje, con la debida utilización del estilo de aprendizaje apropiarse de ese proceder didáctico donde el estudiante podrá aprender teniendo en cuenta sus características y estilos inherentes de cómo le gusta recibir la información de tal forma que será más sencillo de procesarlo, también se podrá aplicar en las diversas asignaturas e incluso a otras áreas curriculares. 
Para Pérez (1998), considera que la investigación cualitativa es un proceso activo, sistemático y riguroso de indagación dirigida, por lo cual se toman decisiones del objeto de estudio en el campo al cual fue sometido el proceso de investigación, en tanto el sustento científico se avala en la capacidad interpretativa debido al rigor científico del investigador.

La investigación se realizó teniendo en cuenta el método cualitativo, para lograr los objetivos, se aplicaron teorías y técnicas como la entrevista el cuestionario y la observación de clases, los cuales permitieron el análisis e interpretación de los datos, lo cual fue aplicado a los docentes que ayudará a profundizar la información.

\section{Metodología de la investigación}

\section{Tipo de investigación}

La investigación educativa establece un proceso dialectico de obtencion y construccion del conocimiento cientifico multidisciplinar teniendo en cuenta la realidad educativa como esencia compleja del sistema de ciencias de la educacion, con el fin de comprender y transformar en un contexto historico determinado. La realidad educativa como objeto de estudio de las ciencias de la educacion, permite un analisis profundo de las necesidades del estudiante, haciendo posible tomar desiciones idoneas para el buen desarrollo de la calidad educativa. IPLAC Instituto Pedagogico Latinoamericano y Caribeño (2010).

A su vez IPLAC indica que las investigaciones educativas deben tener en cuenta elementos esenciales para la comprension de la educacion y la proyeccion de innovaciones encaminadas a la mejora, asumir la complejidad de la educacion siendo visto como un fenomeno social, de carácter clasista e historico concreto. La investigacion pertenece a los paradigmas positivista, interpretativo y sociocritico, con criterios y posiciones teoricas.

En tal sentido para Grinnell (1977), y Creswell (1997), describen a las investigaciones cualitativas como un conjunto de acciones donde la recolección de datos está estrechamente influida por las experiencias y prioridades de los participantes en el mproceso investigativo, 
más que por la aplicación de un instrumento de medición generalizado, estructurado y predeterminado (p. 10).

\section{Diseño de la investigación}

Teniendo en cuenta el punto de vista metodológico los resultados de la investigación van hacer sistematizados en una estrategia didáctica de orden práctico que contribuirá a que los docentes puedan mejorar el estilo de aprendizaje. En el proceso de investigación se realizó el recojo de información de forma directa a través de una entrevista abierta semi estructurada lo cual se aplicó a dos docentes para diagnosticar las estrategias pedagógicas que se aplican en las sesiones de aprendizaje, un cuestionario que se aplicó a quince estudiantes para medir si se toman en cuenta el estilo de aprendizaje que caracterizan a cada uno de los alumnos y una guía de observación de clases para clasificar los estilos de aprendizaje.

\section{Métodos, técnicas de nivel teórico}

Se aplican de acuerdo a las concepciones, experiencias, estilo y las necesidades del investigador, quien determinara las técnicas y herramientas que utilizará en su investigación, para realizar su estudio.

\section{Métodos del nivel teórico}

Para resumir los objetivos presentados en la presente investigación se empleará como referencia los contenidos planteados y estudiado por el Instituto Pedagógico, Latinoamericano y Caribeño (IPLAC).

\section{Histórico - lógico.}

Se empleará este método para establecer los antecedentes históricos, fuentes de datos, testimonios, ilustraciones biográficas relacionados con el origen, la evolución y el estado actual de los estudios que contribuye al desarrollo de los conocimientos, habilidades y estilos de aprendizaje de los estudiantes en la especialidad Cosmética Dermatológica. 


\section{Análisis - síntesis.}

Se usará en el análisis de los trabajos de investigación y fuentes documentarias, resultados de la aplicación de instrumentos, datos que posibilitaron enriquecer los diferentes estilos de aprendizaje y así formular estrategias didácticas con fundamentos teóricos y contribuir al desarrollo del proceso de enseñanza-aprendizaje en los estudiantes del primer ciclo.

Para Cisterna, (2005). Indica que el investigador debe ser capaz de decodificar la información para lo cual es necesario identificar los elementos para el análisis.

\section{Inductivo - deductivo.}

Las técnicas e instrumentos pedagógicos utilizados nos van a permitir establecer el estilo de aprendizaje experiencial en base a fundamentos científicos de carácter teórico, dirigidas a cambios metodológicos y didácticos aportando, en la construcción de las categorías y subcategorías.

\section{Modelación.}

Se representara a través de un esquema que reflejara una composición integrada por los elementos, procesos del objeto de investigación, la estructura será diseñada con un solo tipo de grafico así como ayudas visuales como flechas serán indicadores de movimiento del objeto investigado en este diseño se visualizaran la estrategia didáctica que tendrá en cuenta los fundamentos teóricos, metodológicos y otros elementos del estilo de aprendizaje para el desarrollo de las sesiones de clase en las alumnas del I ciclo de la carrera de Cosmética Dermatológica.

\section{Técnicas e instrumentos}

Durante la investigación se emplearon varios métodos del nivel empírico, conocidos también como técnicas y fueron los siguientes: 


\section{Observación a clases.}

Se usará con el propósito de constatar el nivel de atención a la estrategia metodológica que aplica el docente durante el proceso de enseñanza- aprendizaje de la asignatura de estética facial en el primer ciclo de la carrera de Cosmética Dermatológica y poder determinar el grado de atención y entendimiento que propician los recursos utilizados por el docente, en este proceso se aplicó la guía de observación de clase.

La observación es un instrumento usada en la investigación de tipo cualitativa, permite apreciar los hechos en su contexto natural, es fundamental para el proceso de triangulación. La observación cualitativa surge debido a muchos estudios etnográficos lo cual permite cumplir con las pretensiones de la metodología cualitativa, cuyo objetivo es captar los fenómenos en su naturaleza sin alteraciones del discurso del entrevistado o de las fuentes documentales. Delgado, (1997).

\section{Encuesta.}

Se aplicará a los estudiantes del primer ciclo para conocer sus preferencias en cuenta a los diferentes estilos que tienen durante el desarrollo de enseñanza-aprendizaje y, el grado de interés que manifiestan por el estilo de enseñanza del docente, para tal fin se elaboró y aplico un cuestionario.

\section{Entrevista.}

Se aplicó a los docentes para detectar sus inquietudes en relación al comportamiento que manifiestan los estudiantes respecto a la forma de aprender y que indique que cambiaría del proceso de enseñanza-aprendizaje. Para ello se empleó una guía de entrevista estructurada.

Hay que considerar que en una investigación cualitativa, fundamentalmente se trata de profundizar el objeto de estudio, por lo tanto las entrevistas son en profundidad. Es un método de la investigación cualitativa, en el cual el investigador y el o los informantes están frente a frente, Mediante la entrevista el investigador debe conseguir la mayor cantidad de información 
inherente al objeto de estudio comprendiendo al sujeto entrevistado en su contexto y bajo sus circunstancias concretas. Taylor y Bodgan (1996).

\section{Criterio de expertos.}

Los expertos serán especialistas en didáctica y metodología, en asignaturas técnicas de la especialidad de la carrera de Cosmética Dermatológica, cuya contribución permitirá reconocer sus criterios científicos sobre el uso y aplicación de diversas estrategias educativas.

\section{Métodos estadísticos y matemáticos.}

Son usados por el investigador para el análisis de los datos empíricos que se obtuvo, para ordenar, reducir y así favorecer el estudio del objeto y obtener resultados significativos, el proceso de la información se realiza mediante la estadística descriptiva para el diagnóstico y análisis correspondientes.

\section{Perspectiva del investigador en el análisis de los datos}

El proceso de análisis de datos permite clasificar, cuestionar, construir y probar las conjeturas apriorísticas desde la práctica empírica, así como profundizar la teoría, para eliminar las argumentaciones, valoraciones que permitan diseñar la estrategia didáctica de acuerdo a los estilos de aprendizaje que contribuirá a transformar la realidad educativa analizada desde la literatura científica y la experiencia pedagógica del autor. 


\section{Capítulo I}

\section{Marco Teórico}

\section{Fundamentación teórica de la investigación}

\section{Antecedentes de la investigación.}

Distintos autores han investigado sobre los estilos de aprendizaje para mejorar el proceso enseñanza aprendizaje.

\section{Antecedentes internacionales}

Monroy (2018), el objetivo del siguiente estudio, es conocer el estilo de aprendizaje que presentan los alumnos de Magisterio de la Universidad de Extremadura de Madrid, observando las modificaciones que se producen a lo largo de su formación. La muestra que compone el estudio está formada por 401 estudiantes de dicha titulación, el instrumento que empleamos para la recogida de datos es el cuestionario CHAEA. Alonso (1992), para su posterior análisis. Los resultados indican que el perfil de aprendizaje de estos alumnos pertenece al estilo reflexivo, no presentando diferencias significativas en los cuatro estilos analizados. A lo largo de los años, los docentes se han preocupado por conocer los estilos de aprendizaje que caracterizan a cada uno de sus alumnos, y la injerencia que tiene en el desarrollo de los procesos de enseñanza-aprendizaje a lo largo de su formación.

Vinagre, (2017), presenta un estudio con el propósito de comprobar la posible relación entre los diferentes estilos de aprendizaje de los alumnos que cursan la asignatura de Dibujo Técnico de Bachillerato y su rendimiento académico en la misma. Concretamente, para hallar las preferencias de los estilos de aprendizaje de los alumnos se utilizó el cuestionario HoneyAlonso de Estilos de aprendizaje (CHAEA) (Alonso, Gallego, \& Honey, 1994). El estudio llevado a cabo fue transversal y correlativo Dado el tamaño de la muestra y la naturaleza de las variables, se optó por la realización de pruebas no paramétricas. Se revela que la preferencia 
del estilo pragmático en los alumnos tiene una relación significativa con la calificación obtenida en los trabajos.

Castaño (2017), en el siguiente trabajo de investigación se desarrolló los estilos de aprendizaje y su independencia con respecto a la inteligencia y la personalizada, además, de analizar la relación entre los estudios de aprendizaje y sexo. Para estos dos problemas se analiza, el marco conceptual de Estilos de Aprendizaje. El cual se delimita la relación entre estilos de aprendizaje y otras dimensiones tanto psicológicas como estilos cognitivos, estrategias de aprendizaje, inteligencia y personalidad, además de características sociodemográficas como sexo, edad y estudios académicos. Se presenta distintos modelos e instrumentos de evaluación de estilos de aprendizaje, de forma detallada. Se analiza, tres instrumentos: Inventario de Estilos de aprendizaje de Kolb (1985) Estilos de Aprendizaje de Alonso-Honey (1991) CHAEA y Learning Type Measurement de Macarthy y St Germain (1994).

Díaz, (2017), la investigación surge de la observación de las dificultades de aprendizaje de un grupo de estudiantes de la Facultad de Medicina de la Universidad Mayor y el uso de métodos pedagógicos que no eran idóneos en el proceso de enseñanza- aprendizaje, bajo esta perspectiva, se planteó identificar los estilos de aprendizaje dominantes y evaluar la apreciación de los estudiantes sobre las técnicas de enseñanza, para proponer métodos pedagógicos alternativos, el reconocimiento del estilo de aprendizaje permite mejorar los procesos formativos y movilizar los recursos eficientemente y orientada al logro y fin del aprendizaje, esto le permite al docente, directivo y administradores.

Se presentó un diseño de tipo descriptivo, con alcances comparativos e inferenciales, no experimental y transversal, centrado en los estilos de aprendizaje, mediante la aplicación del cuestionario CHAEA, en una muestra de estudiantes de tres Facultades de la Universidad Mayor de Chile. La muestra fue de tipo no probabilístico y el muestreo estratificado e 
intencional por conveniencia, el componente cualitativo, se configuró a partir del aporte de los estudiantes, docentes y directivos Los resultados muestran que no existe un predominio significativo de uno de los estilos de aprendizaje, también se demuestran que no existe un solo de estilo de aprendizaje en el aula.

Ullauri (2016), realizo el siguiente trabajo donde se investigó la influencia del estilo de aprendizaje en el rendimiento académico del idioma Inglés de las estudiantes de la facultad de ciencias de la educación, humanas y tecnologías de la Universidad Nacional de Chimborazo. La población y la muestra fue de 200 estudiantes y está divida en dos grupos control y experimental. El diseño de la investigación es cuasi experimental. El taller de los estilos de aprendizaje se basó en varias sesiones de aprendizaje, cuyo resultado permitió encontrar que existe diferencia significativa entre el grupo de control y el grupo experimental respecto al rendimiento académico, luego de aplicar el taller EAPRAIFE de los estilos de aprendizaje.

Los resultados indican que el instrumento que mejores propiedades psicométricas presenta en el Inventario de estilos de aprendizaje de Kolb, (1985) se puede concluir que los estilos de aprendizaje son independientes de otras dimensiones de inteligencia y personalidad, En la segunda predicción: Indica la pequeña diferencia entre hombres y mujeres. Por un lado, en las mujeres predomina el estilo de aprendizaje adaptador y en varones predomina el asimilador. Pero a su vez los varones tienen una preferencia por un enfoque más abstracto y las mujeres se involucran en experiencias nuevas. Además de presentan un carácter más activo a la hora de aprender.

\section{Antecedentes Nacionales}

Bedrenana, (2019), en la investigación se estableció la relación entre los estilos de aprendizaje y los estilos de pensamiento de los estudiantes de la universidad privada de Lima Sur, el diseño de la investigación es no experimental. La muestra conformada de 477 estudiantes que a su vez 
fue dividido en 283 varones y 194 mujeres, de los primeros y últimos ciclos de las carreras de Ingeniería de Sistemas y Derecho. Los instrumentos usados fue el cuestionario CHAEA, y el cuestionario de estilos de pensamiento de Sternberg-Wagner.

Los resultados mostro una correlación positiva y muy significativa entre los cuatro estilos de aprendizaje y los trece estilos de pensamiento, se halló que el $42.8 \%$ presentan un nivel moderado en el estilo de aprendizaje reflexivo y el $34.2 \%$ su nivel es superior al promedio en el estilo de pensamiento conservador. Finalmente, se halló diferencias significativas en los estilos de pensamiento en función al sexo, en el estilo global y local, no se encontró diferencias significativas en función al ciclo de estudios.

Sobrino (2017), El siguiente trabajo de investigación, es determinar la relación entre los estilos de aprendizaje y sus hábitos de estudio en estudiantes de la Universidad Privada de Lima, con un diseño no experimental, transversal, descriptivo, se aplicó el cuestionario de estilos de aprendizaje de Honey y Alonso y el Inventario de hábitos de estudio en 144 estudiantes de una población de 228 estudiantes, los cuales se seleccionó bajo muestreo aleatorio simple, estudiantes de la UP TELESUP.

Se determinó que existe relación entre los estilos de aprendizaje y los hábitos de estudio, con predominancia en los estilos teórico y reflexivo, en tanto a los hábitos de estudio, los resultados evidenciaron que el alrededor del $66.7 \%$ de estudiantes con hábitos de estudio muy positivos frente al $27.1 \%$ de estudiantes que evidenciaron tener hábitos de estudios negativos.

Chapilliquen (2015), realizo una investigación en estudiantes con diferentes estilos de aprendizaje para conocer el nivel de desarrollo de las competencias digitales cuya muestra fue alumnos en el séptimo ciclo de educación secundaria, en una institución educativa pública de la Unidad de Gestión Educativa Local (UGEL) Este estudio fue un enfoque cuantitativo, nivel explicativo y diseño cuasi experimental, en dos grupos donde se va a explicar el desarrollo de 
las competencias digitales en estudiantes con diferentes estilos de aprendizaje. La muestra de 162 estudiantes, del $3^{\circ}, 4^{\circ}$ y $5^{\circ}$ de secundaria.

Distribuidos en dos grupos uno de control y otro grupo experimental. El cuestionario de los estilos de aprendizaje se aplicó, a ambos grupos y permitió ubicar a los estudiantes en una de las ocho tendencias: activo - reflexivo, sensorial - intuitivo, visual - verbal y secuencial - global, el cuestionario de competencias digitales fue analizado a partir de cinco sub estilos de variables. Los resultados comprobaron que el nivel de desarrollo de las competencias digitales que alcanzaron los estudiantes con diferentes estilos de aprendizaje, del grupo experimental en el post test es nivel medio.

López (2015), realizo una investigación en el cual se tuvo el propósito de conocer el grado de relación entre los estilos de aprendizaje y la comprensión de lectura en los estudiantes de Maestría de la sede del Callao de la Universidad Nacional de Educación Enrique Guzmán y Valle la muestra es censal. Los análisis estadísticos fueron aplicadas a cincuenta estudiantes estos indican que los instrumentos son válidos y confiables.

El estudio demostró que el estilo de aprendizaje tienen relación con la comprensión de lectura, algunas, mediante un trabajo interactivo, comunicativo y colaborativo por lo cual, se ha ejecutado esta investigación por lo cual se relaciona los diferentes estilos de aprendizaje, se desarrolló en cuatro capítulos: Marco teórico, planteamiento del problema, desarrollo de la metodología aplicada, instrumentos de investigación y los resultados. Por lo cual se concluye que los estilos de aprendizaje y la comprensión de lectura se relacionan significativamente.

Rettis (2015), realizo la presente investigación cuyo objetivo fue establecer la relación del estilo de aprendizaje y el rendimiento académico de la asignatura de estadística en los estudiantes del III ciclo, de la facultad de Ciencias Administrativas de la Universidad Nacional Mayor de San marcos. La investigación es de enfoque cuantitativo. Donde se encontró una 
relación positiva entre los diversos estilos de aprendizaje y el rendimiento académico, el sujeto aprende bien con un estilo de aprendizaje que vaya de acuerdo a sus necesidades, se afirma que el estilo con mayor predominio fue el estilo convergente y asimilador, la relación de ambos y el rendimiento académico, es casi perfecto. Así mismo, el estilo divergente y el rendimiento académico, se concluye que no existe relación entre las variables propuestas.

El análisis de las investigaciones revisadas relacionadas con el tema objeto de estudio ha permitido ampliar y enriquecer el campo de conocimientos teóricos y metodológicos del autor acerca de la problemática. Se aprecia que existe el interés por describir desarrollar y aplicar los estilos de Aprendizaje y la influencia sobre el proceso tan complejo de EnseñanzaAprendizaje mejorando estrategias, técnicas de aspecto pedagógico y didáctico teniendo en cuenta las características individuales del alumno, algunas propuestas, permite mejorar incluso el proceso de evaluación, así como determinar el Estilo de Aprendizaje que más se adapte al contexto educativo.

\section{Fundamentos teóricos}

\section{Bases teóricas y conceptuales sobre estilos de aprendizaje.}

Con respecto a la definición de estilo para Capella (2003), desde un punto de vista pedagógico se señala una serie de comportamientos externos e internos del individuo bajo una perspectiva de cómo es la manera que le gustaría que le transmitan la información. Para algunos autores el estilo está compuesto por una serie de comportamientos superficiales externos, pero vamos a considerar que el estilo es más que una serie de apariencias.

Coloma (2005), indica que los estilos se pueden considerar como la forma en que actúan las personas se podría indicar que son conclusiones después de analizar los diferentes comportamientos.

Teniendo en cuenta una perspectiva fenomenológica las características estilísticas o de estilos son aquellos indicadores de dos niveles profundos de la mente del ser humano, el 
primero el sistema total de pensamiento y las cualidades inherentes de la mente que el ser humano utiliza para establecer lazos con la realidad Este punto de vista significa que características personales como la preocupación por el detalle o el uso fácil de la lógica para determinar la verdad, la búsqueda de significados, la necesidad de opciones, no son simples casualidades sino aspectos muy unidos a elementos psicológicos.

En el estudio de Gregorc (1979), y de otros autores, en los años 70, se observaron ciertos comportamientos en estudiantes brillantes y muy sobresalientes, dentro y fuera del aula, en los cuales se encontraron comportamientos contradictorios, algunos tomaban apuntes, y otros no mientras otros estudiaban de noche y otros sólo antes de los exámenes, recurriendo este comportamiento en otras áreas y actividades.

Los investigadores concluyeron que estas manifestaciones se debían, por una parte, a disposiciones de cada individuo y por otra parte, a resultados de experiencias y aprendizajes pasados, por lo que surgen cuatro aspectos en el funcionamiento cognoscitivo. Un espacio concreto y abstracto que se conecta con los sentidos, las emociones, la inteligencia y la imaginación. El tiempo, los procesos mentales pueden ser de inducción y deducción.

\section{Aprendizaje.}

M. Poggi (1999), conceptualiza el aprendizaje escolar partiendo de las experiencias y las relaciones educativas que se establecen entre los sujetos participantes, atribuyéndoles algunos rasgos o características, por lo que se puede decir que la intención es explicita de intervenir en el proceso de aprendizaje, en las instituciones se deben promover intercambios comunicativos, que no quedan sometidos al azar o a las contingencias, asimétrico y temporal, el docente tiene una posición diferente a la del alumno a partir de su dominio en un campo determinado del saber en el que se ha formado y ejerce su profesión.

Para Hilgard (1979), define al aprendizaje como un proceso complejo que se desarrolla a través de una actividad que puede variar a otra situación siempre que sus características de 
este cambio no tengan explicación con base científica en respuestas innatas, procesos de maduración y alteraciones transitorias del organismo, afirma que es poco satisfactorio desde un enfoque formal por contener muchos términos indefinidos en su contenido. (p.17).

Para Díaz (1986), indica que define de manera más integral el aprendizaje, donde manifiesta como una modificación que puede ser permanente o transitoria en la disposición o capacidad del ser humano, desencadenada como resultado de su actividad por lo cual no solo se le puede atribuir al proceso de crecimiento y maduración o a otras causas como alteraciones, enfermedades o trastornos genéticos, para el autor el aprendizaje puede ser comprendido como un producto es decir es la consecuencia de la experiencia o el cambio que acompaña a la práctica, a su vez indica que es el proceso donde hay un cambio de comportamiento y como último punto indica la función como el cambio del sujeto se relaciona con la información.(p.40).

Para Cotton (1989), el aprendizaje lo define como un proceso donde se adquiere nuevos conocimientos y habilidades a través del procesamiento de información para ser determinado como aprendizaje y no solo una retención pasajera de la misma, para esto debe implicar un sostenimiento del conocimiento o conjunto de habilidades que permitan su manifestación en el transcurso del tiempo presente y futuro. También define el aprendizaje de manera más formal considerando un cambio constante o permanente en el comportamiento resultado de la experiencia. (p.367).

\section{Los estilos de aprendizaje.}

El estilo de aprender es una definición relevante para los educadores, porque modifica su estrategia para enseñar, muchas veces el maestro educa como le gustaría ser educado, es decir, muchas veces toma modelos que le agrada, dando como respuesta a que enseñara teniendo como referencia su propio estilo, es un proceso interno de muchos docentes, por lo tanto, esta experiencia será aplicada en su estilo de enseñar. 
Para (Rossoff, 1984), al hacer un análisis de los diferentes estilos de aprendizaje se encuentra diferentes indicadores que ayudan a guiar las interacciones del ser humano con las realidades existenciales. Esto facilita el camino, aunque limitado, de autoconocimiento. Existe en algunas publicaciones de Learning Style Based Education (Educación Basada en los Estilos de Aprendizaje), donde se proponen estrategias y recomendaciones para docentes y estudiantes. (p.45).

Pero no para todos los autores la definición de estilo de aprendizaje es la misma, pero hay que resaltar que la mayoría coincide que se trata del fenómeno de cómo la mente procesa la información y cómo influyen las percepciones de cada individuo. Cuando hablamos de estilos de aprendizaje hay que tener en cuenta rasgos, incluir estudios de psicología cognitiva, que explican la diferencia en los sujetos respecto a las formas de conocer.

Para Dunn, Dunn y Price (1979), citado por Palomino (1998), nos indica que el estilo de aprendizaje se basa en cuatro estímulos básicos. Elementos del medio ambiente el sonido, luz, temperatura y el mobiliario. Elementos emocionales la motivación, persistencia, responsabilidad. Elementos sociológicos y físicos la percepción, hora y movilidad éstos determinan la habilidad, procesamiento y retención de información. Esta es una definición descriptiva adaptada a la misma taxonomía de estilos que estos autores propugnan, una crítica contra esta definición es señalar la ausencia del elemento inteligencia, así como aspectos importantes del proceso de aprendizaje como son la capacidad de analizar.

Para Quiroga y Rodríguez (2002), describen al estilo de aprendizaje cognitivo como la confluencia entre la inteligencia y la personalidad, los estilos cognitivos reflejan diferencias cualitativas y cuantitativas individuales en la forma mental fruto de la integración de los aspectos cognitivos y afectivo motivacionales del funcionamiento individual, por lo tanto, determinan la forma como el aprendiz percibe, atiende, recuerda y piensa. (p.21).

Para Mato, (1992), Considera la forma en la cual diferentes estímulos básicos afectan 
la práctica de una persona para interiorizar la información, indica que son los contextos educativos en las que el educando tiene la mejor situación de aprender o la infraestructura qué necesita para poder hacerlo, para otros, es la forma como cada quien percibe el mundo, de acuerdo a su forma de pensar, concluir juicios, adquisición de valores sobre sus experiencias. Según Witkin, (1975), indica que uno de los estilos de aprendizaje más estudiados se refiere a la dependencia e independencia de campo estudiada por el autor, se han caracterizado por ser bipolares, donde uno de ellos percibe el estímulo como un todo, el otro percibe distintas partes y es analítico. La dependencia de campo, es aquel que, manifiesta orientación impersonal y relativamente insensibles a claves sociales, preocupado por ideas y principios abstractos, trabajan bien con materiales sin estructura, prefieren resolver problemas en forma individual no están a gusto en equipos. Por otra parte la independencia de campo busca seguridad en referentes externos manifiestan conducta interpersonal y atiende a claves sociales proporcionados por otros, prefieren resolver problemas en equipos. (p.48).

Para Hunt (1979), describe al estilo de aprendizaje como una condición educativa donde el estudiante se encuentra en la mejor situación para aprender, manifiesta que la estructura tiene relevancia en el proceso de aprendizaje, además que el nivel conceptual va a caracterizar el estilo de aprendizaje, esto último es una característica sustentada en la teoría del desarrollo de la personalidad en la cual se describe a la persona en una jerarquía de desarrollo creciente de la complejidad conceptual, autorresponsabilidad e independencia.( p.27).

Según Gregorc (1979), indica que el estilo de aprendizaje consiste en distintos comportamientos que sirven como indicadores de cómo una persona aprende y se adapta a su ambiente, facilita claves, características o signos de cómo opera la mente de una persona permitiendo entender procesos complejos propios del cerebro y la psicología del ser humano frente a respuestas dadas por diferentes estímulos. (p.57).

Para Riechmann (1978), el estilo de aprendizaje es un conjunto particular de 
comportamientos y actitudes relacionados con el contexto de aprendizaje coincidiendo con la definición de otros autores donde también toman en cuenta el contenido del proceso educativo, indica una diferencia porque determina el concepto de contextualización como los comportamientos y actitudes de la persona, refiriendo así una situación holística por desarrollarse procesos más complejos del ser humano, tan solo no la parte cognitiva sino un todo, de manera más integral de la persona. (p.80).

Butler (2004), manifiesta que los estilos de aprendizaje son el significado natural de una persona quien desarrolla más fácil y eficientemente haciendo que se comprende a sí misma, al mundo y la relación de los dos elementos, así como una manera específica y característica donde el estudiante se acerca a un proyecto o un proceso de aprendizaje, independientemente de si incluye una decisión explícita o implícita del estudiante.

Para Gallegos (1994), determina diferentes destrezas y características que muestran con claridad el campo de habilidades en cada uno de las personas, resultado del análisis factorial, el autor indica cuatro estilos de como las personas les gusta estudiar y recibir la información, los activos, los reflexivos, los teóricos y los pragmáticos.

Para Valerdi (2002), señala que es recomendable varios materiales de instrucción que se puedan aplicar a los distintos estilos de aprendizaje, desde su perspectiva reconoce a un estilo activo, muy participativos, prefieren materiales con aplicaciones prácticas, mediante la propuesta de ejercicios y casos a resolver, también refiere al estilo reflexivo, quienes se basan en sus propios pensamientos y sentimientos, para formular sus opiniones así como su manera de actuar, requieren materiales con preguntas que despierten el interés y curiosidad.

Mientras que, Alonso (1992) considera que los teóricos, quienes se dejan llevar por las primeras impresiones, prefieren la intuición y la subjetividad. Por ello se deben elaborar materiales densos que provoquen el pensamiento, hacer práctica la detección de incoherencias o puntos débiles en los argumentos de otras personas, en informes o artículos de prensa.(p.71). 
Para David Kolb (1984), citado por Mato, (1992), incluye el concepto de estilos de aprendizaje dentro de su modelo de aprendizaje por la experiencia y lo describe como algunas capacidades de aprender que se destacan por encima de otras como resultado del aparato hereditario de las experiencias vitales propias, y de las exigencias del medio ambiente actual, llegamos a resolver de manera característica, los conflictos entre el ser activo y reflexivo y entre el ser inmediato y analítico.

Para el autor algunas personas desarrollan mentes que sobresalen en la conversión de hechos dispares en teorías coherentes, y, sin embargo, estas mismas personas son incapaces de deducir hipótesis a partir de su teoría, o no se interesan por hacerlo; otras personas son genios lógicos, pero encuentran imposible sumergirse en una experiencia y entregarse a ella, al inspeccionar las fortalezas y debilidades que los estudiantes tienen para aprender, señala que existen cuatro estilos de aprendizaje convergente, divergente, asimilador y acomodador.

Kolb (1984), además indica, que en un aprendizaje realmente efectivo es necesario trabajar esas cuatro categorías, un aprendizaje óptimo es el resultado de trabajar la información en cuatro fases, porque la manera de seleccionar, organizar y trabajar con la información implica una serie de hechos que deben tomarse en cuenta en el salón de clases, para que el estudiante aprenda más fácilmente (p.22).

Teniendo en cuenta a David Kolb el autor desarrolla un modelo de aprendizaje basado en experiencias donde refiere que todas las actividades nos permiten aprender, también incluye un concepto donde un estilo son algunas capacidades de aprendizaje que van a sobresalir como resultado de una herencia de nuestra propia vivencia enfocada a experiencias propias así como la participación del medio ambiente.

En donde alcanzamos reconocer problemas o conflictos entre el ser activo y reflexivo, ya que algunas personas siempre desarrollaran mentes sobresalientes en teorías coherentes, sin embargo estas mismas personas son incapaces de deducir hipótesis a partir de su teoría, o 
no se interesan por hacerlo, otras personas son genios lógicos, pero encuentran casi imposible sumergirse en una experiencia y por lo tanto entregarse a ella (p.47).

Las etapas por las que pasamos en el proceso de aprendizaje son modos de adquirir una nueva información, la cual transformaremos en algo significativo y utilizable los estilos, Según el autor, para que haya un aprendizaje efectivo, se pasa por 4 etapas, resume este proceso a un ciclo de aprendizaje cuya descripción se traduce como la experiencia del sujeto en relación a las definiciones que se emplean a su vez como guías de elección de nuevas experiencias.

Figura 1: Ciclo de aprendizaje según kolb.

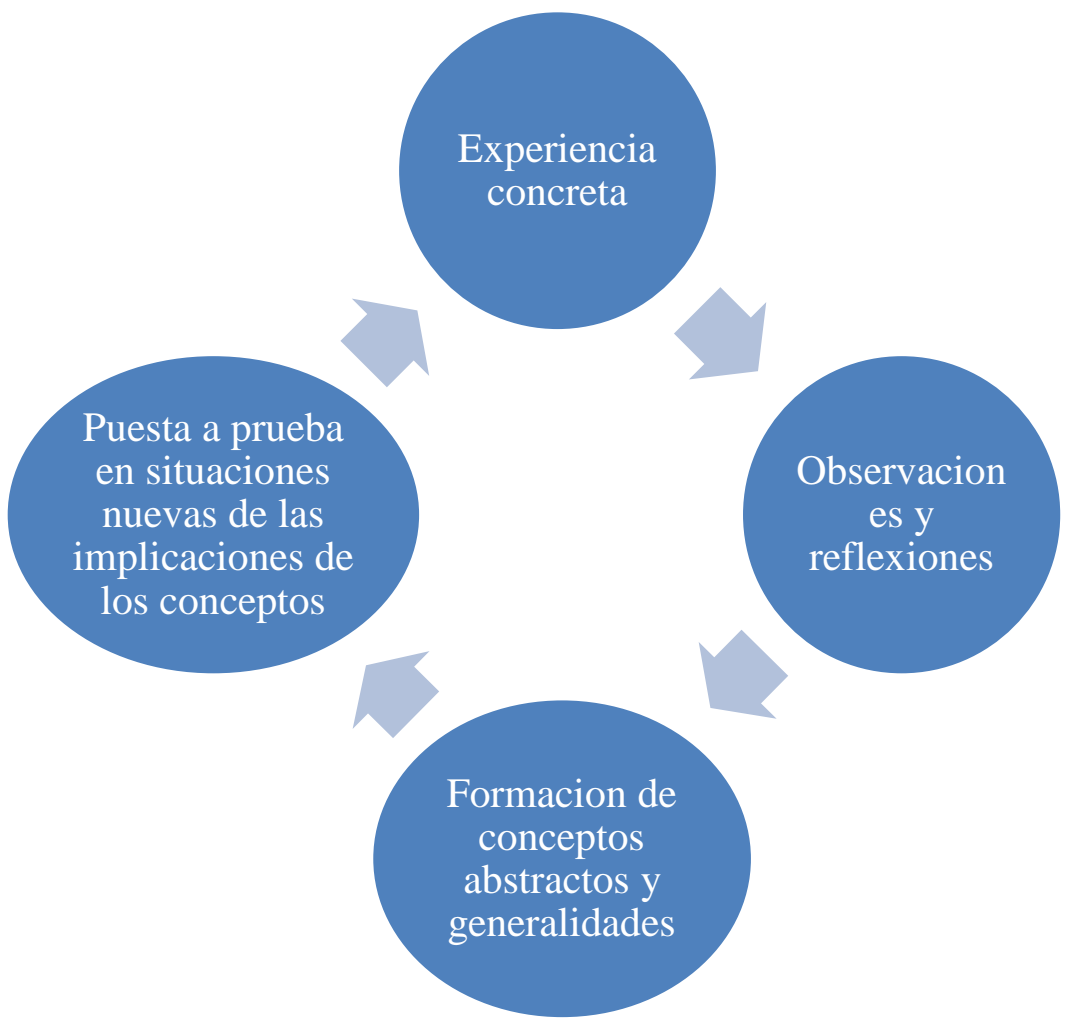

Kolb, (1984) citado por Lozano. (2000).

Cada etapa descrita manifiesta un proceso muy particular de cómo se genera la información, observar y hacer desarrollando conceptos generalizando y experimentando con ideas, teniendo diferentes modos de crear conocimiento, para lograr un aprendizaje efectivo 
hay que cruzar las cuatro etapas del ciclo.

Para Mack (2000), la percepción y procesamiento de la experiencia del proceso de aprender tiene que ver con el sentido que le damos, para lo cual hay que desarrollar actividades que intervienen en este proceso, la percepción como la forma de transformar la información en algo significativo a lo largo del ciclo del aprendizaje, según la etapa en la que nos encontremos. En tal sentido considera la experiencia concreta, cuando a través de los sentidos captamos nueva información, es decir tener contacto con lo concreto.

Por otra parte indica que la observación reflexiva, es la experiencia que se desencadena de los actos ejecutados, la conceptualización abstracta, permitirá obtener nuevo conocimiento a través del pensamiento desencadenado en conceptos, ideas y teorías que orienten la acción, y por último la experimentación activa, donde la información será procesada involucrando nuevas prácticas de manera activa.(p.42).

\section{Estilo de aprendizaje convergente}

Para Hudson (1966), indica que las personas con este estilo tienen un predominio por la conceptualización abstracta y la experimentación activa, son aquellos que piensan y actúan, tienen características muy marcadas en las actividades prácticas de lo aprendido, se manejan muy bien en pruebas de inteligencia donde hay una sola respuesta del problema, son organizados de tal forma que se concentran en soluciones donde se evidencia el razonamiento hipotético deductivo, son relativamente insensibles tienen preferencia tener trato con cosas antes que con las personas, tienen la capacidad de aplicar teorías así como ideas en situaciones reales y una gran capacidad de resolución de problemas, toma de decisiones.

Para Gómez (2005), el estilo de aprendizaje está orientado a los hechos y resultados, sus definiciones e ideas son muy centrados, indica métodos y modelos de aplicación en el estilo pragmático y convergente proponiendo tareas y actividades, relacionadas con las personas, en tal sentido las fortalezas más grandes siempre estarán dirigidas a solucionar problemas y 
toma de decisiones, la característica de su pensamiento es de tipo hipotético deductivo. Hace referencia que en el estilo convergente tiene relación con ciertas especialidades profesionales de economía, ingeniería, medicina, así como informática y ciencias tecnológicas. (p.14).

Para Gallegos (1994), considera activos o convergentes aquellos estudiantes que se involucran en los asuntos de los demás y centran a su alrededor todas las actividades que emprenden con entusiasmo, son de mente abierta, nada escépticos, desarrollan días de mucha actividad, no se dan por vencidos siempre lo intentan, son espontáneos, así como creativos e innovadores con muchos deseos de aprender y resolver problemas.

Para Honey y Munford (1986), la conceptualización abstracta y la experimentación activa es un predominio en el estilo pragmático, desarrollan de manera muy asertiva pruebas convencionales de aplicación práctica, debido a que sus conocimientos están organizados, otra importante característica es el análisis, se desenvuelven con mucha eficiencia en situaciones técnicas y de experimentación, pero son poco empáticos y a veces herméticos por lo que es muy importante que el docente debe observar para poder aplicar métodos estratégicos y técnicas didácticas pertinentes.

Es importante recordar que partiendo de sus preferencias innatas de cómo es su estilo de aprender también hay que tomar en cuenta que hay situaciones completamente desfavorables y que hay que evitarlos dentro del proceso de enseñanza aprendizaje como son la programación de actividades que no tengan una relación ante una situación concreta y práctica, así como las actividades no estructuradas ya que estas personas cuidan la secuencia de actividades ya que estas serían actividades sin valor, los contenidos teóricos y la lectura tienen que tener una relación con la aplicación de las mismas.

\section{Estilo de aprendizaje divergente}

Para Alonso (1990), el estilo divergente es característico de aquellas personas que tienen la tendencia y la preferencia por sentir y observar, más que actuar tienen la habilidad por lo 
objetivo por lo tanto pueden observar a un mismo fenómeno desde muchas perspectivas, pueden escuchar con profundidad mental, considerando diferentes puntos de vista de una misma situación, es un estilo completamente opuesto al estilo convergente ya que en este estilo se desempeña mejor en la experiencia concreta y la observación reflexiva su fortaleza y su punto más fuerte reside en su capacidad imaginativa.

Según el autor se destaca por la consideración desde muchas perspectivas de las situaciones concretas, calificamos este estilo divergente ya que las personas que cuentan y lo desarrollan se definen mejor en situaciones donde hay una exigencia y una producción de recolección o lluvias de ideas como la que se da en una sesión. (p.40).

En los trabajos de Hudson (1996), recalca que los estudiantes con un predominio o estilo de aprendizaje divergente demuestran interés por interrelacionarse, son muy imaginativos y sensibles, también es bueno destacar que se inclinan por los aspectos y por las opciones artísticas, gracias a ello desarrollan la capacidad de sensibilidad, se puede encontrar este estilo en directivos con dominio en humanidades. Los jefes de personal suelen tener esta característica como estilo ya que se adaptan con facilidad ala trabajo.

Para Honey y Munford (1986), las características del estilo divergente es muy interesante, facilita a los docentes las estrategias del proceso de enseñanza por ser muy sociables, empáticos, espontáneos, con capacidad de síntesis, son buenos generadores de ideas, facilitando el trabajo en equipo y evitando dificultades en el proceso de socialización, se desempeñan de manera muy eficiente y eficaz en problemas sociales, su interés se centra en el proceso humano, y los fenómenos sociales, así como aspectos artísticos y culturales.

Así mismo el autor indica que en los diversos procesos de investigación se encontró relación entre el estilo divergente y las carreras artísticas, de ciencias sociales y psicología, así como con la educación debido a ese gran desarrollo innato de sensibilidad y la capacidad de trabajo en grupo, teniendo un buen desenvolvimiento debido a sus características propias. 
Para Kolb (1984), denomina al estilo divergente a las personas que tienden a recabar, información y de esa manera generan muchas ideas originales, haciéndolos aptos para situaciones donde se debe generar conceptos por ejemplo para procesos de lluvia de ideas, son personas con muchas tendencias imaginativas que justamente y valga la redundancia utilizan la imaginación para resolver problemas, su pensamiento es de tipo inductivo, es decir ellos van de lo particular a lo general.

\section{Estilo de aprendizaje asimilador.}

Para Hunt (1979), este estilo de aprendizaje se observa predominio en el pensamiento y la observación, estas personas poseen un enfoque conciso, lógico y preciso, la capacidad de comprender, organizar y sistematizar en un formato muy claro la información son muy destacables, para ellos la experiencia de aprender y buscan integrarla a marcos más amplios de teorías abstractas, requieren explicaciones precisas y claras y debidamente oportunas.

Las conceptualizaciones abstractas y la observación reflexiva es una de sus características más fuertes, así lo indica el autor, ahí se encuentra su mayor riqueza permitiéndoles la capacidad de crear modelos teóricos, ellos se destacan en el razonamiento inductivo, en la asimilación de observaciones para una explicación integral a diferencia del estilo de aprendizaje convergente, se interesa menos por los otros individuos siendo más prioritario los conceptos abstractos, siendo menor su preocupación por la aplicación práctica de las teorías, ya que para ellos es más importante que estas sean lógicamente sólidas y precisas.(p.85).

De esta manera se puede concluir que este estilo de aprendizaje es más característico de las ciencias básicas que el de las ciencias aplicadas, este tipo de estilo se encuentra con más frecuencia en las organizaciones, departamentos de investigación y planificación, que se ajusta a su personalidad, poco sociable y empáticos, pero con un buen dominio de síntesis, pueden generar modelos, son muy reflexivos y casi disfrutan la teoría, son muy buenos 
pensadores abstractos,

Para schmeck (1982), resalta que el estilo teórico y reflexivo desarrollan la capacidad por la paciencia, su naturaleza e inclinación hace que sean observadores, racionalistas y reflexionen, sus fortalezas se evidencian en su capacidad de definir y aclarar problemas, definen muy bien lo que observan, planifican y crean modelos teóricos su racionamiento es de tipo inductivo, las preferencias de este estilo tienen relación con la elección de ciertas especialidades de biología, ciencias matemáticas y todas aquellas especialidades relacionadas con el manejo de mucha información como es en el campo de la investigación y las ciencias.

Según Gregorc (1979), considera otro grupo de estilo reflexivo o asimilador, aquellos que gustan observar y considerar las experiencias desde diferentes perspectivas, reuniendo y analizando datos con detenimiento antes de llegar a alguna conclusión, son prudentes y observadores, consideran todas las alternativas posibles antes de realizar una actividad, escuchan a los demás y no actúan hasta apropiarse de la situación.

\section{Estilo de aprendizaje acomodador.}

Para Honey (1986), Las personas con este estilo de aprendizaje son opuestos al estilo asimilador, se desempeñan mejor en la experiencia concreta y la experimentación activa, su punto más fuerte reside en hacer cosas llevando a cabo proyectos y experimentos así logran involucrarse en prácticas nuevas, son arriesgados a diferencia de otras personas que pertenecen a otros estilos de aprendizaje, podríamos calificar a este estilo de aprendizaje porque tienden a destacarse en las situaciones en las que debe adaptarse, así como a circunstancias inmediatas específicas.

Para Kolb (1984), indica que en ciertos casos donde la teoría no se ajustan a los hechos, es muy probable que estas personas lo descarten, los estudiantes con este estilo de aprendizaje se sienten bien con las personas, aunque a veces se les note impacientes, su formación se desarrolla en aspectos técnicos, otra de las características de estos alumnos es que son muy 
sociables, así como organizados, tienen la tendencia a aceptar retos, buscan objetivos, también son orientados a la acción que dependen de los demás.

Para el autor las personas de estilo tienen un acercamiento predominantemente práctico y experimental, es un estilo muy útil para el ejercicio de roles que requieran acción e iniciativa, establecen objetivos y trabajan activamente en el campo probando diferentes alternativas para alcanzar los objetivos, les atraen los nuevos desafíos y experiencias, tienen facilidad para involucrarse en proyectos y adaptarse a nuevas situaciones.

Por su parte Witkin (1975), indica que para los pragmáticos hay una gran afinidad por reunir técnicas, modos prácticos de hacer las cosas, así como cualquier cosa que pueda ser útil, prefiere usar técnicas analíticas, interpersonales, de asertividad, de presentación que ameriten un ahorro de tiempo, técnicas para mejorar la memoria, busca oportunidades para experimentar algunas de las técnicas recién halladas, ensayarlas y ponerlas en práctica.

Para Gómez (2005), indica a estas personas con cualidades de arreglárselas sacando adelante sus planes, son capaces de correr los riesgos que sean necesarios, se guían y aprenden de la experiencia dejándose llevar por sus instintos que por análisis lógicos, por lo general escogen a otras personas para los procesos de análisis a desarrollarlos ellos mismos, confían en otras personas para obtener la información, le ponen más énfasis en las tareas antes que pensar, se desenvuelven muy bien en trabajos en equipo con empatía hacia sus compañeros, tienen preferencia por situaciones nuevas de aprendizaje, se sienten muy cómodos, muchas veces manifiestan espontaneidad pero también falta de paciencia.

Para Alonso (1990), así mismo indica que para estos estudiantes es muy fácil realizar simulaciones y dramatizaciones, así como tareas y actividades, aunque estas se tengan que realizar en un tiempo limitado, tienen la capacidad de dirigir una discusión o liderar una reunión, tienen la habilidad de resolver problemas y la facilidad de proponer múltiples soluciones, siempre prefieren realizar trabajos y experiencias de naturaleza práctica, tienen 
facilidad de realizar trabajos con otras personas y también como líderes, ellos prefieren un aprendizaje activo esto les permitirá desarrollar soluciones teniendo en cuenta los riesgos y, poder resolver problemas, se desempeñan bien cuando se requiere una reacción inmediata a las circunstancias utilizan la intuición y realizan actividades que posibiliten aprender de manera independiente con un autodescubrimiento, prefieren buscar posibilidades ocultas y prefieren la variedad y flexibilidad.

Analizando sus preferencias a su estilo de aprendizaje es importante tener en cuenta que no logran un buen proceso de enseñanza aprendizaje cuando se enfatiza la teoría más que la acción, por lo tanto hay que evitar la pasividad y cuando se desarrolla actividades de planificación no pueden ser estricta y precisa sin posibilidad de intervención personal, así como evitar el trabajo individual, la lectura y trabajo puramente intelectual ya que ellos son muy pragmáticos.

\section{Estrategias.}

Por su parte la Real Academia de la Lengua Española RAE, (2014) precisa que la palabra estrategia tiene dos acepciones: 1. Arte de proyectar y dirigir las operaciones militares y especialmente las de guerra y 2. Serie de acciones muy meditadas, encaminadas hacia un fin determinado. En concordancia con el segundo aspecto.

Sierra (2004) plantea que denominamos estrategia al proceso que permite construir una posición que sea tan sólida y potencialmente flexible en ciertas áreas que la organización pueda lograr las metas, a pesar de lo impredecible del comportamiento cuando se presenta la acción de la fuerza externa.

Según Pérez, (1995) el concepto de estrategia hace referencia a un conjunto de acciones que se proyecta y se ponen en marcha de forma ordenada para alcanzar un determinado propósito. De esta forma, todo lo que se hace tiene un sentido dado por la orientación general de la estrategia. En el campo educativo, las estrategias didácticas se refieren a planes de acción 
que pone en marcha el docente de forma sistemática para lograr objetivos de aprendizaje.

\section{Estrategia didáctica}

Se define como aquellos procedimientos donde se agrupan una serie de métodos, técnicas y actividades donde el docente y los estudiantes, constituyen los trabajos de manera consciente para construir metas previstas, imprevistas durante el proceso de aprendizaje, adecuándose a las necesidades de los participantes de modo significativo.

Para Feo (2009), estas estrategias se clasifican en estrategias de enseñanza, instruccionales, aprendizaje y de evaluación. Las estrategias de enseñanza, son las reuniones pedagógicas que se realizan de forma presencial, donde se presentara un comentario pedagógico efectivo tomando en consideración las faltas de los estudiantes, así mismo indica que las estrategias de instrucción son las interrelaciones entre el docente y el estudiante que no siempre son necesarias para tomar conocimiento de los procesos escolares para aprender, esta estrategia se basa en algunos materiales impresos que van a establecer un diálogo didáctico, pueden contar con asesorías entre el docente y el estudiante.

En relación a las estrategias de aprendizaje, son formas que ejecuta el educando de modo consciente, intencional para aprender, para lo cual se emplean diversas técnicas de estudios haciendo el uso de destrezas cognitivas que potencializan sus habilidades ante una actividad o trabajo escolar, estos procedimientos son característicos y únicos del estudiante, teniendo en cuenta que todo ser humano tiene una experiencia distinta de la vida. Y finalmente el autor hace referencia que las estrategias de evaluación, son procedimientos que se generan de la reflexión en función a la valoración y descripción de los logros o metas alcanzada del estudiante y docente en el proceso de enseñanza- aprendizaje. 
Figura 2: La estrategia didáctica, su clasificación.

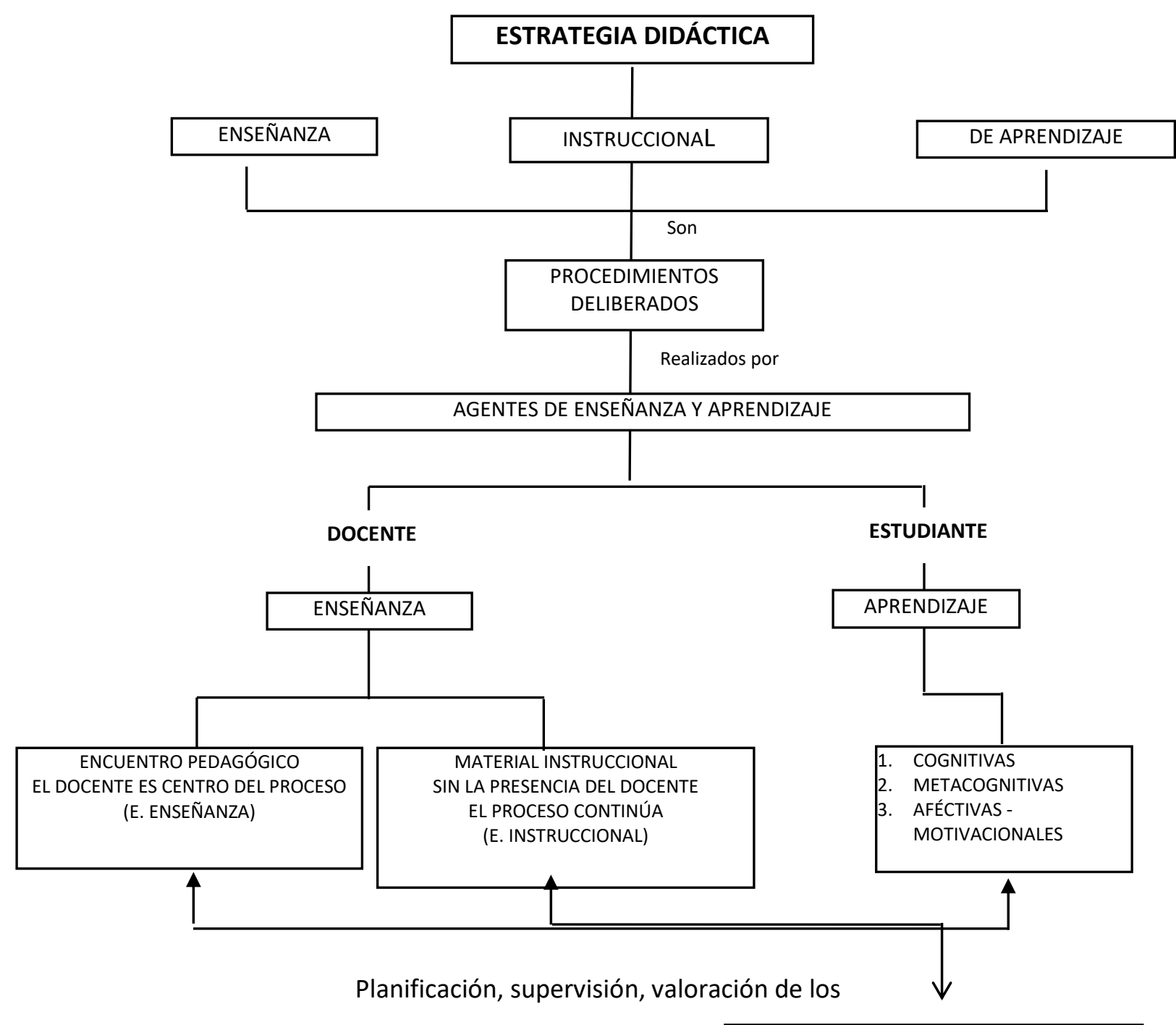

ESTRATEGIA DE EVALUACIÓN

Fuente: Feo Ronald, (2009).

\section{Secuencia didáctica.}

Para Smith y Ragan (1999), se denomina momento de inicio a la orientación preliminar, introducción, que el docente propiciara para preparar a los estudiantes, con el fin de aclarar la finalidad de la actividad, haciendo uso de la información y las habilidades del estudiante durante su participación, para lo cual se utilizan estrategias como mostrar información nueva, saberes previos del estudiante, describir la secuencia de la tarea a desarrollar, dar un contenido que se relacione con las prácticas anteriores del estudiante. 
Los autores indican que en el proceso de desarrollo las estrategias usadas por el docente al ejecutar la actividad tiene relación con el contexto de la clase, para lo cual debe organizar grupos cooperativos, tendrá en cuenta una evaluación individual, y los resultados grupales, brindar el máximo de opciones de acción para proporcionar la percepción de autonomía, orientar la motivación del estudiante poniendo énfasis al proceso de solución que en el resultado.

Para el cierre se emplean diversas estrategias por el docente para finalizar la actividad desarrollada, asegurando el logro de un aprendizaje significativo, en el cierre hay que tener en cuenta los propósitos y principios de la actividad, son aprendidos de manera que exista una relación del nuevo conocimiento con el ya existente. Las estrategias de cierre orientaran la atención de los estudiantes hacia la tarea, promoviendo de manera explícita la adquisición del aprendizaje.

En el proceso de evaluación, se concibe la supervisión de la instrucción, se realiza con fines instruccionales este es un proceso constante. En este contexto se entiende el monitoreo como el proceso constante y permanente de la actividad del estudiante para lograr evidencias de su progreso en el proceso de enseñanza- aprendizaje, y la retroalimentación es la información oportuna para el estudiante sobre su desempeño, para asegurar una mejora en su ejecución futura, el análisis es una diligencia fundamental para la proyección eficaz de la instrucción, así como para probar los cambios, producto del aprendizaje logrado por los estudiantes. Para una mejor comprensión se propone observar siguiente figura: 


\section{Momento de Inicio}

> Activar la atención

- Establecer el propósito

> Incrementar el interés y la motivación

Visión preliminar de la lección

\section{Momento de Desarrollo}

Procesar la nueva información y sus ejemplos

Focalizar la atención

$>$ Utilizar estrategias de enseñanza y aprendizaje

$>$ Practicar

\section{Momento de Cierre}

$>$ Revisar y resumir la lección

> Transferir el aprendizaje

- Remotivar y cerrar

Proponer enlaces

\section{Momento de Evaluación}

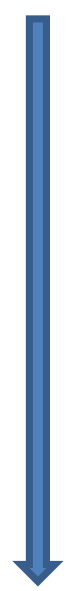

Fuente: Alfonso (2003).

Para Álvarez (1991), la estrategia didáctica es un sistema de planificación aplicado a un conjunto articulado de acciones que permiten conseguir un objetivo y sirve para obtener determinados resultados. De manera que no se puede hablar de que se usan estrategias cuando no hay una meta hacia dónde se orienten las acciones. A diferencia del método la estrategia es flexible puede tomar forma con base en las metas a donde se quiere llegar.

En ese mismo orden de argumentos, Fernández (1998), considera que la estrategia didáctica es el conjunto de procedimientos apoyados en técnicas de enseñanza, que tienen por 
objeto llevar a buen término la acción didáctica, es decir, alcanzar los objetivos de aprendizaje. La estrategia se concreta en las acciones o actividades del maestro para el tratamiento y el análisis del conocimiento donde se orienta el proceso de aprendizaje del alumno e implica acciones o actividades visibles e invisibles para aprender.

Por su parte Addine (1999), indica que la estrategia didáctica es un proceso que se aplica durante el proceso de aprender concretándose en las secuencias integradas extensas y complejas de acciones, así como en los procedimientos organizados que atienden a todos los componentes o las categorías didácticas que persiguen alcanzar los objetivos de un aprendizaje significativo en los procesos educativos.

Otra posición teórica aborda Tobón (2009), al considerar la estrategia didáctica como una construcción lógica, pensada para orientar el aprendizaje y la enseñanza de las competencias en los diversos niveles educativos. Se basa en procedimientos compuestos por un conjunto de etapas que pretenden facilitarles el aprendizaje de las mismas en los estudiantes.

En congruencia con ello Feo (2010), al considerar la estrategia didáctica como un modelo, compuesto por métodos, procedimientos, técnicas y actividades a través de los cuales el docente y estudiante organizan acciones de manera reflexiva para construir metas en el proceso enseñanza- aprendizaje, adecuándose a las necesidades de los participantes de manera significativa.

Para Velasco y Mosquera (2010), la estrategia didáctica responde a un procedimiento organizado, formalizado y orientado para la obtención de una meta claramente establecida; su aplicación en la práctica requiere de procedimientos y de técnicas cuya elección y diseño son responsabilidad del docente. La estrategia didáctica implica la planificación del proceso de enseñanza- aprendizaje para el cual el docente elige las técnicas y actividades que puede utilizar a fin de alcanzar los objetivos propuestos y las decisiones que debe tomar de manera 
consciente y reflexiva en los educandos.

Una estrategia didáctica para la competencia literaria, constituye una variante específica de estrategia de enseñanza-aprendizaje, ya que la etapa de planificación está dirigida fundamentalmente a la enseñanza, y la etapa de ejecución está destinada al aprendizaje, aunque ambos procesos se dan juntos y en unidad dialéctica.

En resumen hay que diferenciar la estrategia didáctica que se aplica en desarrollo de una clase determinada del programa de asignatura que llevamos a cabo en la docencia de una sala de clase, con la estrategia didáctica como un modelo teórico- práctico resultado del proceso de investigación que se sustentan desde posiciones teóricas interdisciplinarias y científicas en general, y se constituyen en un aporte al campo pedagógico como precisa Hernández (2002).

\section{Creación de espacio para favorecer la atención de los estudiantes.}

Los componentes de las competencias demanda por parte de los estudiantes la puesta en acción en relación a la atención selectiva de manera planeada y consiente Díaz y Hernández, (1999), indica para mantener la atención hay que recordar las diferentes estrategias que van a favorecer la motivación a continuación indicaremos algunas definiciones con respecto a la motivación.

El termino motivación se deriva del verbo latino moveré, cuyo significado es moverse, es decir estar siempre listo para la acción. Para Moore (2001), este término implica impulsos o fuerzas que nos van a permitir tener energía y poder actuar de la manera en la que lo hacemos. (p.222).

Según Woolfolk (1996), la motivación es el estado interno de quien va mantener y dirigir la conducta, este término es un constructo teórico que hoy en día se emplea para explicar las conductas propias del comportamiento, especialmente aquello que está orientado a metas específicas, así un motivo es un elemento de conciencia que entra en la determinación de un 
acto, es lo que induce a una persona a llevar a la práctica una acción. (p.330).

Para Rickards (1980), la realización de preguntas intercaladas, tienen que insertarse a determinadas partes de una exposición o de un texto con el fin de despertar la atención y de ese modo facilitar el aprendizaje. Esta estrategia debe mantener la curiosidad del educando en un tema, ayudará a mostrar aspectos relevantes de una exposición, favoreciendo la reflexión y la comprensión de la información, hay que considerar algunas recomendaciones como no abusar de las preguntas, mínimamente formular preguntas al inicio, mitad y final de una exposición, brindar retroalimentación sobre las respuestas dadas a las preguntas.

Para Díaz y Hernández, (1999), indica el uso de las ilustraciones, son recursos que permitirán ilustrar ideas como fotografías, esquemas, graficas e imágenes, estos recursos van a permitir despertar el interés de los estudiantes favoreciendo la atención y concentración en el desarrollo de un tema, ayudando a entender y comprender la secuencia de acciones. Para el uso de estos recursos es recomendable variar las ilustraciones utilizados en las exposiciones de los trabajos.

\section{Espacios académicos para generar la personalización de la información}

Para Cooper (1990), son programaciones proyectadas y metódicas que el docente realiza con la finalidad de que los estudiantes asuman los componentes de la competencia con un sentido personal, teniendo en cuenta su proyecto de vida con actitud crítica y pro activa, se pueden considerar como estrategias que permita orientar a los estudiantes a relacionarse con la competencia para aprender de acuerdo a sus metas y necesidades personales, facilitara los espacios y las intenciones pedagógicas así como los recursos necesarios para cada estudiante, por lo tanto tomen la iniciativa en la formación de sus competencias.(p.226).

Para Lewis (2000), considera que una actividad que genere la información o la personalización de la misma, es aquella estrategia de búsqueda de conocimientos previos, lo cual permite a los estudiantes activar, reflexionar y compartir información previa sobre un 
tema determinado, para otros autores refieren a esta estrategia como lluvia o tormenta de ideas, esto permite una participación de los alumnos en una tarea individual, en equipos o pequeños grupos, incluso cuando los alumnos ya saben elaborar mapas conceptuales.(p. 150).

Para Hartley (1985), es indudable reconocer que existen diversas estrategias que son recomendables al personalizar la información, las ilustraciones como fotografías, dibujos, pinturas, retratos, esquemas, hacen posible comunicar ideas concretas, así como de algún nivel de abstracción, nociones de tipo objetivo que facilita la elaboración de procedimientos, técnicas o instrucciones con diversas ilustraciones, complementando la información de manera parcial o total según sea la necesidad del proceso de aprendizaje.

Para el autor hay muchas interrogantes que el docente realiza al estudiante con el propósito de control y seguimiento del proceso en el aula, se indica que las preguntas más efectivas son aquellas que están destinadas al esfuerzo de construcción y personalización de la información, así como otras estrategias que sirven para retroalimentar, con la intervención y participación espontanea de los educandos.

Según Lemke (1997), manifiesta que el dialogo es una de las estrategias empleadas, que sirven para incorporar las participaciones de los estudiantes, esta estrategia también sirve para enfatizar y generar la intervención de forma verbal del estudiante, permitiendo un mejor desenvolvimiento e interrelación con sus compañeros y con el docente, quedando legitimado considerándose correcto además de enriquecedor al proceso educativo. (p.159).

Espacio pedagógico en la sesión de clases para alcanzar la adquisición de la información.

Para Cooper (1990), indica que las estrategias dirigidas a activar y adquirir la información previa de los estudiantes o generarlos cuando estas no existan, la importancia de aflorar los conocimientos previos es muy importante para el proceso de aprendizaje, la activación da un 
doble sentido para tener un referente de lo que saben los alumnos, poder utilizar este conocimiento con una base para la adquisición de nuevos aprendizajes, podemos incluir aquellas estrategias que sirvan de apoyo en las intenciones educativas y así poder lograr la secuencia educativa, desarrollando expectativas adecuadas sobre la sesión instruccional y lograr un sentido y valor funcional de los aprendizajes involucrados.( p.145).

Para Wolff (1991), las estrategias para la codificación de la información para aprender estarán encaminadas a facilitar al estudiante la oportunidad que ejecute una sistematización consecutiva, suplementaria o alternativa a la indicada por el docente, la intención a través del uso de las estrategias alcanzar una nueva información de calidad, facilitando la contextualización en su proceso de elaboración, donde los estudiantes tengan una mejor asimilación, por lo que es necesario que las estrategias se usen en forma coinstruccional. Tomando como ejemplo la gama de información gráfica como son ilustraciones, gráficos y demás.

Por lo tanto Ausubel (1976), incluye a los organizadores previos como una estrategia de los docentes para facilitar la recolección de información, esta técnica se puede aplicar de manera introductoria con el fin de ofrecer un contexto general pudiendo incluir nuevos aprendizajes, estos organizadores facilitan comprender nueva información desde los saberes previos, permitiendo una visión general de cualquier tema que se incluyan nueva información y poder construir nuevos conocimientos, el autor recomienda que su uso pueden ser textuales, como mapas conceptuales o se pueden aplicar de ambas formas.

Para Tobón y Fernández (2003), demuestra como una estrategia para adquirir la información, hace uso de la cartografía conceptual como un procedimiento grafico fundamentado en mapas mentales, donde el objetivo es la estructura de conceptos científicos mediante ejes de efecto de la noción, la categoría, la diferenciación y la ejemplificación, caracterización, sub división y de vinculación, estos ayudan a edificar la memoria a largo 
plazo, la clasificación de un concepto lo cual permite la construcción sistemática de las mismas, en una área determinada.(p.225).

\section{Construcción lógica del conocimiento.}

Conociendo la importancia en la construcción del conocimiento, esta actividad reconstructiva no sería posible sin la información previa de manera simple y sencilla que permita entender e interpretar la nueva información y a través de ella reestructurar y transformar nuevas contingencias. Miras, (1993).

Piaget (1976), en la década de los 50 se inaugura el centro de filosofía, donde sus estudios están ligadas al proceso cognitivo de la información, su interés en una gran interrogante acerca del conocimiento, y como es que el hombre pasa de un estado de conocimiento inferior a otro de orden superior, partiendo de estas interrogantes, para Piaget el sujeto es epistémico, es decir construye el conocimiento de la realidad, pero también es abstracto porque lo describe de manera general y universal. En sus obras de psicología genética como de epistemología buscan respuestas acerca de la construcción de conocimiento, sus diferentes investigaciones sobre el dominio del pensamiento infantil demostraron que la lógica del niño no solo se construye progresivamente, sino que además se desarrolla durante toda la vida, pasando por diferentes etapas antes de lograr el nivel adulto.

La contribución del autor sobre el conocimiento fue demostrar que el niño tiene maneras de pensar específicas diferentes al adulto, así mismo indica que los pensamientos cambian lenta y significativamente de la niñez hasta la madurez, a través de varios elementos, la maduración, la transmisión social donde ocurre un desarrollo intelectual y la actividad y tendencia al equilibrio desencadena la interacción entre la mente del sujeto y el medio ambiente. El niño asume un papel activo en la construcción del conocimiento, a partir del descubrimiento de nuevos problemas y situaciones desconocidas, busca información que no comprende y soluciones para alcanzar niveles superiores de pensamiento. 


\section{Capitulo II}

\section{Diagnostico o trabajo de campo}

Se describirán hallazgos en tal sentido después de aplicar diferentes técnicas e instrumentos de recolección de datos (ver el anexo 3). Se aplicó el cuestionario a 15 estudiantes con la finalidad de constatar el nivel de satisfacción que experimentan con la manera que el docente desarrolla la sesión de clases teniendo en cuenta que los procesos de motivación, de desarrollo de información y de evaluación tenga relación con los gustos, preferencias y/o estilos de aprender que poseen los estudiantes del I ciclo de la carrera de Cosmética Dermatológica; así mismo, también se trabajó una guía de entrevista a tres docentes y su finalidad es comprobar los conocimientos teóricos, prácticos así como sus diversas estrategias didácticas y metodológicas que posee cada uno, en relación a las características de los estilos de aprendizaje y finalmente se aplicó la observación de clase en dos sesiones de aprendizaje, con la finalidad de identificar las estrategias, la metodología y los instrumentos de aplicación por cada docente, y si estos están acorde con la manera de preferencia o estilo de aprender de los estudiantes de una institución estatal de Lima.

\section{Análisis e interpretación de los hallazgos por técnicas e instrumentos}

En el proceso del trabajo de campo, se hizo la reducción de datos encontrados en la aplicación de los instrumentos; el análisis e interpretación de estos datos paso a un proceso de reducción a través de la codificación, identificando ideas, claves y códigos, para lo cual se realizó un proceso exhaustivo, microanálisis y examen minucioso palabra por palabra y línea por línea.

La fase de análisis e interpretación de los datos cualitativos se llevaron a cabo de manera manual y los datos cuantitativos a través de del programa SPSS. Según Creswell (1998), citado por Hernandez, Fernandez y Baptista (2014, p. 461), en este proceso de análisis cualitativo se desarrolla en forma de espiral, por lo cual el objeto de estudio es observado desde varias perspectivas. 
La recolección de los datos desde el enfoque cualitativo según los mismos autores indican que al igual para el enfoque cuantitativo, la recolección de datos es un producto fundamental, con la diferencia que su propósito no es medir variables para realizar inferencias y análisis estadístico, diferente a lo que se busca en un estudio cualitativo que es obtener datos donde posteriormente se convertirán en información de personas, seres vivos, comunidades, contextos o situaciones en profundidad, al tratarse de personas los datos de interés son definiciones, percepciones, imágenes mentales, creencias, opiniones, emociones, interacciones, pensamientos, experiencias, procesos y vivencias manifestadas a través del lenguaje de los participantes, ya sea de manera individual, grupal o colectiva.

Se recolectan con la finalidad de analizarlos y comprenderlos, para luego responder a las preguntas de investigación y generar conocimiento, este tipo de datos es muy útil para capturar lo más que sea posible, los significados y las razones internas del comportamiento humano, no se reducen para ser analizados estadísticamente, aunque en algunos casos sí se pueden efectuar ciertos análisis cuantitativos, pero no es el fin del estudio cualitativo. (p.583).

\section{Validación de instrumentos.}

La elaboracion y construcción de los tres instrumentos aseguró la importancia del contenido de las categorias, sub categorias de los indicadores, a través de la consulta de los especialistas, quienes después de una revisión y correccion constante , análisis de cada uno de los ítems, permitió mejorar la sintáctica, semántica y redaccion de cada uno de los indicadores y construir las preguntas para su respectiva aplicación en el campo y recojo de datos respectivos.

Tabla 3

Expertos seleccionados para validar los instrumentos

\begin{tabular}{|l|l|l|l|c|}
\hline $\begin{array}{l}\text { Nombre y } \\
\text { Apellidos }\end{array}$ & $\begin{array}{l}\text { Grado } \\
\text { académico }\end{array}$ & Especialidad profesional & Ocupación & $\begin{array}{l}\text { Años de } \\
\text { experiencia }\end{array}$ \\
\hline $\begin{array}{l}\text { Fernando Goñi } \\
\text { Cruz }\end{array}$ & Doctor & $\begin{array}{l}\text { Doctor en Ciencias de la } \\
\text { Educación }\end{array}$ & $\begin{array}{l}\text { Docente } \\
\text { investigador }\end{array}$ & 20 años \\
\hline
\end{tabular}




\begin{tabular}{|l|l|l|l|c|}
\hline $\begin{array}{l}\text { Serpa Jesus } \\
\text { Montes de oca }\end{array}$ & Doctor & Doctor en Psicología & $\begin{array}{l}\text { Docente } \\
\text { investigador }\end{array}$ & 20 años \\
\hline $\begin{array}{l}\text { Medina Zuta, } \\
\text { Patricia }\end{array}$ & Doctor & $\begin{array}{l}\text { Doctor en Psicología de la } \\
\text { Educacion y Desarrollo } \\
\text { Humano }\end{array}$ & $\begin{array}{l}\text { Docente } \\
\text { investigador }\end{array}$ & 22 años \\
\hline
\end{tabular}

Fuente: Elaboración propia (2020).

\section{Presentación de resultados por técnicas e instrumentos de investigación}

En este sentido, se hizo la descripción de situaciones, acciones y comentarios surgidos en la observación de sesión de clases, entrevista a docentes, cuestionario a estudiante.

Al respecto Mayz (2009) refiere que, en el proceso de análisis e interpretación de datos es necesario la descripción permanente de situaciones, actitudes, acciones y comentarios que surgen de los sujetos involucrados, ya que se busca comprender qué piensan, cómo actúan y cómo lo realizan en una realidad socio educativa concreta. Se ordenó la información registrada agrupando por técnicas e instrumentos, tal como se detalla a continuación:

\section{Cuestionario realizado a los estudiantes}

Teniendo en cuenta la realidad del estudio, y siendo la investigación de tipo aplicada educacional, el cuestionario nos permite conocer la realidad y resolver una serie de problemas de fenómenos sociales, tal vez el instrumento más utilizado para recolectar los datos es el cuestionario.

El cuestionario consiste en un conjunto de preguntas respecto de una o más variables a medir, para Chasteauneuf (2009) estos enunciados deben ser congruente con el planteamiento del problema, debe existir una coherencia entre la elaboración de los interrogantes en relación al problema de investigación, debe ser clara, concisa y de fácil entendimiento para los participantes, permitiendo una respuesta que permita avizorar soluciones.

Por su parte Brace (2013) los cuestionarios se usan en todo tipo de encuestas, para calificar diversos desempeños, conocer las necesidades y evaluar la percepción sobre ciertos 
problemas de índole educativo, de gestión, también se implementan en otros campos, es una herramienta para que expertos aporten opiniones calificadas con el fin de resolver ciertas problemáticas, las características de las preguntas deben tener en cuenta el contexto de la formulación del problema.

Durante la aplicación del cuestionario, la encuesta de opinión se realizó a 15 estudiantes del I ciclo de la carrera de Cosmética Dermatológica de un instituto público de Lima con la finalidad de constatar los gustos, preferencias y/o estilos de aprendizaje que poseen.

Por lo cual se diseñó un cuestionario estructurado tomando en cuenta las sub categorías apriorísticas para lo cual se elaboró 20 preguntas cuyo fin fue constatar si los docentes toman en cuenta la manera como desean aprender de acuerdo al estilo de aprendizaje y así aportar en el proceso de construir el conocimiento, para lo cual fue procesada mediante el paquete estadístico SPSS-v25, instrumento de tipo cuantitativo que permite describir los hallazgos de la encuesta a los estudiantes de educación técnica.

Para lo cual, se describen los hallazgos encontrados en la encuesta de opinión a los estudiantes, en cuanto al enunciado si el docente empieza las clases relatando experiencias motivadoras. Los resultados indican que el $64.29 \%$ considera que el docente empieza las clases relatando experiencias motivadoras a veces, así mismo el $21.43 \%$ indica que siempre el docente empieza las clases relatando experiencias motivadoras, el $7.14 \%$ indica que casi siempre el docente empieza las clases relatando experiencias motivadoras así mismo el 7.14\% casi nunca el docente empieza las clases relatando experiencias motivadoras. $46.67 \%$.

En referencia a la pregunta: el docente desarrolla la lluvia de ideas como estrategia de motivación el $50.00 \%$ de los estudiantes encuestados considera que a veces el docente desarrolla la lluvia de ideas como estrategia de motivación, sin embargo, el $14.29 \%$ de estudiantes indicaron que casi nunca el docente utiliza o desarrolla lluvia de ideas como estrategia de motivación. 
Con respecto si el docente presenta gráficos, ilustraciones para despertar el interés durante el inicio de clases, se observa que el $42.86 \%$ de las estudiantes considera que casi siempre el docente presenta gráficos, ilustraciones para despertar el interés durante el inicio de clases, así mismo el $28.57 \%$ indica que a veces el docente presenta gráficos, ilustraciones para despertar el interés durante el inicio de clases, el $21.43 \%$ indica que siempre el docente empieza las clases presentando gráficos, ilustraciones para despertar el interés durante el inicio de clases así mismo el $7.14 \%$ de las estudiantes indica que casi nunca el docente presenta gráficos, ilustraciones para despertar el interés durante el inicio de clases.

En la proposición si el docente plantea actividades en las cuales se evidencia la transferencia de los nuevos conocimientos a la vida cotidiana se indica que el $42.86 \%$ de las estudiantes considera que el docente plantea actividades en las cuales se evidencia la transferencia de los nuevos conocimientos a la vida cotidiana, así mismo el $28.57 \%$ indica que casi siempre el docente plantea actividades en las cuales se evidencia la transferencia de los nuevos conocimientos a la vida cotidiana, el $14.29 \%$ indica que a veces el docente plantea actividades en las cuales se evidencia la transferencia de los nuevos conocimientos a la vida cotidiana así mismo el $14.29 \%$ indica que casi nunca el docente plantea actividades en las cuales se evidencia la transferencia de los nuevos conocimientos a la vida cotidiana.

En cuanto a la pregunta si el maestro realiza procedimientos teniendo en cuenta la sistematización de una práctica, los encuestados indican que el 50.00\% de las estudiantes considera que el docente realiza procedimientos teniendo en cuenta la sistematización de una práctica, así mismo el $21.43 \%$ indica que casi siempre el docente realiza procedimientos teniendo en cuenta la sistematización de una práctica, el $21.43 \%$ indica que a veces el docente realiza procedimientos teniendo en cuenta la sistematización de una práctica así mismo el 7.14\% casi nunca el docente realiza procedimientos teniendo en cuenta la sistematización de una práctica. 
Sobre el enunciado de si antes del desarrollo de clases el docente pregunta si es que los estudiantes saben algo sobre el tema que va a explicar indican que el $28.57 \%$ de las estudiantes considera que casi siempre antes del desarrollo de clases el docente pregunta si es que los estudiantes saben algo sobre el tema que va a explicar, así mismo el $28.57 \%$ indica que a veces antes del desarrollo de clases el docente pregunta si es que los estudiantes saben algo sobre el tema que va a explicar, el $21.43 \%$ indica que casi siempre antes del desarrollo de clases el docente pregunta si es que los estudiantes saben algo sobre el tema que va a explicar así mismo el $21.43 \%$ indica que casi nunca antes del desarrollo de clases el docente pregunta si es que los estudiantes saben algo sobre el tema que va a explicar

En la pregunta si el docente promueve el desarrollo de la información de manera ordenada, coherente y dinámica, indican que el $42.86 \%$ de las estudiantes piensa que siempre el docente promueve el desarrollo de la información de manera ordenada, coherente y dinámica, así mismo el $28.57 \%$ de las alumnas indica que casi siempre el docente promueve el desarrollo de la información de manera ordenada, coherente y dinámica, el $14.29 \%$ indica que a veces el docente promueve el desarrollo de la información de manera ordenada, coherente y dinámica y el $14.29 \%$ casi nunca el docente promueve el desarrollo de la información de manera ordenada, coherente y dinámica.

En cuanto a la pregunta sin el docente desarrolla lecturas de análisis de fácil comprensión durante la sesión de clases, indican que el $35.71 \%$ de las estudiantes desarrolla lecturas de análisis de fácil comprensión durante la sesión de clases a veces, así mismo el $35.71 \%$ indica que siempre el docente desarrolla lecturas de análisis de fácil comprensión durante la sesión de clases y el 21.43\% indica que casi siempre el docente desarrolla lecturas de análisis de fácil comprensión durante la sesión de clases así mismo el 7.14\% casi nunca el docente desarrolla lecturas de análisis de fácil comprensión durante la sesión de clases. 
Con respecto a la pregunta si en la sesión de clases el docente toma en cuenta la información previa para crear nuevas definiciones sobre determinado tema, responden que el $35.71 \%$ de las estudiantes considera que en la sesión de clases el docente casi siempre toma en cuenta la información previa para crear nuevas definiciones sobre determinado tema así mismo el $28.57 \%$ indica que siempre en la sesión de clases el docente toma en cuenta la información previa para crear nuevas definiciones sobre determinado tema, el $21.43 \%$ indica que a veces en la sesión de clases el docente toma en cuenta la información previa para crear nuevas definiciones sobre determinado tema así mismo el $14.29 \%$ casi nunca En la sesión de clases el docente toma en cuenta la información previa para crear nuevas definiciones sobre determinado tema.

Sobre la interrogante si se construye resúmenes de las clases anteriores tomando en cuenta los previos y nuevos conocimientos, los encuestados indican que el $35.71 \%$ de las estudiantes considera que el docente casi siempre construye resúmenes de las clases anteriores tomando en cuenta los previos y nuevos conocimientos así mismo el $28.57 \%$ indica que a veces el docente construye resúmenes de las clases anteriores tomando en cuenta los previos y nuevos conocimientos mientras que el $21.43 \%$ indica que siempre el docente construye resúmenes de las clases anteriores tomando en cuenta los previos y nuevos conocimientos y el $14.29 \%$ casi nunca construye resúmenes de las clases anteriores tomando en cuenta los previos y nuevos conocimientos.

En la pregunta si el docente promueve el análisis de la información a través de ayudas visuales, indican que el $28.57 \%$ de las estudiantes considera que el docente promueve el análisis de la información a través de ayudas visuales a veces, así mismo el $28.57 \%$ indica que siempre el docente promueve el análisis de la información, el 21.43\% indica que casi siempre el docente empieza las clases relatando experiencias motivadoras así mismo el $21.43 \%$ casi nunca el docente promueve el análisis de la información a través de ayudas visuales. 
Concerniente si el docente desarrolla casuísticas, ejemplos promoviendo la resolución de problemas, Indican que el $50.00 \%$ de las estudiantes considera que el docente desarrolla casuísticas, ejemplos promoviendo la resolución de problemas, a veces, así mismo el $28.57 \%$ indica que casi siempre el docente promueve la resolución de problemas, el $21.43 \%$ indica que siempre el docente desarrolla casuísticas, ejemplos promoviendo la resolución de problemas.

Sobre la pregunta si el docente desarrolla los trabajos prácticos con un respaldo científico, indican que el $28.57 \%$ de las estudiantes considera que el docente desarrolla trabajos prácticos con respaldo científico a veces, así mismo el $28.57 \%$ indica que siempre el docente desarrolla trabajos prácticos con respaldo científico, el $28.57 \%$ indica que casi siempre el docente desarrolla trabajos prácticos con respaldo científico así mismo el 14.29\% casi nunca el docente toma en cuenta el enunciado.

Con respecto a la pregunta: El profesor realiza proyectos, prácticas y experimentos para desarrollar la indagación científica el $57.14 \%$ de los estudiantes encuestados indican que a veces el docente realiza proyectos, prácticas y experimentos para desarrollar la indagación científica mientras que el $14.29 \%$ considera que casi siempre su docente programa proyectos y prácticas que les permite sustentar a nivel científico.

En la pregunta si el docente promueve el trabajo en equipos y permite que los estudiantes comuniquen y sustenten los resultados obtenidos en la experimentación o investigación, los encuestados indican que el $42.86 \%$ de las estudiantes considera que el docente a veces, promueve el trabajo en equipos y que los estudiantes sustenten su investigación, asi mismo el $28.57 \%$ indica que siempre el docente promueve el trabajo en equipos y permite que los estudiantes comuniquen y sustenten los resultados obtenidos en la experimentación o investigación, el $28.57 \%$ indica que casi siempre el docente promueve el 
trabajo en equipos y permite que los estudiantes comuniquen y sustenten los resultados obtenidos en la experimentación o investigación.

En la proposición de si el docente promueve la ejecución de prácticas en equipo durante la sesión de clases, que el $35.71 \%$ de las estudiantes considera que el docente a veces, promueve la ejecución de prácticas en equipo durante la sesión de clases a sí mismo el $28.57 \%$ indica que siempre el docente, promueve la ejecución de prácticas en equipo durante la sesión de clases el $21.43 \%$ indica que casi siempre el docente promueve la ejecución de prácticas en equipo durante la sesión de clases así mismo el 14.29\% casi nunca promueve la ejecución de prácticas.

En la pregunta si el docente ordena el desarrollo de los trabajos prácticos los encuestados indican que el $64.29 \%$ casi siempre el docente ordena el desarrollo de los trabajos prácticos, el $21.43 \%$ indica que a veces, mientras que el $14.29 \%$ manifiestan que siempre el docente ordena el desarrollo de los trabajos prácticos..

En la proposición de si el docente desarrolla problemas para promover tu toma de decisiones en la sesión de clases, los encuestados indican que el $35.71 \%$ de las estudiantes considera que siempre y casi siempre el docente desarrolla problemas para promover tu toma de decisiones en la sesión de clases, mientras que el $28.57 \%$ indica que solo a veces el docente promueve el desarrollo de problemas y la toma de decisiones durante la sesión de clases.

Cuando se le pregunta sobre si el profesor realiza análisis de la información en párrafos de lecturas seleccionadas en la sesión de clases a las estudiantes afirma que el $35.71 \%$ considera que a veces el profesor realiza análisis de la información en párrafos de lecturas seleccionadas en la sesión de clases, mientras que el $14.29 \%$ indica que casi nunca el profesor realiza análisis de la información en párrafos de lecturas seleccionadas durante el desarrollo de la sesión de clases. 
Finalmente, sobre la sugerencia la pregunta si su docente promueve la ejecución de prácticas en equipo durante la sesión de clases. Las estudiantes indican que el $35.71 \%$ considera que el docente siempre promueve la ejecución de prácticas en equipo en el proceso de enseñanza así mismo el $14.29 \%$ indica que casi nunca el docente realiza la ejecución de prácticas en equipo.

\section{Conclusión}

Teniendo en cuenta las respuestas de los estudiantes en la aplicación del cuestionario, el docente no cuenta con buenas estrategias para el análisis de las diversas lecturas, así como no hay procesos que inculquen el proceso de investigación o el desarrollo de proyectos relacionados con la carrera, siendo esto una de las principales dificultades no solo a nivel del Alumnado sino también a nivel de los docentes, también cabe resaltar que faltan estrategias de motivación que mantengan y despierten el interés en el desarrollo de la sesión de clases.

\section{Entrevista semiestructurada a docentes.}

A continuación, los hallasgos se describen en relación a las veinte preguntas realizadas a los dos docentes del área tecnica de las unidades didacticas de dermatologia y estetica facial, diseñadas en relación a las subcategorías apriorísticas, y sus respectivas conclusiones.

Por consiguiente, se tomó como base las sub-categorías de el estilo de aprendizaje y estrategias didacticas, por ello, se realizó una entrevista semiestructurada a dos docentes cuyo fin es conocer el desarrollo teórico, practico y didáctico que poseen en el tema de estrategias pedagogicas y metodologicas para el estilo de aprendizaje según sus caracteristicas inherentes e individuales, los docentes fueron entrevistados de manera personal e individual en las instalaciones de la I.E. en horarios de clases no lectivas de acuerdo a su carga horaria previa coordinacion con la directora, cada entrevista constó de 20 preguntas que inicialmente fueron un poco tensas, pero al pasar el transcurso de los minutos se dieron mas agradables por lo que 
se fueron adaptándose conforme se desarrollo cada pregunta, tuvieron una duración promedio de 55 minutos las cuales fueron grabadas en equipos estereofónicos.

Los hallazgos encontrados en las entrevistas realizadas a los docentes, con respecto al conocimiento que tienen sobre los estilos de aprendizaje indicaron algunos conceptos errados sobre el tema ya que manifestaron los tipos de aprendizaje, la complejidad del proceso enseñanza aprendizaje, por lo tanto, se percibió que no existe una claridad en lo referente a estilos de aprendizaje

Al respecto, en los resultados logrados en el proceso de codificación las respuestas proporcionadas por cada uno de los docentes en la guía de entrevista semiestructurada. Los docentes revelan una falta de seguridad y preparación teórica por parte de los estudiantes para sustentar y argumentar, tambien manifiestan una falta de motivación para buscar información teórica-práctica relevante y así tener multiples posibilidades que les permita desarrollar resolucion de problemas aplicando un criterio propio que les permita solucionar teniendo una valoración objetiva y concreta.

De igual manera, acotaron que existe temor para transmitir sus ideas debido a una falta de costumbre por escuchar opiniones externas, al diálogo comentado, que permite que se cuestionen mutuamente para obtener un beneficio entre ellos, alcanzando como resultado procesos creativos de calidad producto de la meta cognición.

El segundo docente, manifiesta que hay un abandono de parte de la gestión de los directivos en la implementación de materiales de índole pedagógico que limita el proceso de enseñanza aprendizaje, así como una falta de capacitación sobre técnicas metodológicos en los momentos de la motivación para mantener el interés del estudiante permanentemente, realizar un proceso de reflexión para el autoconocimiento de sus capacidades, autoevaluación.

Para Taylor y Bogdan (1994) señalan que estas entrevistas permiten encuentros entre dos o más personas y garantizar la razón de la realidad por parte de ambos, en un ambiente de 
democracia, responsabilidad, empatía, reconocimiento a la labor desempeñada por el investigador, acorde a sus propios términos. Las entrevistas a profundidad tienen como fin internarse de manera subjetiva con los entrevistados, es la clave del estudio, permitiendo obtener información relevante, aproximándose de manera cautelosa, esto posibilita un diálogo fluido, adecuado y empático, desencadenado la reflexión del investigador y el procesamiento interno de la información.

Así mismo, Robles (2011) precisa que la principal finalidad de este tipo de técnica, es permitir el ingreso en la vivencia didáctica del otro, comprender detallando lo trascendente entendiendo sentimientos negativos y positivos como el miedo, angustia, satisfacciones del entrevistado; se busca construir detallada y cuidadosamente la experiencia del otro. La entrevista en profundidad sigue el modelo de razonamiento entre iguales (p.3).

\section{Observación a docentes.}

Se específica los resultados obtenidos de la observación a los dos docentes del área tecnica y de las unidades didacticas de estetica corporal y quimica aplicada, de acuerdo a las quince unidades de observación, diseñadas de acuerdo a las dos subcategorías apriorísticas y sus respectivas conclusiones.

La observación a los docentes se aplicó para evidenciar el estilo de aprendizaje que poseen los estudiantes para desarrollar una estrategia didactica en un Instituto publico de Lima, cada observación, tuvo una duración promedio de 135 minutos las cuales fueron grabadas en equipos especializados. Las observaciones y las entrevistas se utilizaron de fuentes para realizar una correlación y de esta manera evidenciar las carencias y limitaciones de los docentes en el proceso de aprendizaje.

Los hallazgos encontrados durante la observación de clases, evidenciaron que los docentes respetan las normas que exige la institución en relación a la presentación del alumnado dentro del aula, de la misma forma el docente muestra seguridad, dominio y orden 
en la transmisión de información, aunque hay una deficiencia de técnicas que hagan mantener la motivación constante durante el desarrollo de la sesión de aprendizaje, se aplicó la motivación al inicio de la sesión más se fue dispersando cuando ya fueron transcurriendo los minutos, realiza un desarrollo constructivista donde el estudiante analiza y construye sus conocimientos.

Con la supervisión permanente del docente a través del material didáctico como son las separatas que corresponden a la sesión de aprendizaje, se observa que en ciertos momentos se desarrollan relaciones empáticas en los estudiantes y otros momentos el docente se muestra gentil con los estudiantes; sin embargo también se observa en otro momento que es necesario originar relaciones humanas en el aula, debido a la preocupación de mantener el orden, en ciertas situaciones el docente se muestra estricto. Sin embargo, es reconocible y rescatable ver que el docente respeta las opiniones que manifiestan los alumnos en el desarrollo de la actividad.

Así mismo en la observación permitió evidenciar que al segundo docente le cuesta mantener el orden de los estudiantes cando ellos elaboran algunos materiales que les permitirá la explicación de un aspecto conceptual, las estudiantes tienen dificultad en el proceso de expresar sus opiniones e interactuar entre ellos, así como también con el docente, en algunos momentos se observa la perdida de paciencia cuando no hay cumplimiento de las actividades indicadas durante la sesión de clases. Por otra parte, el docente pocas veces promueve la expresión de sentimientos en el aula, demuestra la falta de manejo en cuanto al orden al inicio de la clase, manejando la situación en el proceso y en la evaluación.

De igual modo se pudo evidenciar que hay una deficiencia de parte del docente para desarrollar relaciones empatía, lazos de amistad y confianza entre los estudiantes, lo que más se observa es que el docente se muestra más estricto y menos afectuoso. Es una actitud negativa con falta de liderazgo y empatía, estas son actitudes que apertura una brecha entre el estudiante 
y el docente impidiendo un acercamiento y una buena relación en ambos perjudicando todos los procesos que se deben de dar en el proceso de enseñanza- aprendizaje.

De acuerdo a la observación de clases podemos concluir que hay una deficiencia en el aspecto del rol del docente debido a que prevalece las normas y exigencias que determina la institución, esto dificulta un correcto desarrollo proceso de enseñanza aprendizaje, porque no se crea la parte afectiva y de confianza entre el docente y el alumno, esto dificulta la comunicación fluida que debe de existir para realmente cumplir con el papel de mediador y facilitador de la información.

El docente tiene conocimiento, pero hay una deficiencia de estrategias de motivación e interés permanente en la sesión de clases, por lo tanto, se desarrolla una sesión monótona y sin despertar el interés del estudiante siendo imposible llegar a lograr un aprendizaje significativo.

\section{Análisis e interpretación de categorías emergentes y apriorísticas}

En esta parte luego de analizar y realizar el proceso de reducción de datos, la codificación, categorización y triangulación metodológica, la información que se obtuvo de la aplicación de instrumentos; se establecieron y agruparon en familias, codigos que fueron resultantes finalmente en categorías emergentes encontradas del proceso de investigación de las cuales ocho categorías coinciden con las categorías apriorísticas y las dos restantes son categorías nuevas.

Luego del proceso de la triangulación metodológica y de datos, se llevó a cabo la redacción de las conclusiones aproximativas por cada categoría emergente, lo cual se diseñó en base al conjunto de códigos agrupados por su semejanza.

Para ilustrar lo antes mencionado se puede visualizar en el siguiente cuadro el resumen de las categorías genéricas o explicativas: 
Figura 4: Resultados de diagnostico

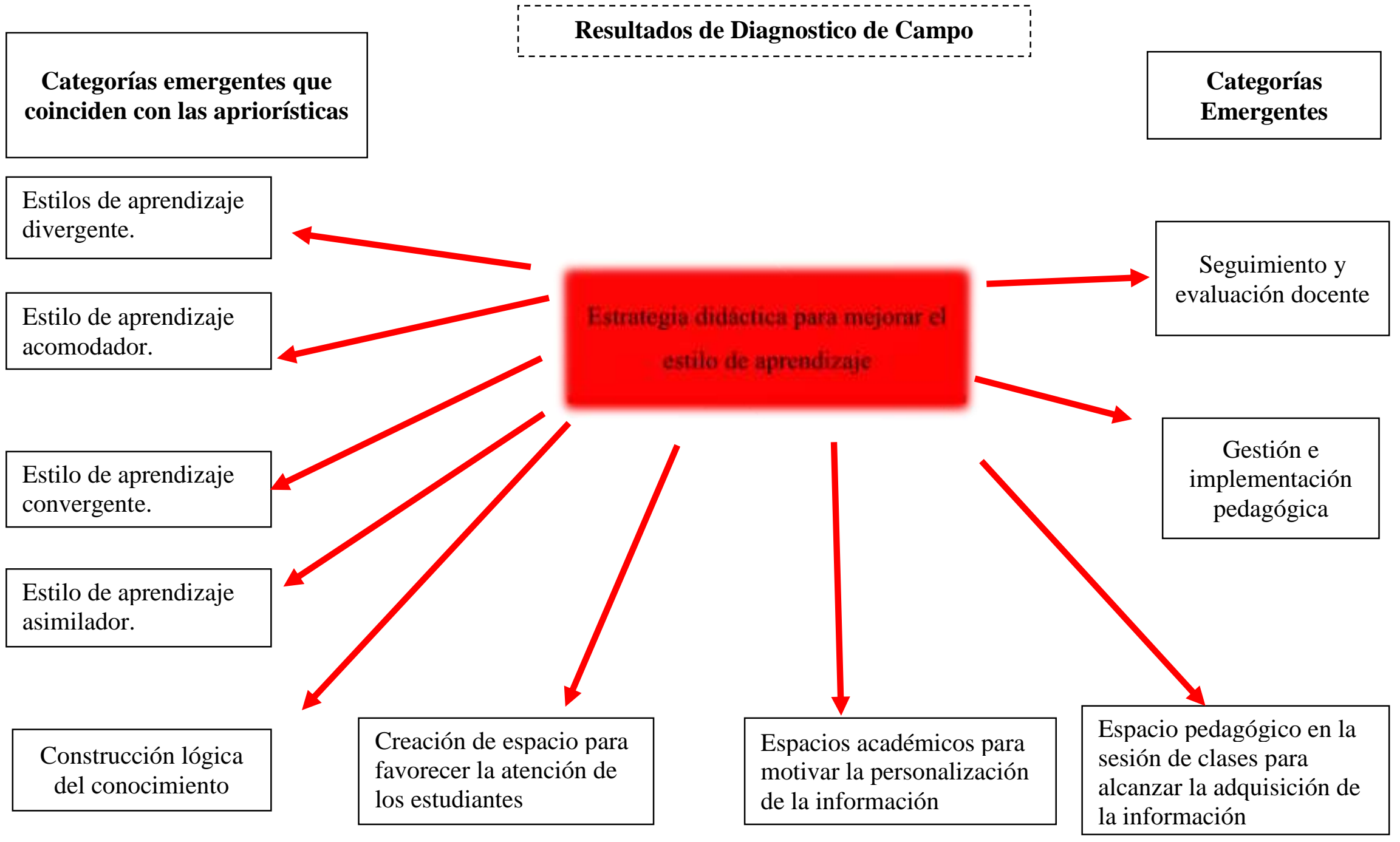

Fuente: elaboración propia. 


\section{Figura 5: Estrategia didáctica}

Estilo de aprendizaje acomodador. En la entrevista, los docentes manifestaron que los alumnos se desenvuelven mejor en las actividades prácticas, siendo pocos los que tienen capacidad de liderar, el docente tiene que dirigir las actividades, además refiere que en las exposiciones hay dificultades para expresar de manera fluida y segura la información, logran esquemas creativos, coloridos y llamativos, desarrollan habilidades practicas manuales con creatividad, pero hay que reforzar la lectura, el análisis.

Estilo de aprendizaje convergente. Los docentes en la entrevista indican que solo un grupo lidera actividades, exponen voluntariamente, manifiestan que hay que trabajar con respecto a la socialización entre compañeros, con los docentes y con las personas fuera del contexto educativo, manifiestan que hay que incidir en el aspecto teórico poniéndole énfasis al

Estilo de aprendizaje asimilador. En el cuestionario los estudiantes manifiestan que en las sesiones de clases hay pocas experiencias que los motiven a procesos de investigación, es fundamental que los docentes, tomen acciones en cuanto a las estrategias a procesos de reflexión, innovación y creación de proyectos, el docente debe crear las condiciones para estimular la curiosidad, originalidad, a partir de casuísticas inmersas en su desenvolvimiento profesional que les permita desarrollar sus capacidades, de innovación, y se relacionen con la comunidad.

Espacios académicos para motivar la personalización de la información En la entrevista, los docentes manifestaron que hay dificultad de los alumnos para el análisis de la información, una desmotivación por falta de dominio en la técnica, resaltaron que es necesario posibilitar espacios y técnicas para que los estudiantes establezcan contacto consigo mismos, y permita la regulación de nrocesns coonitivos

Fuente. Elaboración propia

oropia
Estilo de aprendizaje divergente. En las observaciones de clase, se evidenció una deficiencia en cuanto a los estudiantes teóricos, una falta de control en el manejo de los trabajos grupales, así como también carencia de estrategias motivacionales, falta de orientación en las diferentes actividades para la integración de conocimientos, los procesos de evaluación no se visualizaron durante la sesión de clase.

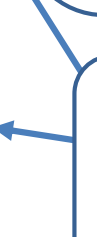

\section{Estrategia didáctica para} mejorar el estilo de aprendizaje

Gestión e implementación pedagógica
Los docentes en la entrevista manifestaron
estar insatisfechos con la gestión en
relación a los materiales y la tecnología
necesaria para poder desarrollar una sesión
de clase, en el aspecto teórico, como los
ambientes de talleres, siendo la
especialidad técnico, por lo que hay un
abandono de la administración en
gestionar necesidades para el docente y el
estudiante, la situación actual en la que nos
desenvolvemos es tecnológica y la
exigencia del mercado laboral también.

Creación de espacio para favorecer la atención del estudiante Los docentes en la entrevista mencionan que es importante par: los estudiantes contar con otros ambientes, que sean fuera de aula, ya que sienten que esos ambientes no logran despertar e interés y su atención, el docente tiene que evaluar la sugerencii implementando espacios, para ser utilizados como ambiente pedagógicos en los que se despierte la atención y concentracióı

Espacio pedagógico en la sesión de clases para alcanzar la adquisición de la información. En el cuestionario los estudiantes indican que en las sesiones de clases tienen pocas oportunidades para organizar sus ideas, analizar y sistematizar la información, por ello, el docente, debe tomar acciones sobre las condiciones para estimular la observación, originalidad en los estudiantes, a partir de espacios que permita explorar, y transformar, proyectos, y desarrollar los procesos cognitivos.

Construcción lógica del conocimiento. En la entrevista los docentes revelan una falta de preparación y técnica por parte de los estudiantes para relacionar, sustentar y argumentar la información cognitiva, presentar argumentos, razonamiento propio de manera reflexiva y coherente, por lo cual, atribuyen falta de motivación en buscar información

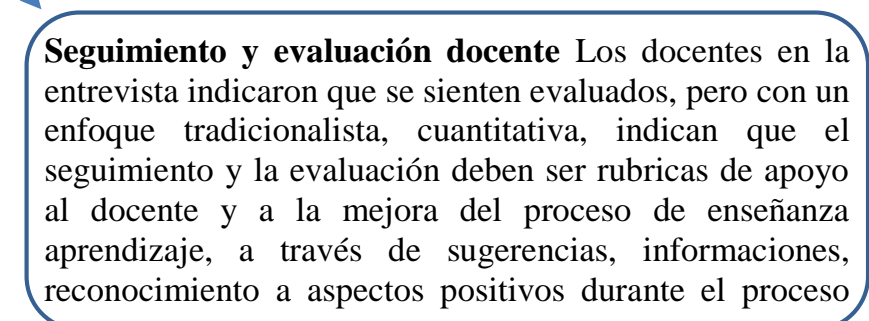




\section{Creación de espacio para favorecer la atención de los estudiantes}

El resultado de los hallazgos demuestra que para los estudiantes es importante contar con otros ambientes estratégicos, que sean fuera del aula de clases, ya que muchas veces estos ambientes no logran despertar, motivar el interés y su atención, el docente juega un papel clave por lo cual debe implementar otros espacios que se adapten y se puedan utilizar como ambientes pedagógicos en los que se puedan desarrollar estratégicas pedagógicas y así lograr despertar y canalizar la atención y concentración del estudiante logrando los objetivos establecidos.

Al respecto, Díaz y Hernández (1999), indican que las técnicas que enseñan las ideas como las imágenes, gráficos, tienen mucha injerencia sobre el interés en los estudiantes favoreciendo su atención y concentración, dichos recursos les permitirá expresar y comprender la información, recomienda su empleo cuando los planteamientos y las definiciones tiene un alto grado de abstracción, indica considerar cambiar el tipo de ilustraciones en los procesos expositivos y en el análisis de textos (p 224).

\section{Figura 6: Creación de espacios para favorecer la atención de los alumnos}

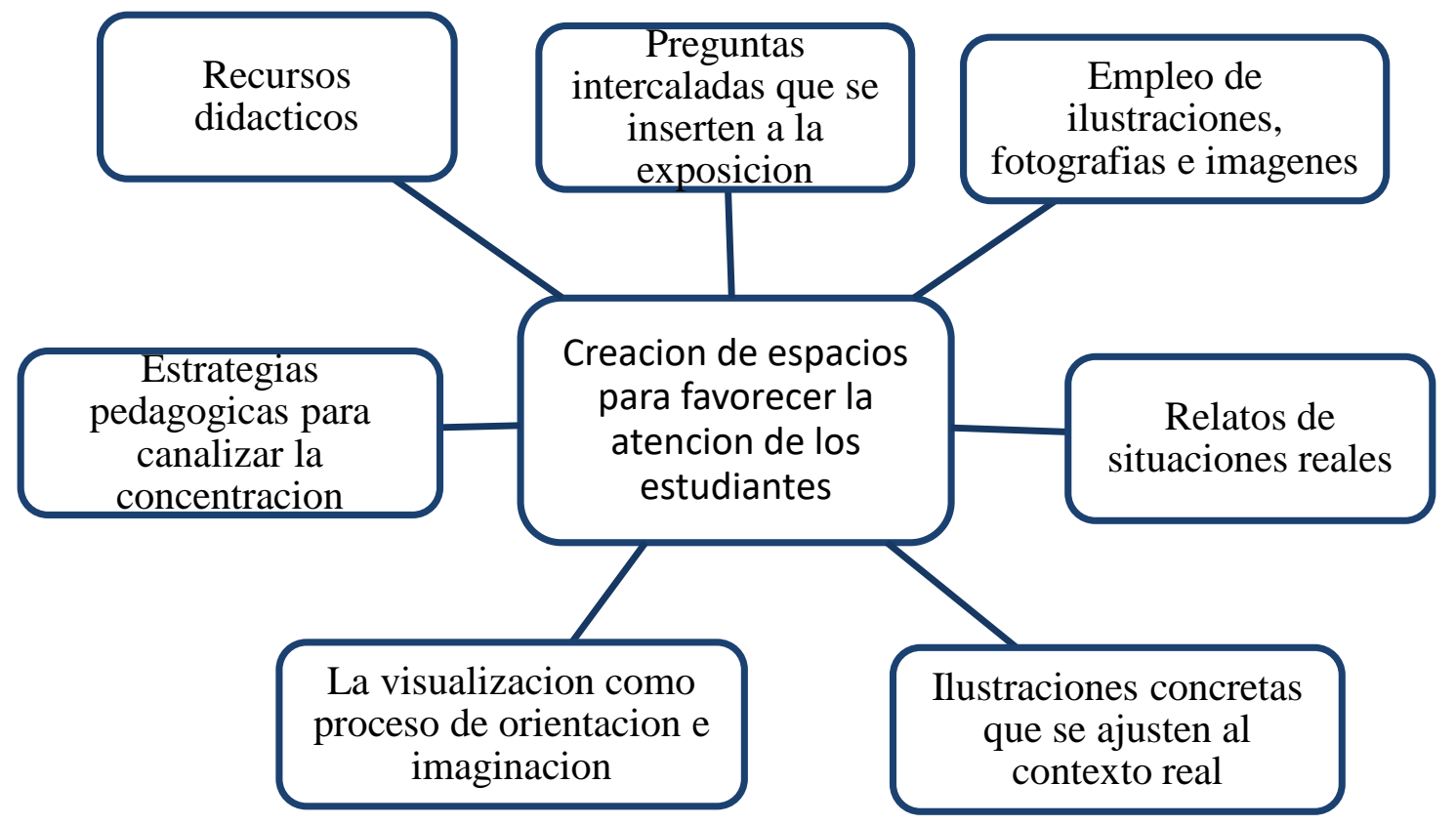

Fuente: Elaboración propia (2020). 


\section{Espacios académicos para motivar la personalización de la Información.}

En la entrevista, los docentes manifestaron que los estudiantes tienen dificultad para el análisis de la información, quizás por falta de motivación, asimismo, presentan desmotivación por falta de dominio en la técnica, resaltaron que es necesario estar motivados por lo cual es necesario posibilitar espacios para que los estudiantes establezcan contacto consigo mismos, esto va permitir la regulación de procesos cognitivos y autorreflexión individual.

En las observaciones de clase, se evidenció una dependencia de los estudiantes y una falta de motivación, en cuanto al docente una falta de control en el manejo de los trabajos grupales, carencia de estrategias motivacionales, así como una falta de orientación en las diferentes actividades para la integración de conocimientos, los procesos de evaluación no se visualizaron durante la sesión de clase.

Para Tobón y Agudelo (2000), afirma que la articulación al proyecto ético de vida con actitud crítica y pro activa, son estrategias del docente para favorecer la personalización de la información, que consiste en procedimientos planeados y sistemáticos que el docente ejecuta donde los estudiantes asumen las competencias.

\section{Figura 7: Espacios académicos para motivar la personalización de la Información}

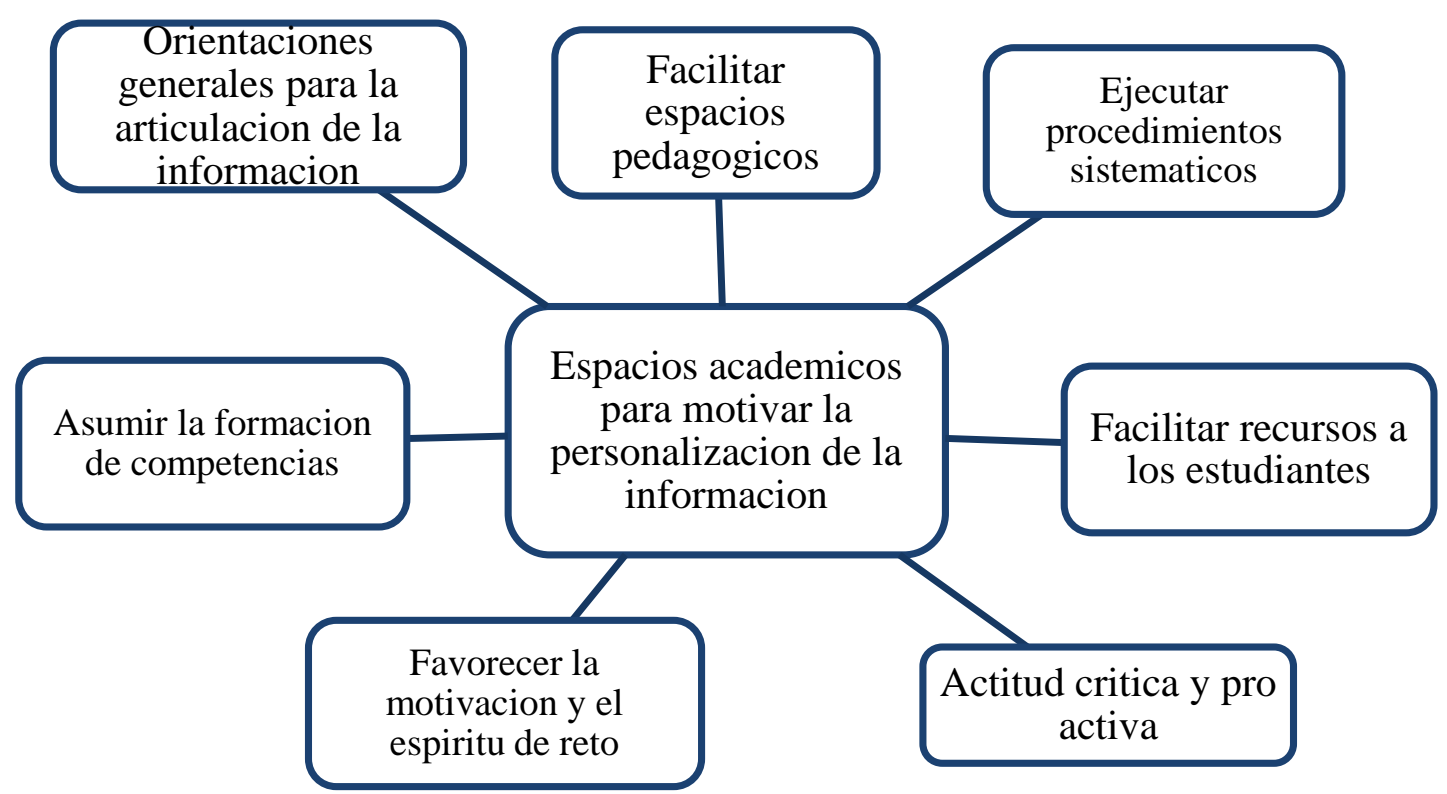

Fuente: Elaboración propia (2020). 


\section{Espacio pedagógico en la sesión de clases para alcanzar la adquisición de la información}

En el cuestionario aplicado a los estudiantes manifiestan que durante el desarrollo de las sesiones de clases tienen pocas oportunidades para organizar sus ideas en cuanto al análisis de la información, descubrir nuevas posibilidades para sistematizar la información; por ello, es fundamental que los docentes, tomen acciones acerca de cuáles son las condiciones necesarias para estimular la observación, originalidad en los estudiantes, a partir del diseño de espacios de transformación, innovación, exploración, indagación, incentivando proyectos desafiantes, por consiguiente, les permite agudizar los procesos cognitivos en el aprendizaje realizar conexiones en el análisis de la información, flexibilidad cognitiva, desarrollar estilos de pensamiento, todo ello, valioso en el proceso enseñanza aprendizaje.

Díaz Barriga, (1993) para llevar a cabo el proceso de adquisición de información se requiere la sistematización meritoria, refiriéndose a estos procesos como estrategias que van a incurrir en cada etapa de la búsqueda y creación de la información, se ha clasificado por el proceso al que preferentemente se asocian, por lo cual, algunas de estas estrategias desarrollaran la generación de expectativas, orientar y guiar la atención del aprendizaje, mejorar la codificación y la organización global de la nueva información.

Figura 8: Espacio pedagógico en la sesión de clases para alcanzar la adquisición de la

\section{información}

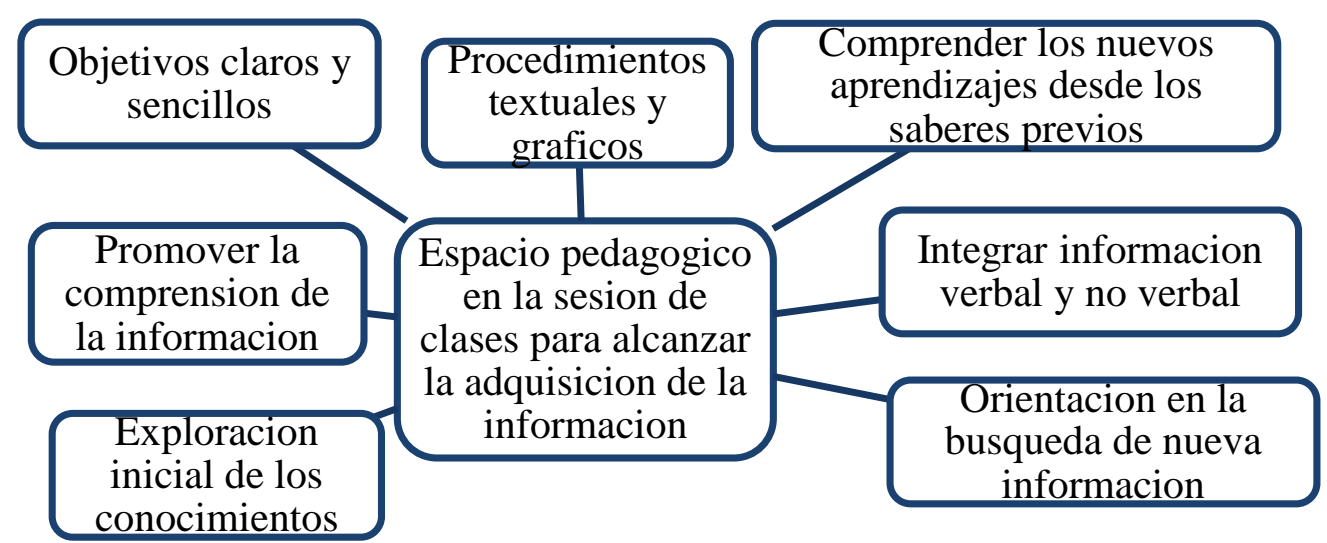

Fuente: Elaboración propia (2020). 


\section{Construcción lógica del conocimiento.}

En la entrevista realizada a los docentes revelan una falta de preparación y técnica por parte de los estudiantes para relacionar, comprender, sustentar y argumentar la información cognitiva, presentar con argumentos sólidos los resultados del razonamiento propio de manera reflexiva y coherente, todo ello, atribuyen a una falta de motivación para buscar información teóricapráctica relevante, muy por el contrario en la observación de clases, se evidenció que muchas veces se aceptan explicaciones sin ser sometidas al cuestionamiento, a clarificar conceptos mal definidos

Piaget (1976), sus estudios están ligadas al proceso cognitivo de la información, su interés en una gran interrogante acerca del conocimiento, y como es que el hombre pasa de un estado de conocimiento inferior a otro de orden superior, partiendo de estas interrogantes, para Piaget el sujeto es epistémico, es decir construye el conocimiento de la realidad, pero también es abstracto porque lo describe de manera general y universal. En sus obras de psicología genética como de epistemología buscan respuestas acerca de la construcción de conocimiento, sus diferentes investigaciones sobre el dominio del pensamiento infantil demostraron que la lógica del niño no solo se construye progresivamente, sino que además se desarrolla durante toda la vida, pasando por diferentes etapas antes de lograr el nivel adulto. 


\section{Figura 9: Construcción lógica del conocimiento}

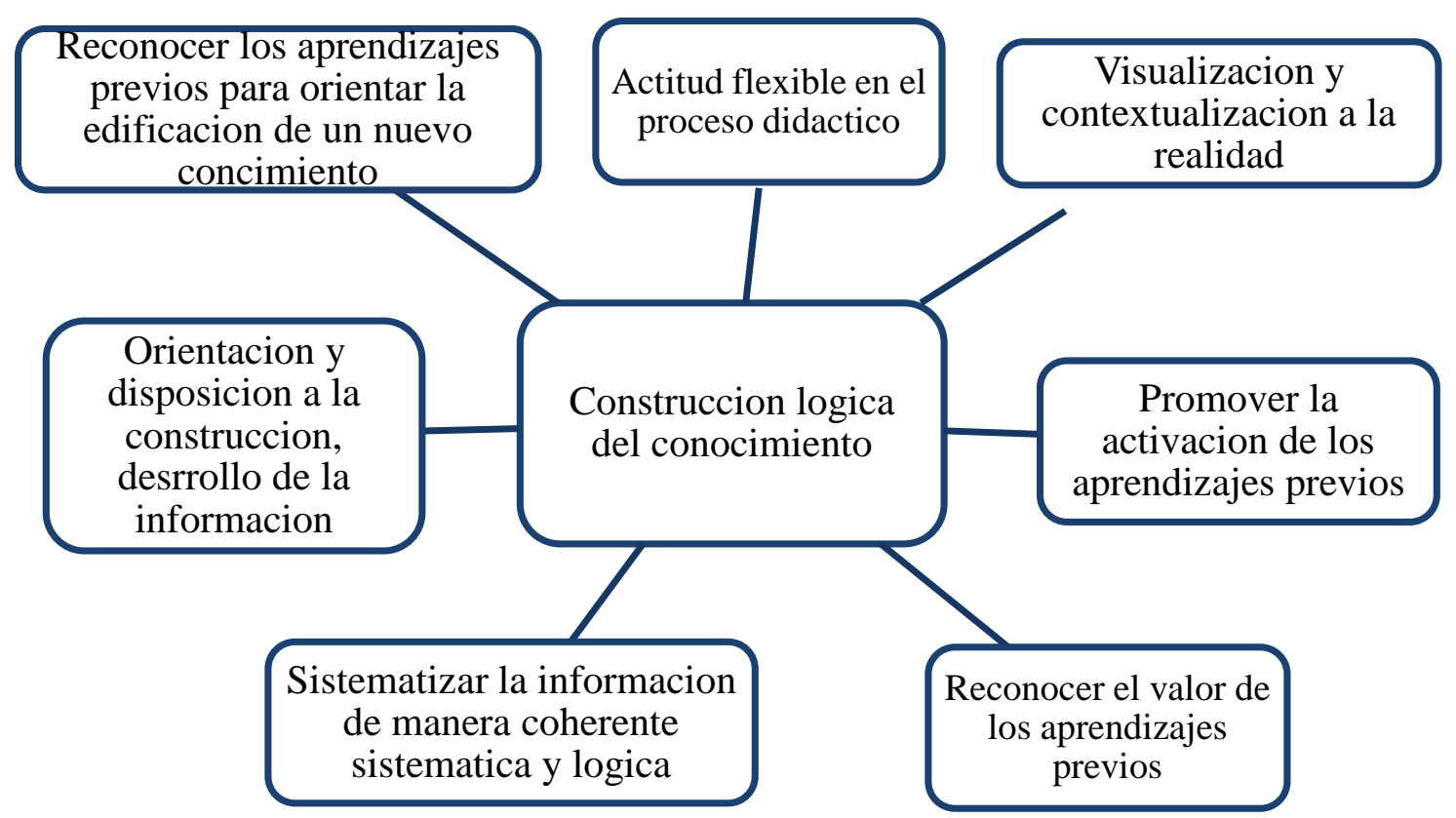

Fuente: Elaboración propia (2020).

\section{Estilo de aprendizaje divergente}

En las observaciones de clase, se evidenció una deficiencia de estudiantes teóricos, no desarrollan en cuanto al docente una falta de control en el manejo de los trabajos grupales, carencia de estrategias motivacionales, así como una falta de orientación en las diferentes actividades para la integración de conocimientos, los procesos de evaluación no se visualizaron durante la sesión de clase.

Los alumnos teóricos adaptan e integran las observaciones que realizan en teorías complejas y bien fundamentadas lógicamente. Piensan de forma secuencial y paso a paso, integrando hechos dispares en teorías coherentes. Les gusta analizar y sintetizar la información y su sistema de valores premia la lógica y la racionalidad. Se sienten incómodos con los juicios subjetivos, las técnicas de pensamiento lateral y las actividades faltas de lógica clara.

Para Cotton $(1989 ; 367)$ afirma que el aprendizaje es un proceso de adquisición de un nuevo conocimiento y habilidad. Para que este proceso pueda ser calificado como aprendizaje, en lugar de una simple retención del conocimiento o de la habilidad en cuestión que permita su 
manifestación en un tiempo futuro. El aprendizaje puede definirse de un modo más formal "como un cambio relativamente permanente en el comportamiento o en el posible comportamiento, fruto de la experiencia.”

\section{Figura 10: Estilo de aprendizaje divergente}

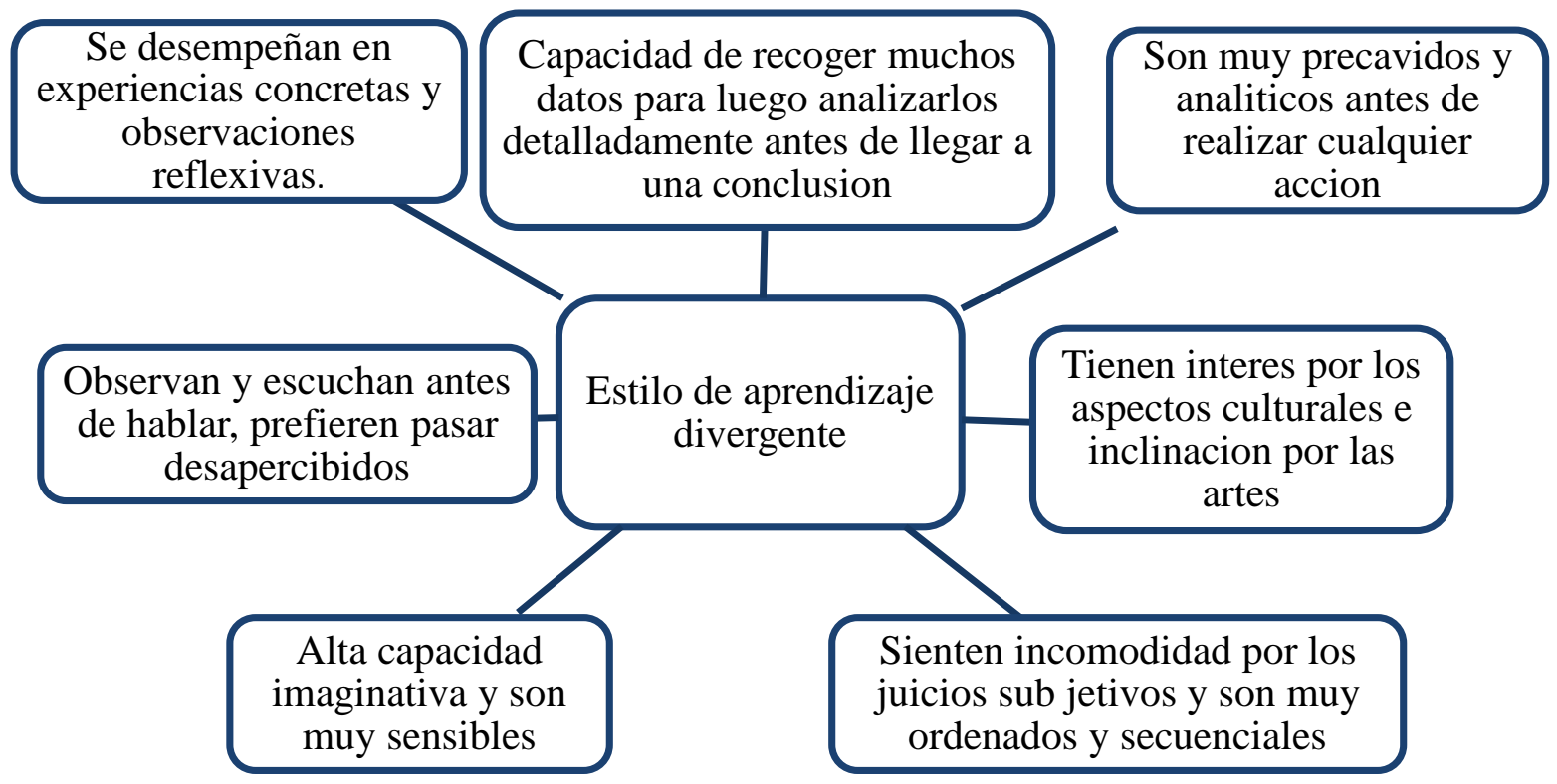

Fuente: Elaboración propia (2020).

\section{Estilo de aprendizaje acomodador}

En la entrevista, los docentes manifestaron que los estudiantes se desenvuelven mejor en las actividades prácticas, son muy pocos los que manifiestan capacidad de liderar por lo que el docente tiene facilitar y dirigir las actividades, además refiere que en las sesiones expositivas hay dificultades para expresar de manera fluida y segura la información, presentan esquemas muy creativos, coloridos y llamativos, desarrollan habilidades practicas manuales con creatividad, pero hay que reforzar en aspectos como la lectura, el análisis, la formación de nuevo conocimiento, además hay que trabajar en la seguridad personal dela mayoría de los estudiantes.

La observación de clases se realizó en una práctica de taller del cuidado del cabello, en lo que se evidenció una clase muy activa con la participación constante de casi el 80 por ciento de los estudiantes, pero con una dependencia del monitoreo del maestro, el otro porcentaje 
manifestó desinterés debido a la falta de equipos y materiales por lo que no pueden desarrollar la práctica.

Para Honey y Munford (1986) nos indican un diseño de toda una metodología del aprendizaje personal diario en lo cual se destaca de manera esquemática etapas fundamentales que el propone, teniendo en cuenta la vivencia en base a experiencias que pueden ser objeto de aprendizaje, dichas experiencias deben tener un enfoque consciente para que se conviertan en elementos enriquecedores en nuestro proceso de aprender, esta idea atrae a los pragmáticos.

\section{Figura 11: Estilo de aprendizaje acomodador}

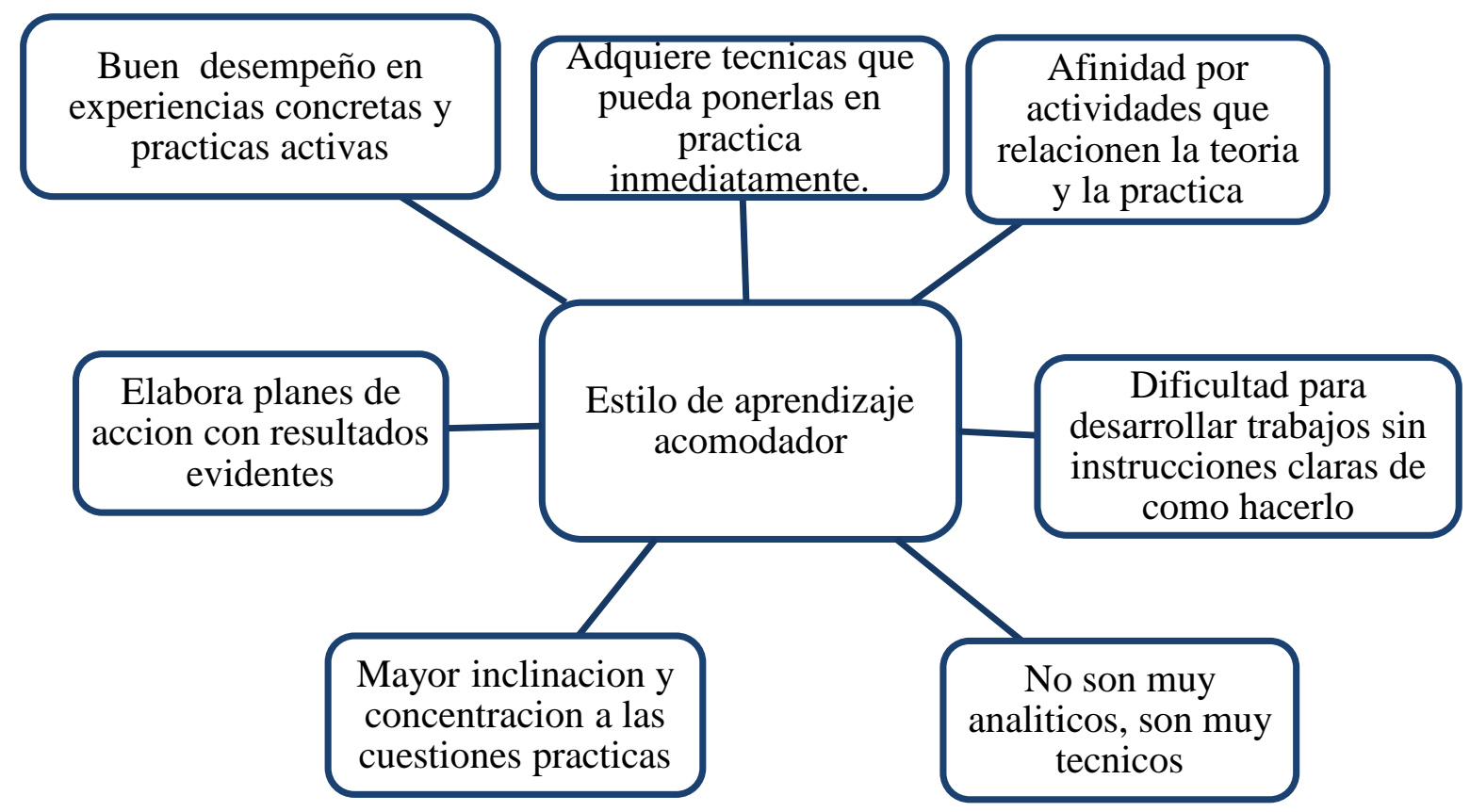

Fuente: Elaboración propia (2020).

\section{Estilo de aprendizaje convergente}

Los docentes manifestaron en la entrevista que un grupo muy pequeño lideran actividades, participan en las exposiciones de manera voluntaria, indican que hay que trabajar bastante con respecto a la socialización entre compañeros, con los docentes y con las personas que necesariamente tienen que interrelacionarse debido a los cursos técnicos, manifiestan que hay que incidir en el aspecto teórico poniéndole énfasis al análisis. 
La observación de clases se realizó en el curso de química cosmética donde los estudiantes realizaban trabajos grupales, pero se observó a tres estudiantes realizando trabajos en forma individual, ante la interrogante de este hecho el docente manifestó que es la característica de algunos estudiantes que desean desarrollar actividades de manera aislada.

Según la Ley de Ordenación General del Sistema Educativo (LOGSE) plantea un cuidado para el aprendizaje eficaz de tal manera que la estructura del proceso de enseñanza aprendizaje avale la atención de la variedad de intereses y de aptitudes de los alumnos, fomente hábitos propios del aprendizaje activo. En uno de sus artículos indica que el sistema educativo tiene un enfoque básico la educación permanente. Para lo cual se dispondrá a los alumnos para educarse por sí mismo. Se entiende que se relata a los estilos de aprendizaje de los estudiantes que aprendan a aprender

\section{Figura 12: Estilo de aprendizaje convergente}

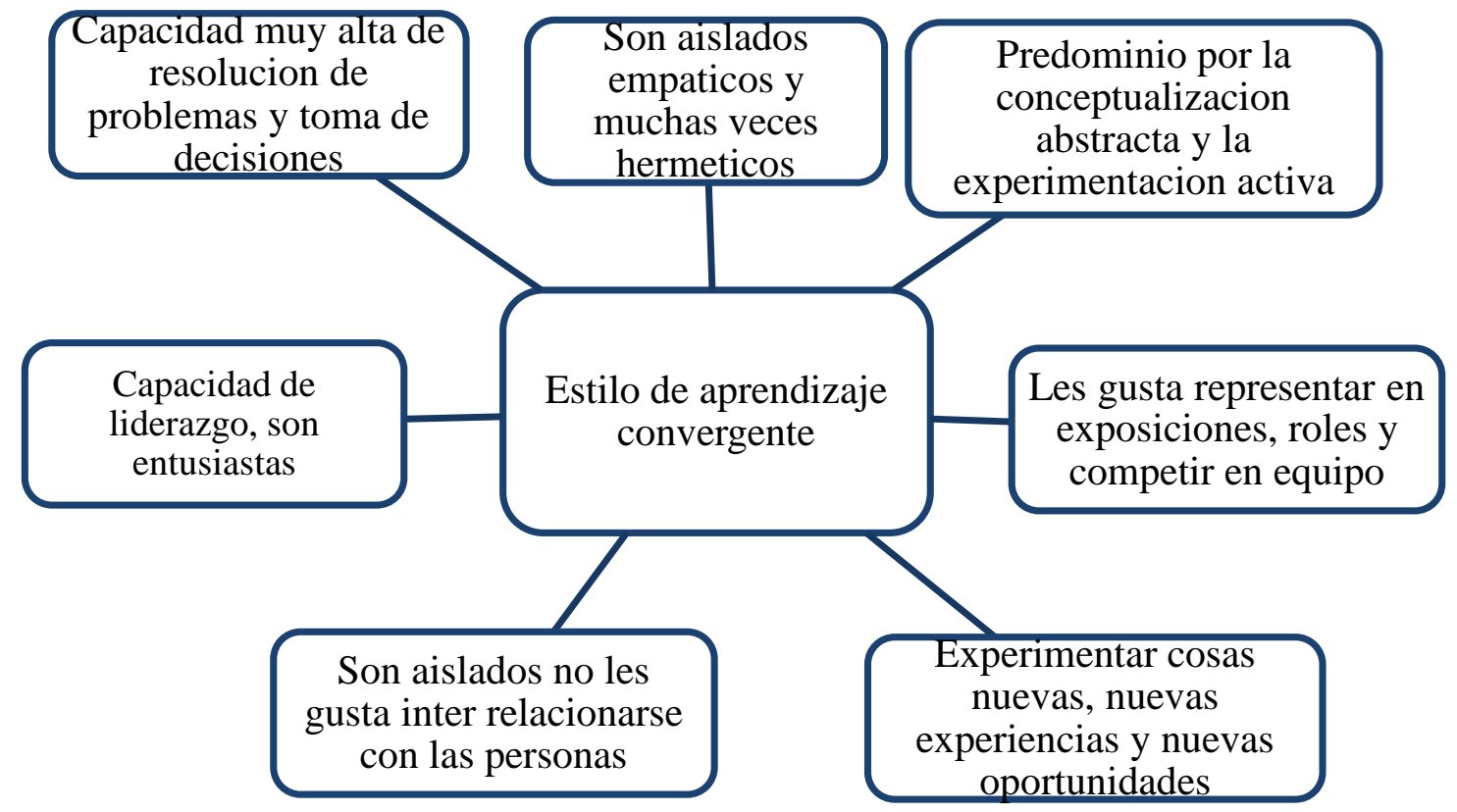

Fuente: Elaboración propia (2020).

\section{Estilo de aprendizaje asimilador}

En el cuestionario aplicado a los estudiantes manifiestan que durante el desarrollo de las sesiones de clases tienen pocas experiencias que los insten a procesos de investigación indican no tener oportunidades para organizar sus ideas, por ello, es fundamental que los docentes, 
tomen acciones en cuanto a las estrategias inherentes a procesos de reflexión, innovación y creación de proyectos relacionados con su especialidad, el docente tiene que crear las condiciones necesarias para estimular la curiosidad, originalidad en los estudiantes, a partir de casuísticas inmersas en su desenvolvimiento profesional que les permita desarrollar sus capacidades de, innovación, indagación, incentivando proyectos donde se relacionen con la comunidad, tareas vivenciales que permitan desarrollar su desenvolvimiento personal, estas experiencias les permite relacionarse con el contexto y poner en práctica los conocimientos adquiridos en su proceso de aprendizaje.

Según Gagne (1989), considera que deben propiciarse la atención y motivación antes de efectuarse, algunas funciones en la enseñanza, para dar inicio a un verdadero aprendizaje, indica, dar información a los alumnos sobre los logros u objetivos esperados, estimular la memoria en relación a los conocimientos, las habilidades previas esenciales y relevantes, dar a conocer el material de aprendizaje, guiar en la estructura del trabajo y evaluar la ejecución, el autor exhorta la primacía del aprendizaje cognitivo por brindar que van a servir no solo a la orientación practica sino van a guiar a la investigación.

\section{Figura 13: Estilo de aprendizaje asimilador}

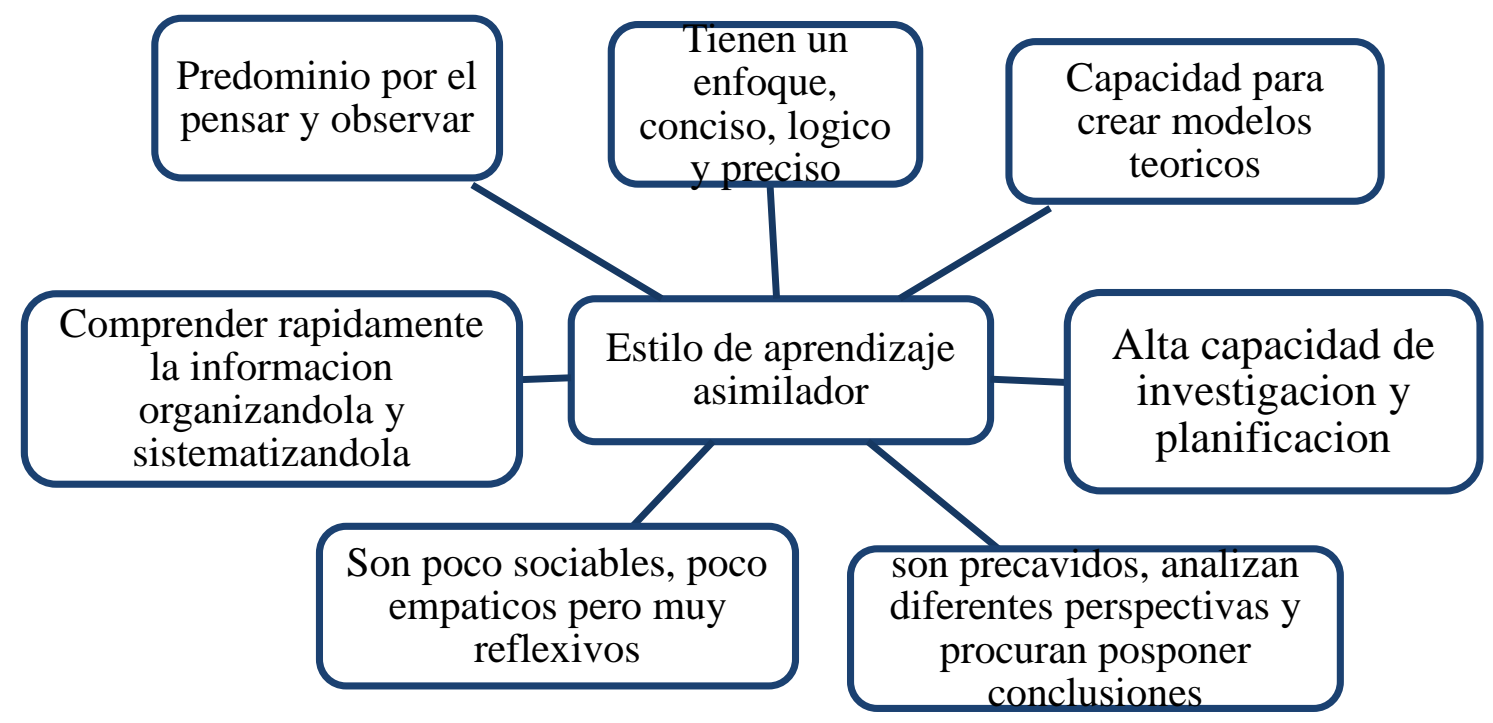

Fuente: Elaboración propia (2020). 


\section{Gestión e implementación pedagógica.}

Los docentes manifestaron en la entrevista que se sienten insatisfechos con algunos puntos de la gestión en relación a que no cuentan con los materiales y la tecnología necesaria para poder desarrollar una sesión de clase adecuada, tanto en el aspecto teórico es decir en las aulas, como los ambientes de talleres, cabe resaltar que la especialidad es netamente técnico, por lo que indican que hay un abandono de la parte administrativa en gestionar necesidades tanto para el docente como para el estudiante, analizando la situación actual hay que resaltar que nos encontramos en una era tecnológica que actualmente nos desenvolvemos, y en la necesidad que en estos momentos exige el mercado laboral donde están muy inmersos esta tecnología, asi como su uso en los diferentes tratamientos y técnicas que el estudiante tiene que ejecutar y que por lo mismo es una preocupación de no poder cubrir ciertas expectativas en cuanto a lo que exigen este mercado laboral y lo que exigen los documentos pedagógicos.

En la observación de clases a una sesión taller práctico se pudo determinar el escaso número de materiales y equipos que los estudiantes hacen uso para el desarrollo de las practicas, lo cual demandaba una pérdida de tiempo y una distracción del alumnado mientras esperaba por un material para poder utilizarlo, esto origina un esfuerzo adicional del docente ya que tiene que tener estrategias para mantener la atención del alumno y a su vez monitorear la ejecución de la práctica de los otros estudiantes.

Según diseño curricular básico de la educación superior tecnológica del Minedu indica que la gestión educativa, se relaciona a los conocimientos fundamentales de característica total, democratización y la cultura de la rendición de cuentas. la calidad total involucra el ordenamiento racional de los métodos educativos para maximizar la eficiencia, el proceso del conocimiento y la calidad completa en la formación de los profesionales técnicos, en el campo de la organización jerárquica debe dar camino a una gestión horizontal, con el uso de redes interactivas de organización y administración, con estas características se busca que 
la comunidad se integre al sistema educativo participando activamente y con efectividad, desarrollando una ética de cooperación y participación ciudadana

Es importante mejorar la calidad educativa, por lo tanto, los Institutos de Educación Superior Tecnológica, asumen los alcances del reglamento de la Gestión del Sistema Educativo establecido en el Decreto Supremo No 009-2005-ED, con los siguientes órganos.

Órganos de dirección y comité directivo

Órgano de participación, consejo educativo institucional concertación y vigilancia: (CONEI) Órgano de asesoramiento: consejo académico

Órgano de apoyo: equipo administrativo

Por lo cual utiliza diversos instrumentos de gestión estratégica, como son, el proyecto educativo institucional (PEI), plan anual de trabajo (PAT), reglamento interno (RI), proyecto curricular de centro (PCC), informe ejecutivo de gestión anual.

Figura 14: Gestión e implementación pedagógica

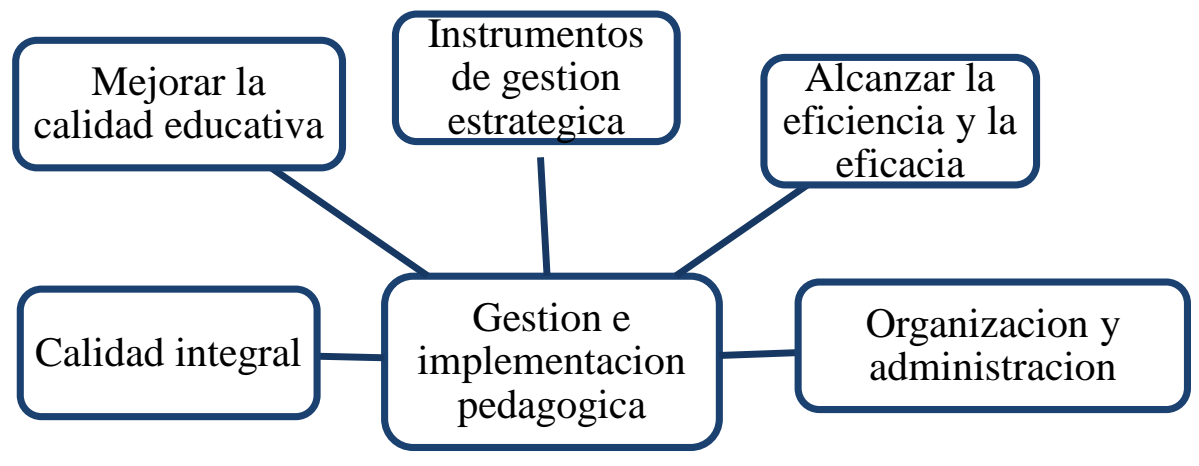

Fuente: Elaboración propia (2018).

\section{Seguimiento y evaluación docente}

Los docentes manifestaron en la entrevista que se sienten evaluados pero con un enfoque tradicionalista con cifras cuantitativas y mas no tomando en cuenta aspectos cualitativos, indican que el seguimiento permanente y la evaluación deben ser rubricas de apoyo a la mejora del proceso de enseñanza aprendizaje, así como del enriquecimiento profesional del docente a 
través de sugerencias, informaciones bibliográficas, reconocimiento a aspectos positivos durante el proceso evaluativo que estos, sean tomados como puntos importantes y meritorios en el quehacer del docente

Durante la observación se sintió un clima tenso de parte del docente, lo que produjo un ambiente forzado y el desenvolvimiento de los estudiantes un poco rígidos, incomodo la presencia del docente que realizaba la observación, se tomó este hecho como una evaluación a la clase y sus componentes, es decir se sintieron evaluados los alumnos y el docente, esto indica que se debe mejorar los procesos de acompañamiento de parte del personal encargado por las jefaturas, seria propicio una capacitación sobre estos procesos pedagógicos.

Según el Diseño Curricular Básico de la Educación Superior Tecnológica del (MINEDU 2009), indica orientaciones para el proceso de evaluación, este proceso debe contener permanente información y reflexión de forma sistemática en relación a los aprendizajes, permitiendo orientar la labor del docente y estudiante, permite tomar decisiones y hacer reajustes en los procesos de enseñanza aprendizaje y permitir aprender de los aciertos y logros para ir mejorando de la misma manera de los errores para poder superarlos, la evaluación debe motivar el trabajo estudiantil.

Se plantean varias técnicas en el proceso de evaluación del aprendizaje, su uso dependerá del objeto de evaluación, la capacidad que se quiera evaluar, se tendrá en cuenta, la observación del proceso, verificar el producto de la información, y por último la observación de las actitudes En cuanto al DCB de la Educación Superior Tecnológica del Minedu (2009), indica que, el Ministerio de Educación a través de sus órganos correspondientes tienen la capacidad para descubrir problemas, apoyar y orientar aspectos técnicos, en sus diferentes fases de investigación, planificación, implementación, ejecución y evaluación curricular, con el objetivo de mejorar la calidad y eficiencia del servicio educativo. 


\section{Figura 15. Seguimiento y evaluación docente}

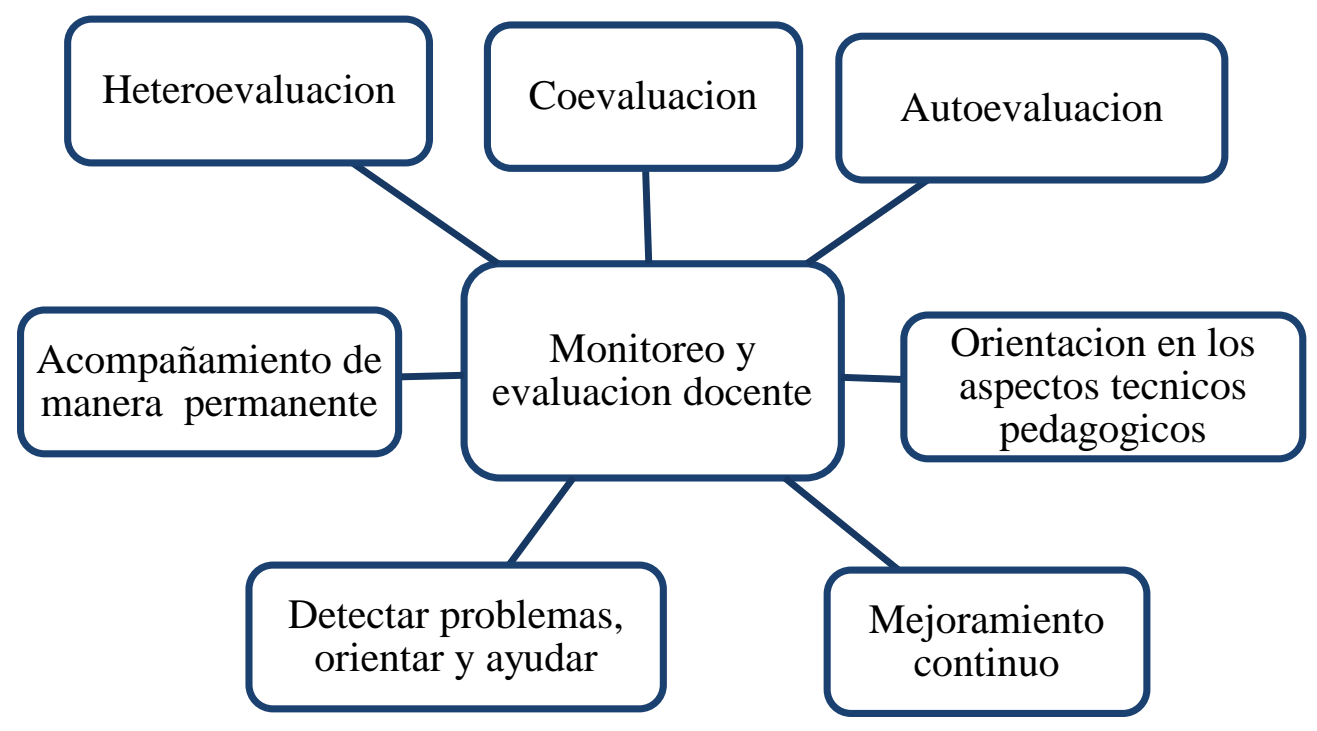

Fuente: Elaboración propia (2020).

\section{Conclusiones aproximativas del estudio de campo resultado del proceso del diagnóstico} de campo

El diagnóstico de campo permitió realizar un estudio integral acerca del estado actual del estilo de aprendizaje en los estudiantes del primer ciclo de la carrera de Cosmetica Dermatologica. La causa principal que se logro evidenciar es una escasa informacion, y conocimientos acerca de todo lo referente al reconocimiento de las caracteristicas que tienen los diferentes estilos de aprendizaje, existe una falta de curiosidad en relacion al tema, comprender la relevancia que tiene investigar los estilos de aprendizaje, que desencadenara en el proceso de enseñanzaaprendizaje, deben buscar por iniciativa propia fuentes de informacion, capacitaciones que les permita entender e identificar si se esta logrando cubrir las expectativas y el estilo de como aprende el estudiante, permitiendo de esta manera poder desarrollar un aprendizaje significativo, ademas de permitir al maestro contar con un repertorio teorico, practico, metodologico, estrategico que le permita desarrollar un buen proceso de enseñanzaaprendizaje 
En relación a lo observado y recogido en el presente capítulo, se evidenció que existen grupos divididos bien marcados en la institución evaluada, están los grupos de maestros nombrados y de muchos años en la institución, son un grupo pequeño, están los docentes contratados que son la mayoría, casi el $\mathbf{9 0 \%}$ de especialidad técnica, que a su vez están divididos por simpatía hacia el director que es casi el 50\% de docentes técnicos contratados; los docentes conocen estrategias y metodologías que aplican en su quehacer diario, existe predisposición en el trabajo que realizan, los docentes entrevistados manifiestan una escasa motivación en el trabajo, falta de reconocimiento y valoración de parte del director y de los jefes de las áreas académicas técnicas por el trabajo desempeñado, un exceso y cruce de actividades que generan malestar y estrés; por lo que es necesario que la gestión encargada evalúe bien sus actividades, cree políticas de reconocimiento y línea de carrera entre el personal docente.

Los entrevistados también perciben que la posición de contratados es una desventaja en comparación a los docentes nombrados de mayor antigüedad y experiencia, ante el personal directivo y administrativo, sienten que tienen más obligaciones y mayor presión que los docentes nombrados más aún si es personal nuevo, solo se toman en cuenta el horario de horas no lectivas de los docentes contratados para planificar y ejecutar una capacitación docente, en la mayoría de veces es obviado las horas no lectivas del personal contratado, lo que dificulta la asistencia de la gran mayoría de personal contratado, sin embargo si existe un monitoreo y evaluación constante de parte de los jefes académicos a los docentes contratados, los desmotiva que teniendo la misma remuneración, el trabajo y el número de horas trabajadas en la semana sean tan diferentes.

Los entrevistados también sugieren que se realicen charlas con psicólogos donde se tengan en cuenta temas de problemas sociales de los adolescentes, de esta manera producir autorreflexión de los estudiantes, y poder detectar problemas específicos de conductas y hábitos 
inadecuados, dependencia emocional, autoestima muy baja, dificultad para socializarse, inseguridad y muchos otros problemas. Sugieren que la institución cree talleres tanto para estudiantes como docentes para poder entender y manejar problemas de los estudiantes que ayuden a mejorar su desenvolvimiento personal y educativo.

Finalmente, se debe resaltar la prioridad y la razón de ser educadores, es el estudiante, es una necesidad, obligación identificarnos y comprometernos por ello, nuestro mayor éxito es ofrecer procesos de enseñanza-aprendizaje con calidad, estos procesos pueden ser complejos, pero si identificamos al estudiante, permitirá facilitar la selección de estrategias, métodos, y técnicas. Por ello en la propuesta que se planteará buscar y establecer estrategias didácticas que permitan desarrollar el estilo de aprendizaje del estudiante, se sienta cómodo, se divierta en el proceso, logré sus capacidades, procese información sin dificultad, desarrolle un aprendizaje significativo, empatía con el docente, de esta manera, la propuesta pueda contribuir a que los docentes desarrollen estrategias didácticas inherentes al estilo de aprendizaje del estudiante. 


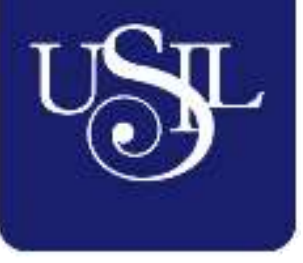

UNIVERSIDAD

SAN IGNACIO

DE LOYOLA

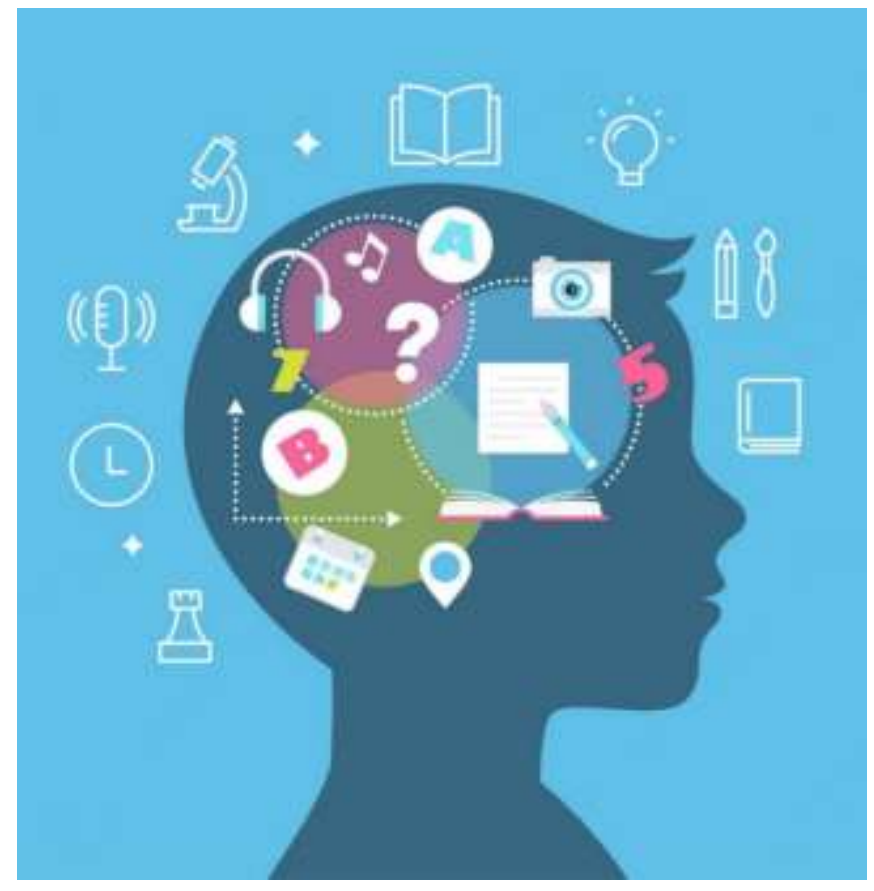

ESTRATEGIA DIDACTICA PARA MEJORAR EL ESTILO DE APRENDIZAJE EN ESTUDIANTES DE LA CARRERA DE COSMETICA DERMATOLOGICA EN UN INSTITUTO PUBLICO DE LIMA

Autor: Nalda Llactahuaman Chavelon

2020 


\section{Capítulo III}

\section{Modelación de la propuesta}

\section{Propósito de la propuesta}

La propuesta se diseñó a partir de la estrategia didáctica para mejorar el estilo de aprendizaje en los estudiantes del primer ciclo de la carrera de Cosmética Dermatológica. Para dicho efecto, se plasmó un trabajo de sistematización y estudio profundo de las insuficiencias del estudiante, donde se consideró los resultados del diagnóstico de campo; de lo cual, surgieron las categorías emergentes que permitieron tener de manera integral la problemática objeto de estudio.

El diseño de una propuesta de la estrategia didáctica en el proceso educativo es buscar de manera legítima, teniendo en cuenta la relevancia de un adecuado seguimiento y evaluación docente y la implementación pedagógica para fomentar una enseñanza de calidad.

\section{Fundamentos científicos}

\section{Fundamentos socioeducativos.}

El diseño de una propuesta de estrategia didáctica dirigido a estudiantes de la carrera de Cosmética Dermatológica del instituto superior tecnológico publico situada en Pueblo Libre, Lima, tiene un prestigio a nivel nacional por su alto nivel en formación académica, tiene una población heterogénea de 655 estudiantes, con 42 docentes nombrados y contratados, de los cuales seis docentes están destinados a las diferentes unidades didácticas del primer ciclo en ambos turnos, diurno y nocturno.

En el proceso de investigación la muestra se realizó a quince estudiantes del primer ciclo. El instituto cuenta con aulas de taller práctico, y de desarrollo teórico, las aulas de taller cuentan con poca iluminación, en la cual también se observó escases de materiales necesarios para el desarrollo efectivo de las sesiones de clase.

Los estudiantes que integran la institución tienen como prioridad lograr la ejecución de prácticas en el quinto y sexto ciclo. En las observaciones de clase en el aula de taller se 
evidenció que no están logrando una preparación adecuada para ejecutar con el record de prácticas que se le va exigir más adelante, no obstante las cualidades que debe desarrollar el estudiante, es ser autónomo, creativo, hábil, desenvuelto, ágil; sin embargo, se visualizó dependencia hacia la figura del docente y asimismo, una falta de determinación para realizar el trabajo técnico.

Al respecto Feldman, Martorelli y Papalia (2012), indica que en la etapa de la adolescencia pueden mejorar la autoconfianza, logrando una actitud activa y transformadora en la sociedad a partir de una variedad de opciones medioambientales, sociales, familiares con estrategias adecuadas, asi como una estimulación pertinente a su etapa de desarrollo, que le permita hacer frente a problemas y exigencias de indole social con soluciones pertinentes y eficaces.

\section{Fundamentos psicológicos.}

En las investigaciones, la neurofisiología y en la psicología han dado como resultado un nuevo enfoque sobre el proceso enseñanza-aprendizaje, de la manera en que los seres humanos aprendemos, siendo estos procesos muy variables, por lo cual resulta relevante diseñar un programa integrado teniendo en cuenta el desarrollo armónico del estudiante, cada persona tiene una forma o estilo particular de establecer relación con el mundo y por lo tanto para aprender. Por lo cual, es necesario realizar un andamiaje legitimo en base a un juicio psicológico asi como tener en cuenta su etapa de desarrollo se encuentran. Teniendo en cuenta este enfoque, se han desarrollado diferentes modelos que aproximan una clasificación de estas distintas formas de aprender. El Programa Nacional de Educación (2001-2006).

Por lo tanto El Programa Nacional de Educación (2001-2006) hace posible aplicar diferentes estrategias, tecnicas metodológicas y didácticas, que permitan aprendizajes significativos y estos perduren a lo largo de sus vidas. 
Los estudiantes en la etapa de la adolescencia están formando su identidad, la presencia de procesos cognitivos juegan un papel protagónico en dicho desarrollo, para Tobon, (2001) afirma que la psicologia cognitiva a desarrollado significativos aportes a partir de conceptos muy relevantes para la comprension de las diversas competencias, estos conceptos estan relacionadas con la inteligencia, las estrategias cognitivas, esquemas heuristicos,

Asi mismo indica que estos proceso psicologicos cognitivos permite ampliamente un adecuado procesamiento de informacion que sera coherente con las demandas del entorno donde se desarrollaran tecnicas, estrategias, asi como esquemas cognitivos permitiendo al ser humano comprender, interpretar, explicar la realidad (p.52).

\section{Fundamentos neuroeducacionales.}

Teniendo en cuenta la complejidad del proceso de educacion, hay que considerar una de las funciones del ser humano, sus emociones, siendo este un factor basico para poder aprender y memorizar, considerada como la energia que mueve el mundo, el cual nos lleva inconscientemente a sentirnos vivos, las emociones positivas haran posible generar procesos mentales coherentes y ensamblados asi como la toma de desiciones acertadas, un buen aprendizaje y memoria solida, facilitando el cumplimiento de las tareas del proceso de enseñanza- aprendizaje. Existe una relacion entre la nerociencia y la pedagogía al conocer los multiples ingredientes cerebrales, que van a participar y van a mejorar los procesos de enseñanza-aprendizaje, que van a facilitar las prácticas pedagógicas, tecnicas metodológicas, haciendo posible la innovación pedagógica.

En este sentido, Mora (2016), resalta que la neuroeducación es una vision donde el proceso de la enseñanza esta ligada a los procesos cerebrales, que estan relacionados e integrados con la psicologia, la medicina y la sociologia. Haciendo posible mejorar y potenciar los procesos de aprendizaje y memoria de los estudiantes, y mejorar el proceso de como enseñar de los maestros. La neurociencia es un campo abierto, nuevo con muchas posibilidades 
de proporcionar diversas herramientas muy utiles al maestro para el proceso de enseñanza, permitiendo despertar el pensamiento critico (p.25).

Cabe resaltar que para Mora los docentes desde hace un tiempo atraz anhelan encontrar tecnicas y medios educativos respaldados en hechos cientificos asi como en la neurociencia en particular y maestros reconocidos como buenos maestros por obtener resultados con los estudiantes que van afirmar y admitir de manera positiva para ellos, y por ende la mejora de las capacidades docentes, donde tomaran en cuenta la emocion, la atencion y la memoria, estos conceptos ayudaran a potenciar la creatividad y el aprendizaje en ciertas disciplinas.

A continuación, se presenta el gráfico que representa los períodos de atención de una clase de 40 minutos.

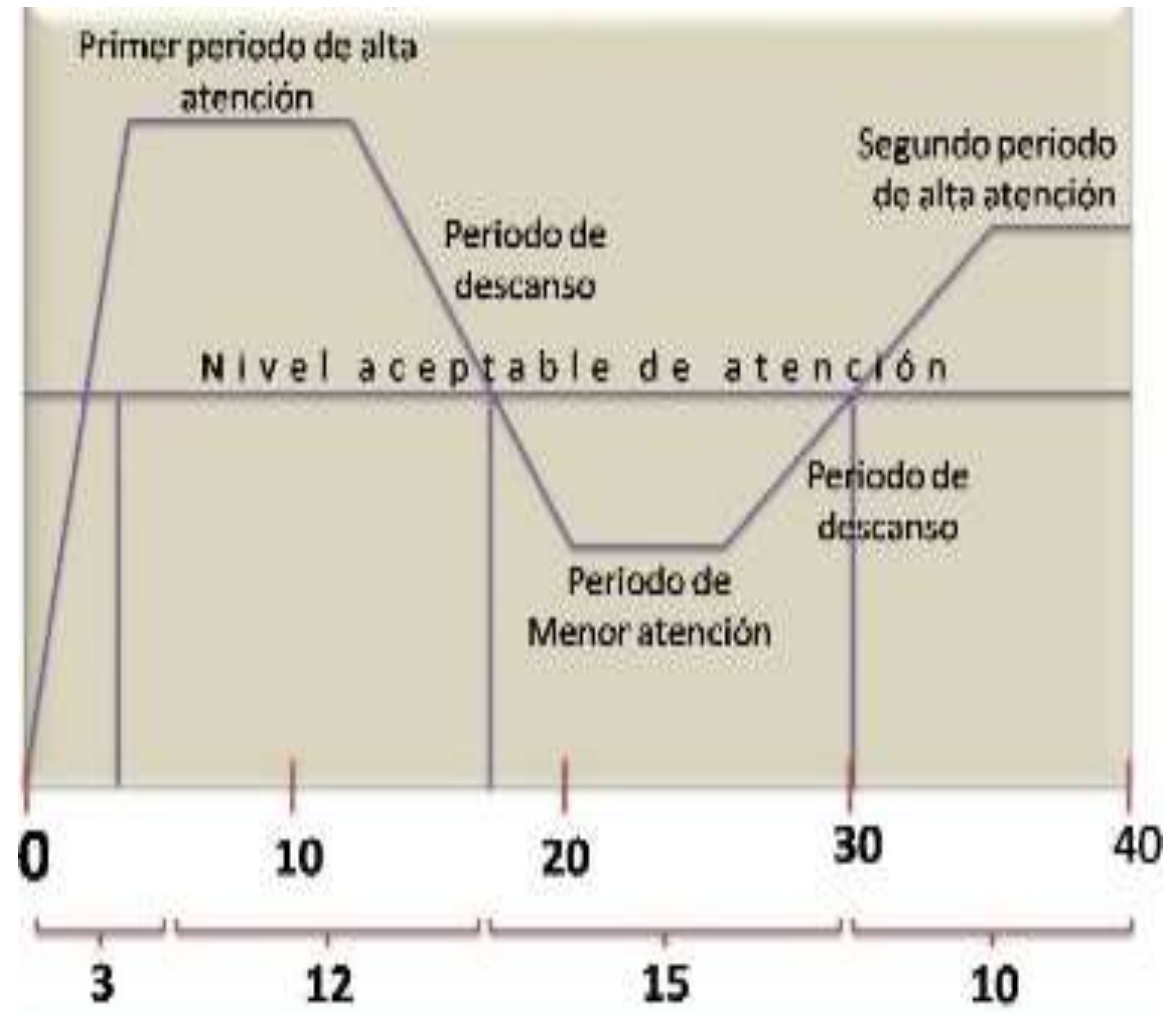

Figura 16.Periodos de atención de una clase de 40 minutos.

Fuente: Revista Taca (2016).

El cerebro ante el esfuerzo y consumo de energía que debe hacer para el aprendizaje cognitivo ejecutivo tiene ciclos de mayor y menor atención. Estos ciclos se manejan de manera 
automática y fuera de la voluntad, por ello hay que desarrollar estrategias de dar tiempo de descanso y actividades motivadoras, según sean las etapas de los ciclos.

\section{Fundamentos pedagógicos.}

La propuesta de diseñar una estrategia didáctica que se adapte a los estilos de aprendizaje, con el diseño de sesiones de clases creativas, motivadoras e innovadoras que provoquen la curiosidad científica. Esto permitirá alcanzar una educación integral, para ello es necesario docentes con competencias pedagógicas que logren identificar potencialidades así como las diversas necesidades de los estudiantes, por lo cual debe existir una mediación pedagógica como proceso para obtener aprendizajes legítimos, de transformación en el sector educativo.

El profesional de la educación debe clasificar y conocer los diferentes modelos pedagógicos que orientan y fundamentan la actividad educativa desarrollados a lo largo de todo este tiempo y estar consciente de que todos estos modelos se articulan en una relación humana que debe considerar como esencia el amor especifico desde una perspectiva ética, reconociendo el amor como el fundamento pedagógico esencial de la educación. (Arias 2009).

Así mismo Arias indica si buscar el bien es amar, y el amor es lo fundamental en las relaciones humanas, entonces buscar el bien es lo esencial de una relación humana, tomando en cuenta que la educación es una relación humana, entonces se puede concluir que educar es amar, donde se busca el bien, y que es necesario saber buscar el bien, encontrarlo para poder enseñar. La correlación entre la definición del ser humano, los modelos y las técnicas pedagógicas en teoría y la práctica docente, en el marco de la educación, son una relación humana y cuando existe una desarticulación, no funciona adecuadamente, impidiendo lograr el bien si no se busca. (p.20).

En la mediación pedagógica un docente va en búsqueda de nuevas estrategias y propuestas metodológicas para atender las necesidades cognitivas, emocionales de los 
estudiantes, lo antes mencionado debe concientizar a promover espacios adecuados, acogedores porque son considerado un recurso indispensable para los diferentes procesos donde se va indagar y explorar diversos procesos educativos

\section{Fundamentos curriculares.}

Teniendo en cuenta la Declaracion de Incheon (2015) de acuerdo a la visión para el 2030 hacia una educación inclusiva y equitativa de calidad y un aprendizaje a lo largo de la vida para todos, el principal objetivo esta centrado en mejorar y transformar la calidad educativa con pertinencia, para cambiar vidas. Por lo cual hay que reconocer el papel importante que desempeña la educacion siendo sin duda el motor principal para el desarrollo y crecimiento profesional y personal por ello, es fundamental que los estudiantes adquieran diversas habilidades pertinentes y efectivas, y de esta manera, obtener resultados de un aprendizaje eficaz.

Del mismo modo, Salvador (1994), Teniendo en cuenta la mejora de la calidad educativa, indica tres ejes de acción donde plantea, cambios curriculares, programas de atención integral y evaluación educativa. Donde cada uno de estos ejes ha considerado un esfuerzo particular porque se entrelazan, apoyándose recíprocamente, frente a este proceso de reforma se exige una articulación profunda entre las estrategias cualitativas, ante la interrogante de que es un currículo de calidad, se indica una serie de desafíos que permita resolver y entender las cosas, para lo cual se requiere capacidades integras, características de un currículo diversificado

Asimismo, en el Marco del Buen Desempeño Docente (Minedu,2014) en el dominio uno contempla la preparación en el aprendizaje de los estudiantes, en cuyo contenido hay dos competencias, en la primera contempla el conocer y comprender las características de todos sus estudiantes así como sus contextos, los contenidos disciplinares que enseña, los enfoques, técnicas pedagógicas, cuyo fin tiene como propósito de originar capacidades de alto nivel y su 
formación integral. En la competencia dos indica la planificación de la enseñanza de manera colegiada, garantizando la conexión que debe existir entre los aprendizajes que desea lograr el estudiante, el proceso pedagógico, el uso de los recursos para la evaluación, en una programación curricular con una revisión permanente. (p. 26).

En relacion a lo antes indicado, según la Resolución de Secretaría General del Minedu (Nº 281-2016 ED) instituye cuáles son los estánderes de enseñanza para obtener una educación de excelencia, contemplado en el sétimo enfoque del currículo Nacional, que involucra conocer diversas estrategias para alcanzar valores y actitudes para la vida comunitaria y estos son, la flexibilidad, la apertura y la superación personal. (p. 20).

\section{Diseño de la propuesta}

A continuación, se presenta el diseño del esquema de la propuesta de estrategias didaticas acorde a los lineamientos planteados en la fundamentación curricular, para tal efecto, se tomó en cuenta el estado real producto del trabajo de campo y de esta manera lograr el estado ideal.

En el cual resume las etapas de investigación propuestas. Iniciando con el diagnóstico que revela la problemática que atraviesan los docentes y los estudiantes de un instituto superior tecnológico estatal de Lima.

Teniendo la necesidad de contar con estrategias didácticas para mejorar el estilo de aprendizaje, se contó con el conocimiento de la fundamentación socioeducativa, curricular, pedagógica, neuroeducacional y psicológica para construirla. Este material da evidencia del estado real y propone un estado ideal teniendo en cuenta las estrategias didácticas para mejorar estos estilos en los estudiantes del instituto superior tecnológico público, para ello hay un soporte teórico pedagógico y una serie de pautas y actividades que debe tener en cuenta los docentes, director y personal administrativo, para fortalecer las sesiones de aprendizaje de cada uno de los docentes. 


\section{Figura 17}

Esquema grafico teórico funcional de la modelación de la propuesta






\section{Desarrollo de la propuesta}

En la figura 14, se aprecia la razón de este esquema, que está basado en los fundamentos científicos que son la base teórica y fundamental de la estrategia didáctica propuesta, que busca conseguir niveles altos que ayuden a potenciar el proceso de enseñanza-aprendizaje en un Instituto superior tecnológico, alcanzando el fin supremo de la educación.

Este esquema funcional demuestra las relaciones del problema, objeto de estudio, buscando la innovación del diagnóstico de la situación real a una ideal, proponiendo una estrategia didáctica diseñada en base a sustentos teóricos, psicológicos y metodológicos presentados.

La modelación de la propuesta, se basa en mejorar el estilo de aprendizaje a través de una estrategia didáctica la cual permite reconocer, valorar y priorizar para mejorar el proceso de enseñanza-aprendizaje.

\section{Fases y actividades de la propuesta}

Las fases y actividades se relacionan con los objetivos establecidos en la propuesta, en los diseños de los talleres, para lo cual la primera es la fase de apertura en donde se evidencia el diagnóstico de la situación sobre los métodos, técnicas y estrategias aplicados en el proceso de enseñanza-aprendizaje en el institución superior tecnológico, este diagnóstico será a partir de un conversatorio con el docente. La segunda fase corresponde al desarrollo de nuestra propuesta y en ella se evidencian tres talleres de capacitación propuestos en la modelación; el primer taller es un proyecto formativo estratégico institucional, en el segundo taller es una estrategia didáctica para desarrollar el estilo de aprendizaje a través del trabajo colaborativo, y el tercer taller, seguimiento y tipos de evaluación constructivista considerando el estilo de aprendizaje estos talleres buscan el fortalecimiento, reconocimiento de la relevancia que tiene el uso adecuado y pertinente de la implementación de recursos pedagógicos así como la evaluación considerando el estilo de aprendizaje, esto permitirá potenciar su desenvolvimiento 
pedagógico mejorando así su desempeño; cada taller tiene una estructura planteada, desde el nombre del taller, el público a quien se va dirigir, título, problema, los objetivos o competencias, tiempo de duración, los equipos y materiales y la evaluación.

\section{Fase de apertura.}

Se realizará el diagnóstico de las actividades anuales que realiza el docente en el instituto superior tecnológico público a través de una charla, además se aplicará una encuesta para medir su grado de aceptación y motivación frente a las actividades institucionales.

\section{Acciones a realizar}

\section{Objetivo.}

Diagnosticar el grado de satisfacción y motivación de los docentes en relación a la implementación de los recursos didácticos.

\section{Acciones.}

Sensibilizar a los docentes sobre su compromiso y trabajo en equipo dentro y fuera de la institución.

Tabla 4

Fase I. Apertura

\begin{tabular}{|c|c|c|c|c|}
\hline Actividad & Propósito & Desarrollo & Recursos & Evaluación \\
\hline $\begin{array}{l}\text { Charla } \\
\text { como } \\
\text { proceso de } \\
\text { diagnóstico. }\end{array}$ & $\begin{array}{l}\text { Concientizar a los } \\
\text { docentes sobre su } \\
\text { quehacer pedagógico } \\
\text { dentro y fuera de la } \\
\text { institución. }\end{array}$ & $\begin{array}{l}\text { Se proyectará video sobre } \\
\text { la labor del docente y el } \\
\text { desenvolvimiento del } \\
\text { estudiante. } \\
\text { A través de la intervención } \\
\text { de los participantes se } \\
\text { describirá las acciones más } \\
\text { sobresalientes del proceso } \\
\text { de enseñanza aprendizaje. }\end{array}$ & $\begin{array}{l}\text { Proyector } \\
\text { Ecram }\end{array}$ & $\begin{array}{l}\text { Intervenci } \\
\text { ones orales }\end{array}$ \\
\hline $\begin{array}{l}\text { Encuesta } \\
\text { para } \\
\text { determinar }\end{array}$ & $\begin{array}{l}\text { Determinar la aceptación } \\
\text { de los docentes en } \\
\text { relación a las diferentes }\end{array}$ & $\begin{array}{l}\text { Se aplicara una breve } \\
\text { encuesta que será de } \\
\text { manera anónima para }\end{array}$ & Encuestas & $\begin{array}{l}\text { Tabulació } \\
\text { n de los } \\
\text { resultados }\end{array}$ \\
\hline
\end{tabular}




\begin{tabular}{|c|c|c|}
\hline $\begin{array}{l}\text { la } \\
\text { aceptación } \\
\text { frente a las } \\
\text { actividades } \\
\text { institucional } \\
\text { es }\end{array}$ & $\begin{array}{lcr}\text { actividades } & \text { de } & \text { la } \\
\text { institución } & \text { que } & \text { se } \\
\text { desarrollan } & \text { y } & \text { los } \\
\text { objetivos concretados } & \text { en } \\
\text { concordancia } & \text { a } & \text { sus } \\
\text { necesidades. }\end{array}$ & $\begin{array}{l}\text { conocer el grado de } \\
\text { aceptación de los docentes, } \\
\text { en relación a la ejecución } \\
\text { de actividades } \\
\text { institucionales. }\end{array}$ \\
\hline
\end{tabular}

Fuente: Elaboración propia (2020).

\section{Fase de desarrollo}

\section{Objetivo.}

Reconocer y tomar en cuenta el desenvolvimiento del estudiante acorde a su estilo de aprendizaje, a través de la identificación de sus capacidades.

Organizar el proyecto teniendo en cuenta las actividades institucionales, con la participación de los estudiantes.

\section{Acciones.}

Realizar un taller práctico para la elaboración de un proyecto de una actividad institucional cuyo fin permita la implementación de recursos pedagógicos, este taller permitirá el desenvolvimiento de los estudiantes donde pondrán en práctica sus habilidades y sus estilos de aprendizaje, esto fortalecerá su autoestima, capacidad de trabajo en equipo, liderazgo, pero sobre todo cada uno se sentirá motivado al desarrollar cada tarea educativa y demostrar sus capacidades.

Con este taller buscamos que para el proceso de enseñanza- aprendizaje hay que tener en cuenta que las actividades tienen que aplicarse de acuerdo el estilo de aprendizaje del estudiante.

El aporte que se va lograr con la aplicación del proyecto es generar ingresos para la adquisición de recursos pedagógicos y didácticos que permitirá la implementación de estrategias para el docente en las sesiones de clase. 
Tabla 5

Fase II. De Desarrollo.

\begin{tabular}{|c|c|c|c|c|}
\hline & Propósito & Desarrollo & Recursos & Evaluación \\
\hline $\begin{array}{l}\text { Primer } \\
\text { taller. } \\
\text { Proyecto } \\
\text { formativo } \\
\text { estratégico } \\
\text { institucional }\end{array}$ & $\begin{array}{lr}\begin{array}{lr}\text { Fortalecer } \\
\text { esquema }\end{array} & \text { del } \\
\text { proyecto } & \\
\text { formativo } & \text { y } \\
\text { adecuarlo a las } \\
\text { actividades } \\
\text { institucionales, } \\
\text { para la } \\
\text { adquisición de } \\
\text { materiales } \\
\text { pedagógicos. }\end{array}$ & $\begin{array}{l}\text { Realizar dos sesiones, talleres } \\
\text { teóricos y prácticos, donde los } \\
\text { estudiantes puedan demostrar sus } \\
\text { capacidades y su estilo de } \\
\text { aprendizaje. Realizar un taller } \\
\text { donde se desarrolle la estructura } \\
\text { del proyecto formativo, donde los } \\
\text { estudiantes darán rienda suelta a } \\
\text { su imaginación, creatividad, así } \\
\text { como a su capacidad de análisis y } \\
\text { creación. }\end{array}$ & $\begin{array}{l}\text { Diapositiv } \\
\text { as } \\
\text { Proyector } \\
\text { Papelotes } \\
\text { Plumones }\end{array}$ & $\begin{array}{l}\text { Participació } \\
\text { n en los } \\
\text { talleres }\end{array}$ \\
\hline $\begin{array}{l}\text { Segundo } \\
\text { taller. } \\
\text { Estrategia } \\
\text { didáctica } \\
\text { tomando en } \\
\text { cuenta el } \\
\text { estilo de } \\
\text { aprendizaje } \\
\text { a través del } \\
\text { trabajo } \\
\text { colaborativo }\end{array}$ & $\begin{array}{l}\text { Motivar a los } \\
\text { docentes, para que } \\
\text { tengan en cuenta } \\
\text { el estilo de } \\
\text { aprendizaje del } \\
\text { estudiante } \\
\text { Recomendar el } \\
\text { uso de estrategias } \\
\text { y el aprendizaje } \\
\text { colaborativo, lo } \\
\text { cual permite } \\
\text { implementar } \\
\text { técnicas } \\
\text { diferentes estilos } \\
\text { de aprender. }\end{array}$ & $\begin{array}{l}\text { Diseñar estrategias, instrumentos } \\
\text { de aplicación a los estudiantes } \\
\text { para el reconocimiento de } \\
\text { algunas características que se } \\
\text { tiene entre un estilo a otro estilo } \\
\text { de aprendizaje, estas } \\
\text { herramientas son parte de la } \\
\text { carpeta pedagógica del docente, } \\
\text { que serán aplicados a los } \\
\text { estudiantes, esto permite crear } \\
\text { estrategias adecuadas que sean } \\
\text { aplicadas en las sesiones de } \\
\text { enseñanza- aprendizaje. } \\
\text { La aplicación de estos } \\
\text { instrumentos deben ser } \\
\text { supervisados por las áreas de } \\
\text { formación académica. }\end{array}$ & $\begin{array}{l}\text { Plumones } \\
\text { Hojas de } \\
\text { colores. }\end{array}$ & $\begin{array}{l}\text { Revisión y } \\
\text { supervisión } \\
\text { por parte de } \\
\text { los jefes del } \\
\text { área } \\
\text { académica, } \\
\text { su } \\
\text { aplicación } \\
\text { es } \\
\text { recomendab } \\
\text { le en la } \\
\text { tercera clase } \\
\text { de inicio del } \\
\text { ciclo } \\
\text { académico. }\end{array}$ \\
\hline
\end{tabular}




\begin{tabular}{|c|c|c|c|c|}
\hline $\begin{array}{l}\text { Tercer } \\
\text { taller. } \\
\text { Seguimient } \\
\text { o y tipos de } \\
\text { evaluación } \\
\text { constructivi } \\
\text { sta } \\
\text { considerand } \\
\text { o el estilo de } \\
\text { aprendizaje }\end{array}$ & $\begin{array}{l}\text { Reconocer los } \\
\text { aportes que brinda } \\
\text { la evaluación } \\
\text { constructivista, } \\
\text { esto permite } \\
\text { adaptar estrategias } \\
\text { y técnicas en los } \\
\text { procesos } \\
\text { evaluativos y que } \\
\text { estos se adapten al } \\
\text { estilo } \\
\text { aprendizaje del } \\
\text { estudiante. }\end{array}$ & $\begin{array}{l}\text { Se evidenciara las mejoras en los } \\
\text { procesos evaluativos mejorando } \\
\text { los resultados del rendimiento } \\
\text { académico de los estudiantes } \\
\text { Se estimulara y reconocerá al } \\
\text { docente por el trabajo de crear } \\
\text { instrumentos de evaluación que } \\
\text { se adapten al estilo predominante } \\
\text { de los estudiantes. } \\
\text { Se publicara el rendimiento } \\
\text { académico de los estudiantes en } \\
\text { el periódico mural. }\end{array}$ & $\begin{array}{l}\text { Separatas } \\
\text { Hojas de } \\
\text { colores } \\
\text { plumones }\end{array}$ & $\begin{array}{l}\text { Revisión de } \\
\text { la } \\
\text { publicación } \\
\text { del } \\
\text { rendimiento } \\
\text { académico }\end{array}$ \\
\hline
\end{tabular}

Fuente: Elaboración propia (2020).

A continuación se detalla el desarrollo del taller propuesto.

Taller 01: Proyecto formativo estratégico institucional

\section{Ficha técnica:}

Público objetivo: Estudiantes que cursan el quinto y sexto ciclo.

\section{Número de sesiones: 2}

Título: Proyecto formativo estratégico institucional.

Problema: Carencia de implementación de recursos didácticos.

Objetivo: Organizar el proyecto teniendo en cuenta las actividades institucionales, con la participación de los estudiantes.

Reconocer y tomar en cuenta el desenvolvimiento del estudiante acorde a su estilo de aprendizaje, a través de la identificación de sus capacidades.

\section{Tiempo: 100 minutos.}

Equipos y materiales: Multimedia, hojas aplicativas, plumones, cinta adhesiva.

Fecha de actividad: 2020 
Tabla 6

Proyecto formativo estratégico institucional

\begin{tabular}{|c|c|c|c|c|}
\hline Objetivos & Actividad & Tiempo & $\begin{array}{l}\text { pos / } \\
\text { riales }\end{array}$ & Evaluación \\
\hline $\begin{array}{l}\text { Reconocer } \\
\text { una } \\
\text { actividad } \\
\text { institucional } \\
\text { que permita } \\
\text { la } \\
\text { aplicación y } \\
\text { ejecución } \\
\text { del proyecto } \\
\text { formativo, } \\
\text { tomando en } \\
\text { cuenta los } \\
\text { potenciales } \\
\text { del } \\
\text { estudiante } \\
\text { en relación } \\
\text { a su estilo } \\
\text { de } \\
\text { aprendizaje. }\end{array}$ & $\begin{array}{l}\text { El docente provoca un diálogo con los } \\
\text { participantes realizando preguntas ¿Qué } \\
\text { estrategias o proyectos podrían desarrollarse } \\
\text { para poder implementar recursos pedagógicos? } \\
\text { ¿Qué materiales didácticos se pueden utilizar } \\
\text { en los estudiantes de estilo convergente y } \\
\text { divergente? ¿Cómo cree usted que afecta la } \\
\text { falta de una buena implementación de } \\
\text { materiales y equipos pedagógicos en el } \\
\text { proceso de aprendizaje? } \\
\text { Se forman } 4 \text { grupos previo reconocimiento a la } \\
\text { afinidad de cuatro situaciones de aprendizaje. } \\
\text { Primera situación, entrega de una separata } \\
\text { con texto que hay que analizar y resumir ideas } \\
\text { principales. (Estilo convergente). } \\
\text { Segunda situación, trabajo en equipo para } \\
\text { formular una presentación innovadora. (Estilo } \\
\text { acomodador). } \\
\text { Tercera situación, redactar y formular } \\
\text { objetivos del proyecto. (Estilo divergente). } \\
\text { Cuarta situación, realizar esquema para el } \\
\text { proyecto con base científica.(estilo asimilador) } \\
\text { pesarrollaran el diseño del proyecto cada } \\
\text { grupo de trabajo de acuerdo a su potencial } \\
\text { cognitivo y practico } \\
\text { Se les orientara su desenvolvimiento de } \\
\text { y la estructura del proyecto. }\end{array}$ & $30 \mathrm{~min}$ & $\begin{array}{l}\text { Hojas de } \\
\text { colores } \\
\text { Plumones }\end{array}$ & $\begin{array}{l}\text { Participaci } \\
\text { ón del } \\
\text { estudiante }\end{array}$ \\
\hline
\end{tabular}




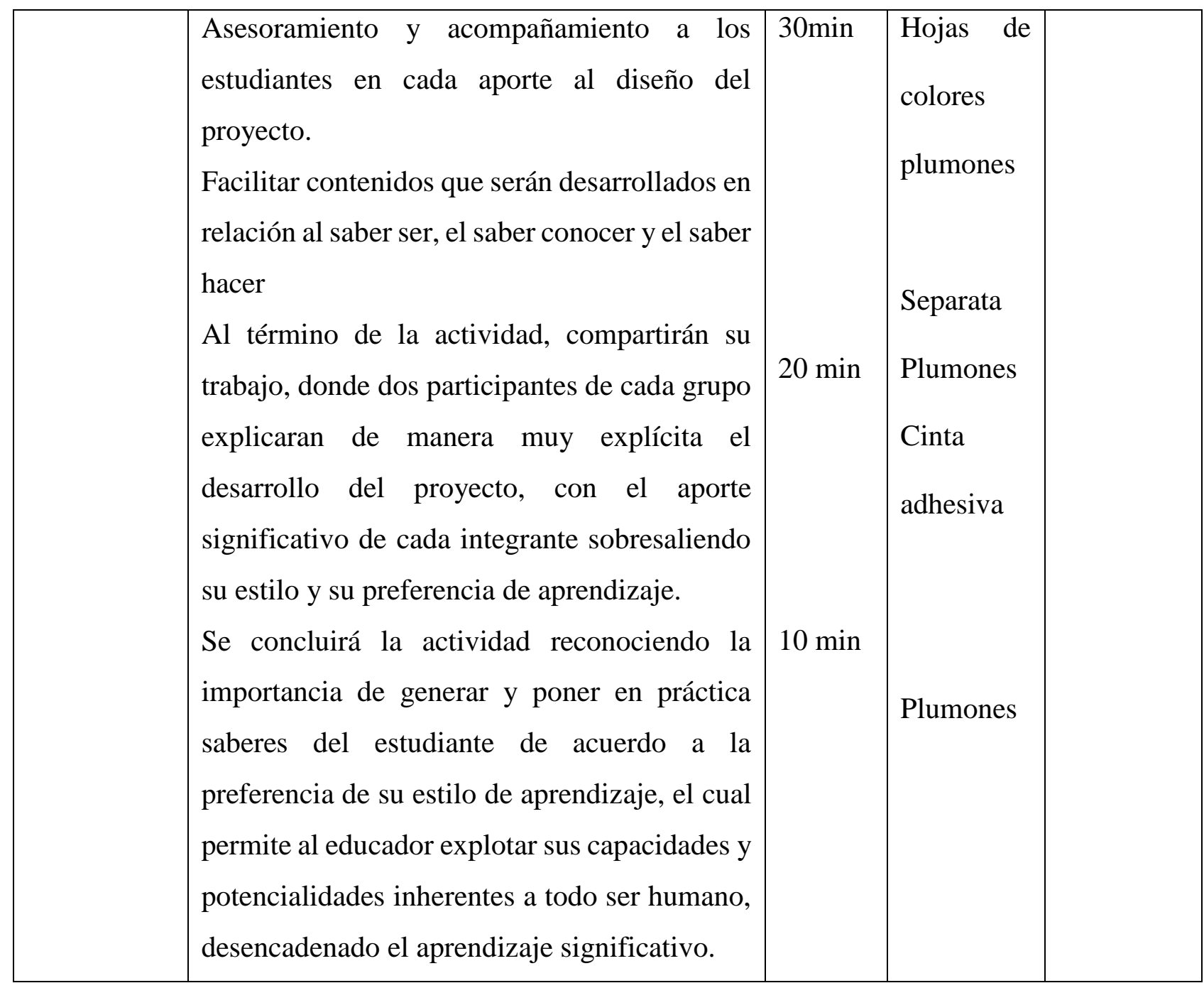

Fuente: Elaboración propia (2020).

Taller 02: Estrategia didáctica tomando en cuenta el estilo de aprendizaje a través del trabajo colaborativo

\section{Ficha técnica:}

Público objetivo: Estudiantes del segundo y tercer ciclo.

\section{Número de sesiones: 2}

Título: Aprendizaje colaborativo en estudiantes de estilo acomodador y asimilador.

Problema: Carencia de recursos didácticos para cubrir las necesidades pedagógicas del docente. 
Objetivo: Crear y elaborar materiales pedagógicos sobre el agua y el proceso de hidratación, teniendo en cuenta los potenciales creativos, cognitivos y prácticos de los estilos de aprendizaje.

\section{Tiempo: 90 minutos.}

Equipos y materiales: Multimedia, hojas aplicativas, plumones, cinta adhesiva, papeles de colores, papelotes, separatas, cuestionario

Fecha de actividad: 2020.

Tabla 7

Estrategia didáctica tomando en cuenta el estilo de aprendizaje a través del trabajo colaborativo.

\begin{tabular}{|l|l|l|l|l|}
\hline Objetivos & \multicolumn{1}{|c|}{ Actividad } & Tiempo & $\begin{array}{c}\text { Equipos / } \\
\text { materiales }\end{array}$ & $\begin{array}{l}\text { Criterio de } \\
\text { evaluación }\end{array}$ \\
\hline & $\begin{array}{l}\text { Recibimiento a los estudiantes y se anota } \\
\text { sus datos en un registro, se les da la } \\
\text { bienvenida con el saludo respectivo y las } \\
\text { felicitaciones de su participación, luego se } \\
\text { les muestra unos solapines con diferentes } \\
\text { esquemas y dibujos donde van a escoger } \\
\text { cada uno de acuerdo a lo que les guste, el } \\
\text { docente invitara que se agrupen de acuerdo } \\
\text { a la similitud de sus gráficos escogidos, } \\
\text { formándose 2 grupos de 6 integrantes. } \\
\text { El docente presenta y explica la importancia } \\
\text { del uso de los diferentes tipos de estrategias } \\
\text { y recursos didácticos. } \\
\text { Indica la elaboración de 2 materiales } \\
\text { didácticos teniendo como tema el agua y la } \\
\text { hidratación. } \\
\text { Se hace entrega de material (separatas) } \\
\text { donde tendrán que leer y observar gráficos } \\
\text { y dibujos, esta información permite la }\end{array}$ & 30 min & Solapines & Formar \\
grupos de \\
acuerdo al \\
estilo de \\
aprendizaje
\end{tabular}




\begin{tabular}{|c|c|c|c|c|}
\hline $\begin{array}{l}\text { Analizar, } \\
\text { diseñar y } \\
\text { elaborar } \\
\text { materiales } \\
\text { didácticos } \\
\text { alusivos al } \\
\text { tema del } \\
\text { agua y la } \\
\text { hidratación, } \\
\text { poniendo en } \\
\text { evidencia la } \\
\text { creatividad } \\
\text { de acuerdo } \\
\text { al estilo de } \\
\text { aprendizaje. }\end{array}$ & 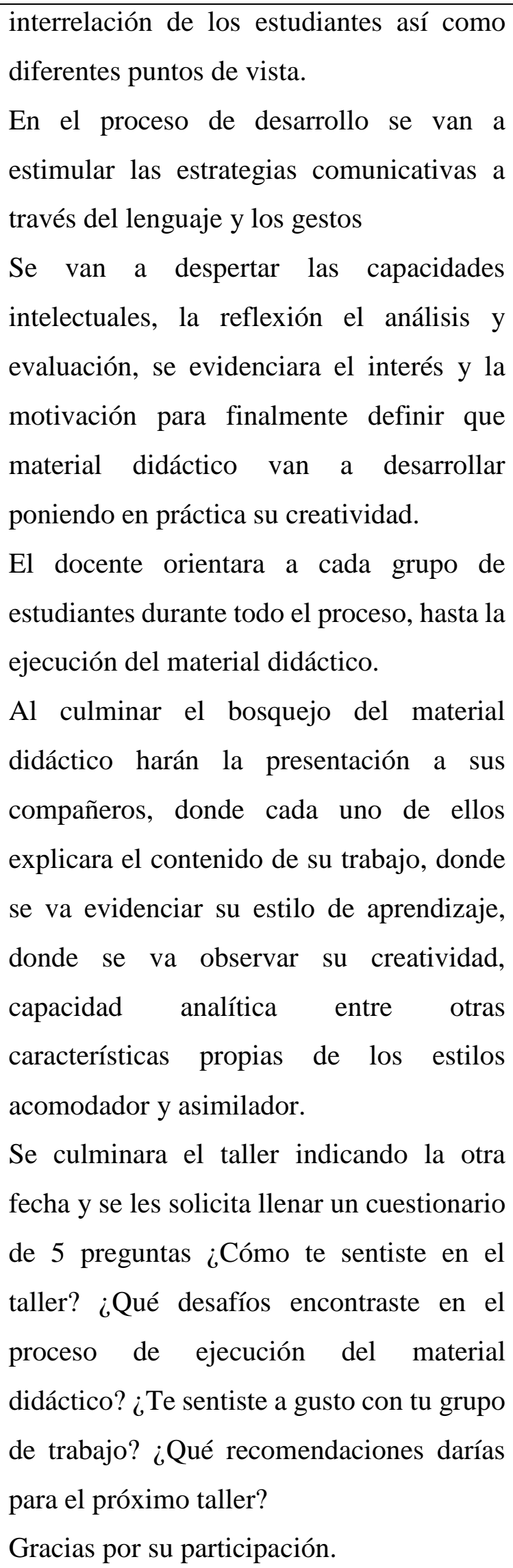 & $15 \mathrm{~min}$ & $\begin{array}{l}\text { Hojas de } \\
\text { colores } \\
\text { Plumones } \\
\text { de pizarra }\end{array}$ & $\begin{array}{l}\text { Aplicación } \\
\text { de la meta } \\
\text { cognición }\end{array}$ \\
\hline
\end{tabular}

Fuente: Elaboración propia (2020). 
Taller 03: Seguimiento y tipos de evaluación constructivista considerando el estilo de aprendizaje

\section{Ficha técnica:}

Público objetivo: Docentes especialistas del área técnica que se desenvuelven del primer al quinto ciclo.

Docentes de unidades didácticas transversales de especialidad que se desenvuelven en el sexto ciclo.

Título: Técnicas e instrumentos de evaluación aplicados en estudiantes de acuerdo al estilo de aprendizaje.

Objetivos: Determinar la funcionabilidad de los criterios e indicadores de las técnicas, instrumentos y procedimientos de evaluación considerando el estilo de aprendizaje.

Reconocer los diversos criterios a considerar en los procesos evaluativos, incluyendo las técnicas formales, semiformales e informales.

Proponer diversas técnicas de evaluación, analizando las características de aprendizaje en los estilos divergentes, convergentes, asimilativo y acomodador.

Tiempo: 130 minutos.

Equipos y materiales: Multimedia, hojas aplicativas, plumones, formatos de exámenes, separatas.

Fecha de actividad: 2020

Tabla 8

Seguimiento y tipos de evaluación constructivista considerando el estilo de aprendizaje

\begin{tabular}{|l|l|l|l|l|}
\hline Objetivos & \multicolumn{1}{|c|}{ Actividad } & Tiempo & $\begin{array}{c}\text { Equipo / } \\
\text { materiales }\end{array}$ & Evaluación \\
\hline & $\begin{array}{l}\text { El especialista en procesos evaluativos da la } \\
\text { bienvenida a los docentes, hace entrega de dos } \\
\text { separatas cuyos contenidos son un extracto de } \\
\text { las características y la definición de los estilos } \\
\text { de aprendizaje teniendo en cuenta a David Kolb, } \\
\text { y contenido de técnicas e instrumentos de }\end{array}$ & $10 \mathrm{~min}$ & Separata & \\
\hline
\end{tabular}




\begin{tabular}{|c|c|c|c|c|}
\hline $\begin{array}{l}\text { Reconocer y } \\
\text { elaborar } \\
\text { instrumento } \\
\text { s de } \\
\text { evaluación } \\
\text { tomando en } \\
\text { cuenta las } \\
\text { técnicas } \\
\text { constructivi } \\
\text { stas. }\end{array}$ & 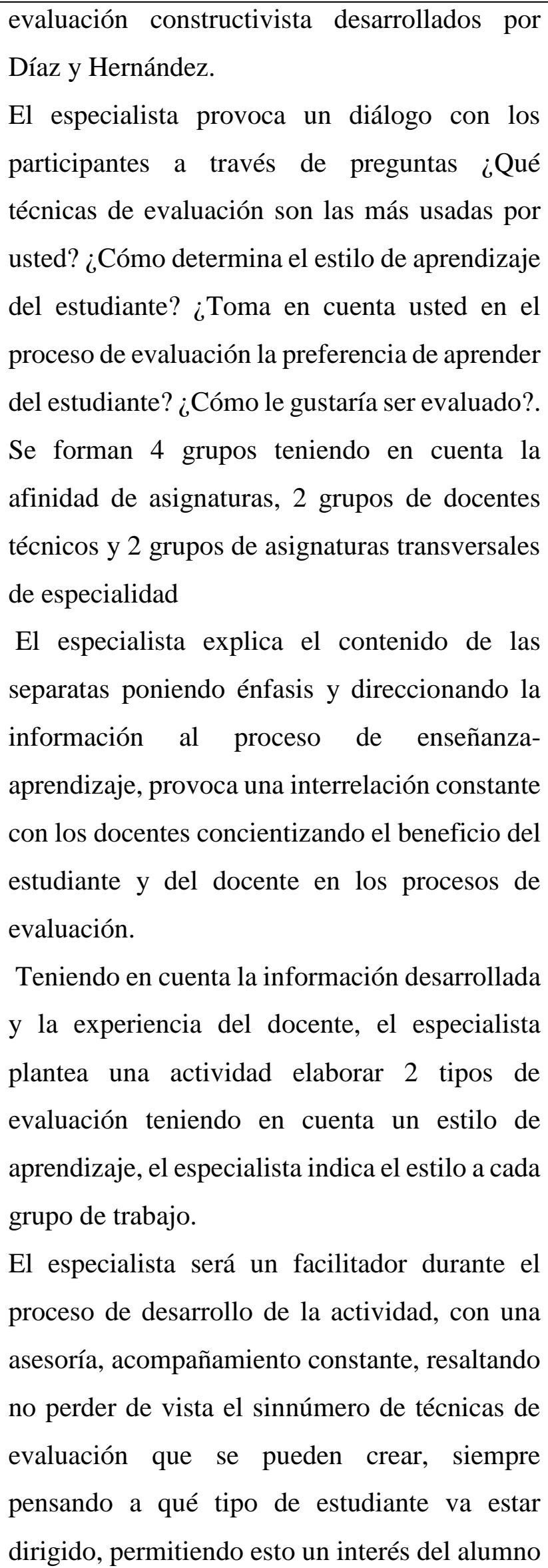 & $20 \mathrm{~min}$ & $\begin{array}{l}\text { Hojas de } \\
\text { colores } \\
\text { Plumón }\end{array}$ & $\begin{array}{l}\text { Participaci } \\
\text { ón de los } \\
\text { docentes. }\end{array}$ \\
\hline
\end{tabular}




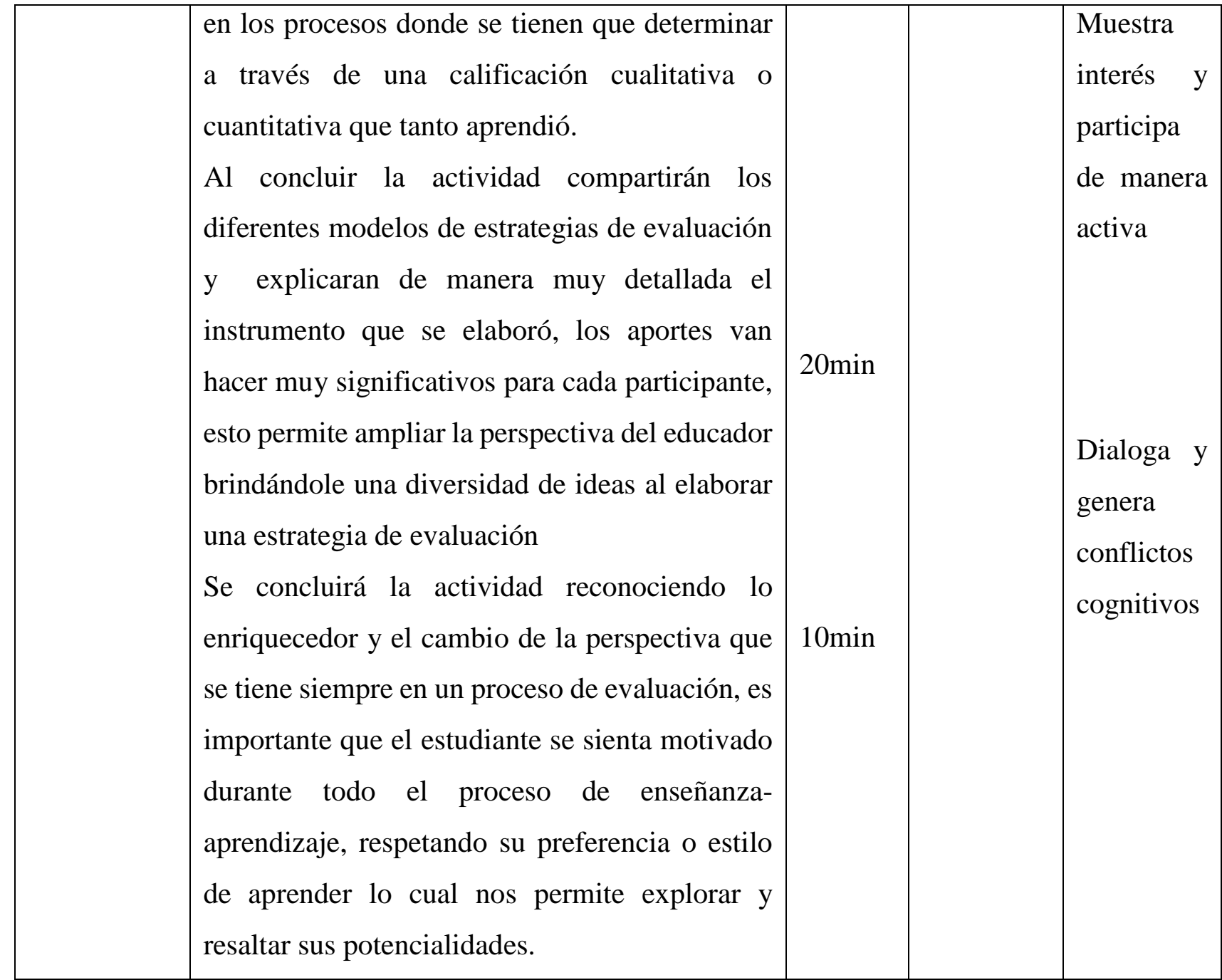

Fuente: Elaboración propia (2020).

\section{Fases de resultados}

\section{Objetivo.}

Recoger información de los docentes y estudiantes, sobre el porcentaje de estilos de los estudiantes y las propuestas para elaborar los instrumentos de evaluación ajustados a las necesidades del educando, será considerado material de la carpeta pedagógica, supervisada por la jefatura de formación académica

Reconocer el compromiso del docente, a través de capacitaciones gratuitas y certificaciones, convocadas por la gestión de la institución, enriqueciendo el desempeño docente. 
Tabla 9

Fase III. De resultados

\begin{tabular}{|c|c|c|c|c|}
\hline Actividad & Propósito & Desarrollo & & \\
\hline $\begin{array}{l}\text { Reconoci } \\
\text { miento del } \\
\text { desempeñ } \\
\text { o docente } \\
\text { en los } \\
\text { procesos } \\
\text { de } \\
\text { evaluación }\end{array}$ & 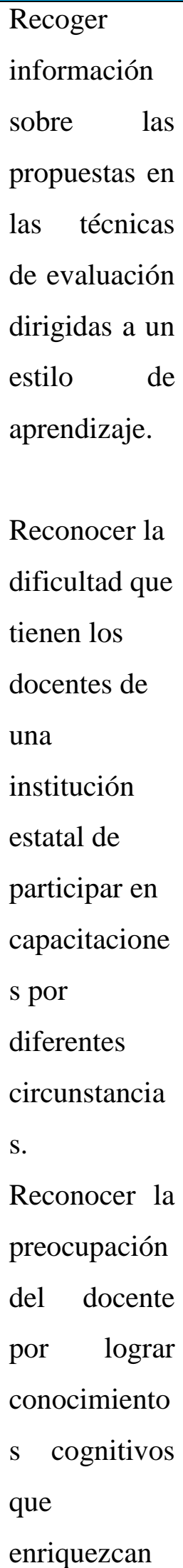 & $\begin{array}{l}\text { Recabar información a través del } \\
\text { monitoreo de la jefatura de formación } \\
\text { académica y del área técnica. } \\
\text { Presentación de proyectos formativos: a } \\
\text { través de los proyectos que se pueden } \\
\text { hacer tomando en cuenta las actividades } \\
\text { inherentes a la institución como el } \\
\text { aniversario, la semana técnica, y el } \\
\text { homenaje a la patrona de la institución, se } \\
\text { pueden generar ingresos que permitan la } \\
\text { adquisición de recursos, equipos y } \\
\text { materiales didácticos que son deficientes } \\
\text { en los procesos de enseñanza- aprendizaje. } \\
\text { Satisfacción de los estudiantes de sus } \\
\text { procesos académicos y de evaluación: } \\
\text { tener en cuenta el estilo de aprendizaje va } \\
\text { permitir seleccionar y clasificar técnicas, } \\
\text { estrategias y métodos para ser aplicados } \\
\text { en los momentos de la sesión de clase, esto } \\
\text { va satisfacer al estudiante provocando un } \\
\text { interés constante y logrando un } \\
\text { aprendizaje significativo. Se logra } \\
\text { potenciar las competencias del docente a } \\
\text { través de las capacitaciones. } \\
\text { Entrega de certificados a los docentes } \\
\text { de parte de la institución: se entregara a } \\
\text { aquellos docentes que hayan participado } \\
\text { en todas las capacitaciones programadas } \\
\text { en el anopartamental, para }\end{array}$ & $\begin{array}{l}\text { Certifica } \\
\text { dos del } \\
\text { instituto } \\
\text { Conveni } \\
\text { os con } \\
\text { institucio } \\
\text { nes } \\
\text { educativ } \\
\text { as }\end{array}$ & $\begin{array}{l}\text { Convenios } \\
\text { con las } \\
\text { institucion } \\
\text { es }\end{array}$ \\
\hline
\end{tabular}




\begin{tabular}{|l|l|l|l|l|}
\hline $\begin{array}{l}\text { su labor } \\
\text { educacional. }\end{array}$ & $\begin{array}{l}\text { buscar subvenciones en estudios de } \\
\text { diplomados, cursos de actualización para } \\
\text { los docentes }\end{array}$ & $\begin{array}{l}\text { superiore } \\
\text { s. }\end{array}$ & \\
\hline
\end{tabular}

Fuente Elaboración propia (2020).

\section{Aplicación y validación de la propuesta por juicio de especialistas}

La validacion de la propuesta, estrategia didactica para mejorar el estilo de aprendizaje de los estudiantes de la carrera de Cosmetica Dermatologica,se utilizo la tecnica de consulta de juicios de expertos cuyo fin es medir los aspectos internos y externos a traves de 10 indicadores, la validacion esta integrada por tres especialistas. Los expertos fueron seleccionados por su capacidad en la investigación educaciónal de tipo aplicada, los especialistas poseen grados académicos, especialidades profesionales y años de experiencia en el campo de la educacion.

\section{Características de los expertos}

Los expertos seleccionados para avalar la propuesta son profesionales que cuentan con los grados requeridos y además cuentan con gran trayectoria en el campo de la educación, lo cual les brinda la autoridad para valorar la propuesta de la tesis.

En seguida, se observa a continuación datos de los tres especialistas.

\section{Tabla 10}

Expertos seleccionados para validar los instrumentos

\begin{tabular}{|l|c|l|l|l|}
\hline $\begin{array}{l}\text { Nombre y } \\
\text { apellidos }\end{array}$ & $\begin{array}{l}\text { Grado } \\
\text { académico }\end{array}$ & $\begin{array}{l}\text { Especialidad } \\
\text { profesional }\end{array}$ & Ocupación & $\begin{array}{l}\text { Años de } \\
\text { experiencia }\end{array}$ \\
\hline $\begin{array}{l}\text { Muñoz Salazar, } \\
\text { Jose Manuel }\end{array}$ & Doctor & $\begin{array}{l}\text { Doctor en } \\
\text { Educacion }\end{array}$ & $\begin{array}{l}\text { Docente EPG- } \\
\text { USIL }\end{array}$ & 35 años \\
\hline $\begin{array}{l}\text { Velásquez } \\
\text { Tejeda, Miriam }\end{array}$ & Doctor & $\begin{array}{l}\text { Doctor en } \\
\text { Educacion }\end{array}$ & $\begin{array}{l}\text { Docente EPG- } \\
\text { USIL }\end{array}$ & 28 años \\
\hline $\begin{array}{l}\text { Goñi Cruz, } \\
\text { Fernando }\end{array}$ & Doctor & $\begin{array}{l}\text { Doctor en Fisica } \\
\text { y Matematica }\end{array}$ & $\begin{array}{l}\text { Docente EPG- } \\
\text { USIL }\end{array}$ & 20 años \\
\hline
\end{tabular}

Fuente: Elaboración propia (2020). 


\section{Valoración interna y Externa.}

Al realizar la validación de la propuesta se recurrió a una descripcion de valoración que incluye puntajes, entre 0-25 deficiente, 26-50 baja, 51-70 regular, 71-85 buena, 86-100 muy buena, cada especialista conceda el puntaje que examine pertinente, de la descripción de los diez indicadores que se encuentran descriptos en la tabla de valoración interna y externa que se muestran a continuación.

Tabla 11

Tabla de valoración

\begin{tabular}{|c|c|}
\hline Descripción & Puntaje \\
\hline Deficiente & $0-25$ \\
\hline Baja & $26-50$ \\
\hline Regular & $51-70$ \\
\hline Buena & $71-85$ \\
\hline Muy buena & $86-100$ \\
\hline
\end{tabular}

Fuente: Documentos de elaboración USIL (2020).

\section{Valoración interna.}

Con respecto a los criterios de evaluación interna, la ficha de validación de la propuesta, informe de opinión de aplicabilidad de los especialista se han considerado diez indicadores de evaluación, escala de valoracion. Asimismo, sugerencias que se pueden superar,asi como señalar aspectos positivos o negativos.

Tabla 12

Criterios de evaluación interna de la propuesta

\begin{tabular}{|c|c|c|c|c|c|c|c|c|}
\hline \multirow[t]{3}{*}{ Indicadores } & \multirow{2}{*}{\multicolumn{5}{|c|}{$\begin{array}{l}\text { Escala de } \\
\text { valoración }\end{array}$}} & \multicolumn{3}{|c|}{ Aspectos } \\
\hline & & & & & & \multirow[t]{2}{*}{ Positivos } & \multirow[t]{2}{*}{ Negativos } & \multirow{2}{*}{$\begin{array}{l}\text { Sugerenc } \\
\text { ias }\end{array}$} \\
\hline & \begin{tabular}{l|l}
1 \\
\end{tabular} & 2 & 3 & 4 & 5 & & & \\
\hline $\begin{array}{l}\text { Factibilidad de aplicación del resultado que se } \\
\text { presenta. }\end{array}$ & & & & & & & & \\
\hline
\end{tabular}




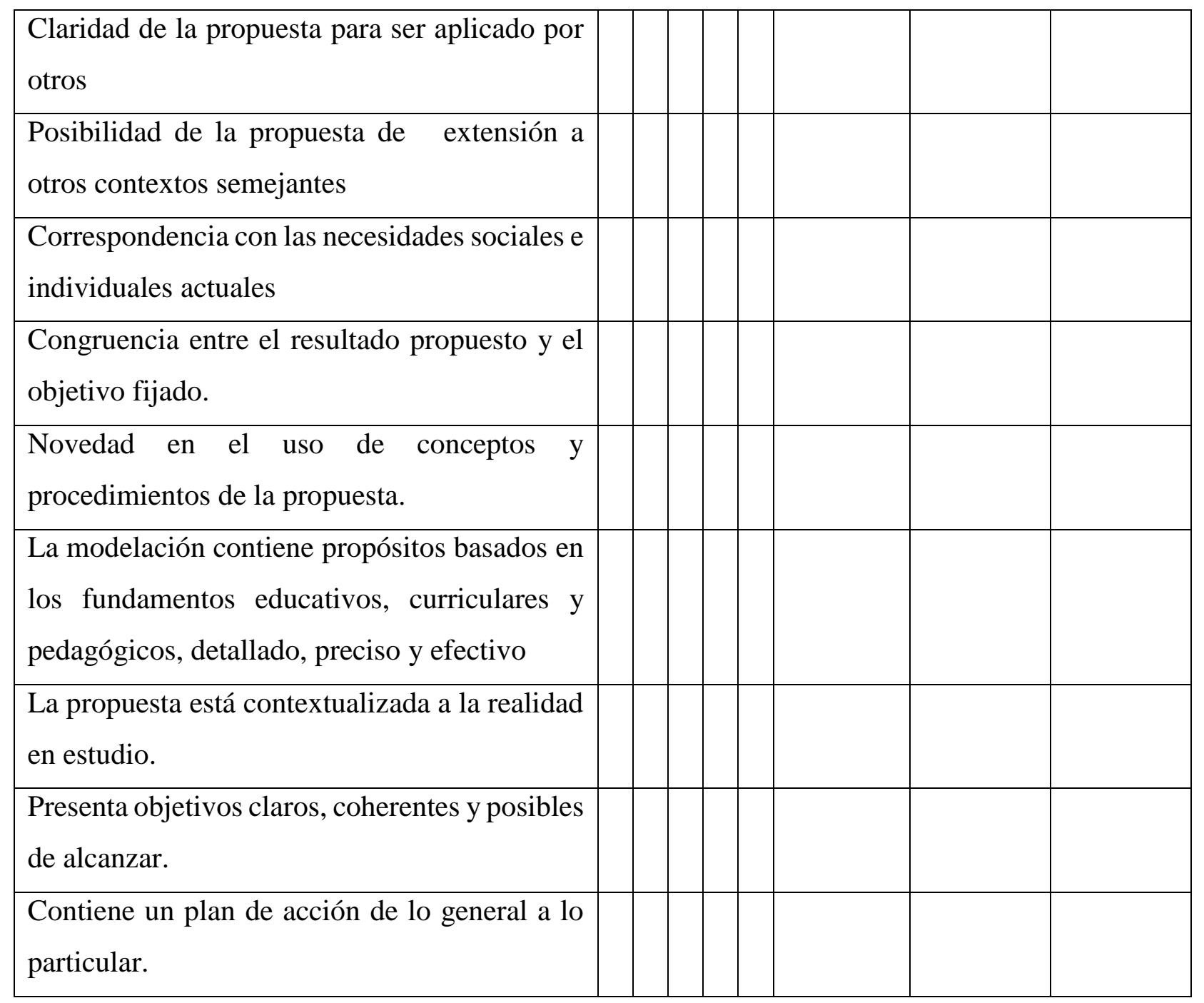

Fuente: Documentos de elaboración USIL (2020).

Seguidamente, se muestra la valoración del puntaje designado por cada uno de los especialistas.

Tabla 13

Valoración interna por criterios de expertos.

\begin{tabular}{|l|c|l|c|}
\hline Nombre y apellidos & Grado académico & Ocupación/ años de experiencia & Valoracion \\
\hline $\begin{array}{l}\text { Muñoz Salazar, } \\
\text { Jose Manuel }\end{array}$ & Doctor & Docente EPG-USIL 35años & 44 \\
\hline $\begin{array}{l}\text { Velásquez Tejeda, } \\
\text { Miriam }\end{array}$ & Doctor & Docente EPG-USIL 28 años & 42 \\
\hline $\begin{array}{l}\text { Goñi Cruz, } \\
\text { Fernando }\end{array}$ & Doctor & Docente EPG-USIL 20 años & 45 \\
\hline
\end{tabular}

Fuente: Fichas de validación USIL (2020). 


\section{Valoración externa.}

De igual manera, se muestra la ficha de validación externa, para esta se han considerado diez criterios e indicadores:

Tabla 14

Criterios de validación externa de la propuesta

\begin{tabular}{|c|c|c|c|c|c|c|c|c|}
\hline \multirow[t]{3}{*}{ Indicadores } & & \multirow{2}{*}{\multicolumn{4}{|c|}{$\begin{array}{l}\text { Escala de } \\
\text { valoración }\end{array}$}} & \multicolumn{3}{|c|}{ Aspectos } \\
\hline & & & & & & \multirow[t]{2}{*}{\begin{tabular}{|l} 
Positivos \\
\end{tabular}} & \multirow[t]{2}{*}{ Negativos } & \multirow{2}{*}{$\begin{array}{l}\text { Sugerencia } \\
\text { s }\end{array}$} \\
\hline & & \begin{tabular}{|l|l|}
1 & 2 \\
\end{tabular} & 3 & 4 & 5 & & & \\
\hline Claridad & $\begin{array}{l}\text { Es formulado con lenguaje } \\
\text { apropiado. }\end{array}$ & & & & & & & \\
\hline Objetividad & $\begin{array}{l}\text { Está expresado en conductas } \\
\text { observables. }\end{array}$ & & & & & & & \\
\hline Actualidad & $\begin{array}{l}\text { Adecuado al avance de la } \\
\text { ciencia pedagógica. }\end{array}$ & & & & & & & \\
\hline Organización & $\begin{array}{l}\text { Existe una organización } \\
\text { lógica. }\end{array}$ & & & & & & & \\
\hline Suficiencia & $\begin{array}{l}\text { Comprende los aspectos de } \\
\text { cantidad y calidad. }\end{array}$ & & & & & & & \\
\hline $\begin{array}{l}\text { Intencionalid } \\
\text { ad }\end{array}$ & $\begin{array}{l}\text { Adecuado para valorar los } \\
\text { aspectos de las categorías. }\end{array}$ & & & & & & & \\
\hline Consistencia & $\begin{array}{l}\text { Basado en aspectos teóricos } \\
\text { científicos de la educación. }\end{array}$ & & & & & & & \\
\hline Coherencia & $\begin{array}{l}\text { Entre el propósito, diseño y } \\
\text { la implementación de la } \\
\text { propuesta. }\end{array}$ & & & & & & & \\
\hline Metodología & $\begin{array}{lll}\text { La estrategia } & \text { responde } & \text { al } \\
\text { propósito } & \text { de } & \text { la } \\
\text { investigación. } & & \end{array}$ & & & & & & & \\
\hline Pertinencia & $\begin{array}{l}\text { Es útil y adecuado para la } \\
\text { investigación. }\end{array}$ & & & & & & & \\
\hline
\end{tabular}

Fuente: Fichas de validación USIL (2020). 
En tal sentido, se demuestran los puntajes otorgados por cada especialista, lo cual indica una valoración externa muy buena.

Tabla 15

Valoración externa por criterios de expertos

\begin{tabular}{|l|c|l|c|}
\hline Nombre y apellidos & Grado académico & Ocupación/ años de experiencia & Valoracion \\
\hline $\begin{array}{l}\text { Muñoz Salazar, } \\
\text { Jose Manuel }\end{array}$ & Doctor & Docente EPG-USIL 35años & 44 \\
\hline $\begin{array}{l}\text { Velásquez Tejeda, } \\
\text { Miriam }\end{array}$ & Doctor & Docente EPG-USIL 28 años & 44 \\
\hline $\begin{array}{l}\text { Goñi Cruz, } \\
\text { Fernando }\end{array}$ & Doctor & Docente EPG-USIL 20 años & 39 \\
\hline
\end{tabular}

Fuente: Fichas de validación USIL (2020).

La sumatoria de las valoraciones de cada especialista se muestra a continuación, lo cual permite decidir en qué rango se ubica la validez de la propuesta.

Tabla 16

Expertos seleccionados para validar los instrumentos

\begin{tabular}{|l|c|c|c|c|}
\hline Nombre y apellidos & Grado académico & $\begin{array}{l}\text { Validacion } \\
\text { interna }\end{array}$ & $\begin{array}{l}\text { Validacion } \\
\text { externa }\end{array}$ & $\begin{array}{l}\text { Sumatoria } \\
\text { valorativa }\end{array}$ \\
\hline $\begin{array}{l}\text { Muñoz Salazar, } \\
\text { Jose Manuel }\end{array}$ & Doctor & 44 & 44 & 88 \\
\hline $\begin{array}{l}\text { Velásquez Tejeda, } \\
\text { Miriam }\end{array}$ & Doctor & 42 & 44 & 84 \\
\hline $\begin{array}{l}\text { Goñi Cruz, } \\
\text { Fernando }\end{array}$ & Doctor & 45 & 39 & 84 \\
\hline
\end{tabular}

Fuente: Fichas de validación USIL (2020).

Tabla 17

Escala de valoración

\begin{tabular}{|l|l|l|}
\hline Escala & Rango frecuencia & Rango porcentaje \\
\hline Deficiente & {$[10-17]$} & {$[20 \%-35 \%]$} \\
\hline Bajo & {$[18-25]$} & {$[36 \%-51 \%]$} \\
\hline Regular & {$[26-33]$} & {$[52 \%-67 \%]$} \\
\hline
\end{tabular}




\begin{tabular}{|l|l|l|}
\hline Bien & {$[34-41]$} & {$[68 \%-83 \%]$} \\
\hline Muy bien & {$[42-50]$} & {$[84 \%-100 \%]$} \\
\hline
\end{tabular}

Fuente: Ficha de validación USIL (2020).

Tabla 18

Resultado de valoración interna y externa

\begin{tabular}{|c|c|c|}
\hline $\begin{array}{c}\text { Sumatoria de valoración } \\
\text { total }\end{array}$ & $\begin{array}{c}\text { Promedio de valoración } \\
\text { total }\end{array}$ & $\begin{array}{c}\text { Valoración } \\
\text { final }\end{array}$ \\
\hline 258 & 86 & Muy buena \\
\hline
\end{tabular}

Fuente: Fichas de validación USIL (2020). 


\section{Conclusiones}

Al finalizar la investigación, se realiza se presentan las conclusiones que responden a los objetivos planteados.

\section{Primera.}

Se cumplió con el objetivo general de la investigación que es proponer una estrategia didáctica que contribuya a desarrollar un estilo de aprendizaje en los estudiantes del I ciclo de la carrera de Cosmética Dermatológica de un instituto público de Lima dando respuesta al problema de investigación.

\section{Segunda.}

Se realizó el análisis y el diagnóstico del estado actual del estilo de aprendizaje en estudiantes del I ciclo mediante la aplicación de las técnicas e instrumentos utilizados en el trabajo de campo, en una muestra seleccionada, lo cual permitió reconocer la deficiencia de materiales pedagógicos y didácticos, inadecuado proceso de monitoreo y evaluación, siendo un obstáculo en el desarrollo del proceso de enseñanza- aprendizaje. Por lo cual se cumplió con la primera tarea científica.

\section{Tercera.}

Se alcanzó la segunda tarea científica a través del proceso de codificación y triangulación con las categorías emergentes, sistematizando los fundamentos teóricos y prácticos de la propuesta para proponer una estrategia didáctica, cuyos criterios se basan en el desarrollo de talleres que permita promover recursos para la implementación de material pedagógico, a través de proyectos, enriqueciendo la relación entre el personal directivo, docente y estudiantes.

\section{Cuarta.}

Con la valoración positiva resultado de los fundamentos del criterio de expertos, se pudo determinar las bases científicas y criterios de la propuesta de modelación, donde se desarrollen 
talleres de la estrategia didáctica para mejorar el estilo de aprendizaje en los estudiantes de un instituto superior tecnológico público de Lima. Se cumplió con la tercera tarea científica.

\section{Quinta.}

La estrategia didáctica es muy viable, de acuerdo a los fundamentos curriculares y el juicio de expertos, por ser una propuesta que contribuirá el desenvolvimiento de los maestros y tomando en cuenta el estilo de aprender del estudiante, de esta manera va fortalecer el proceso de enseñanza- aprendizaje, siendo muy enriquecedor y beneficioso para la institución. Se cumplió con la cuarta tarea científica. 


\section{Recomendaciones}

\section{Primera.}

Aplicar la estrategia didáctica, teniendo en cuenta el dominio de ciertas competencias que son características inherentes del perfil del egresado de la especialidad de Cosmética Dermatológica, adaptando acorde a las necesidades del estudiante y al contexto que se desempeñan.

\section{Segunda.}

Es imprescindible que los institutos de educación pública y privada tomen en cuenta diversas estrategias didácticas que permitan a los docentes, reconocer las preferencias y exigencias académicas de los estudiantes sobre su proceso de aprendizaje, la identificación del estilo de aprender permitirá mejorar los procesos didácticos y el empleo pertinente y estratégico de los diferentes recursos pedagógicos.

\section{Tercera.}

Los docentes son un factor fundamental de toda institución educativa, por lo cual los procesos de evaluación, monitoreo y seguimiento deben estar orientados a una mejora constante, a través de una motivación y reconocimiento de la ejecución de sus proceso pedagógicos, donde los principales beneficiados son los estudiantes. 


\section{Referencias}

Acuña, M., Sosa, N. y Valdez, E. (2010). Innovando en los trabajos prácticos de química orgánica. Utilización del aprendizaje basado en problemas como estrategia didáctica. Tesis de Maestría. Universidad Nacional de Misiones. Argentina.

Alfonso, A. (2003). Estrategia instruccionales. Recuperado 15 de febrero 2007, desde www.medusa.unimet.edu.ve/educacion/fbi21/estrategias.pdf.

Alonso, C. (1990). Estilos de aprendizaje, tutorías y enseñanzas a distancia Caracas: Aiesad. Álvarez - Gayou, J. (2009). Cómo hacer investigación cualitativa. México: Paidós.

Aragon, M. (2000). Estilos de aprendizaje. Universidad Rafael Landívar. Guatemala: Profasr. Arias, V. (2009). Fundamentos pedagógicos de la práctica docente desde la academia de Platón hasta la ética en el Modelo por Competencias. M.C.E.

Ausubel, D. (1976). Psicología educativa. México: Trillas.

Ballesteros, O. (2011). La lúdica como estrategia para el desarrollo de competencias científicas. Tesis de Maestría. Universidad Nacional de Colombia. Bogotá.

Bedrenana, B. (2019). Estilos de aprendizaje y estilos de pensamiento en estudiantes de una universidad privada de Lima Sur. Tesis para licenciatura. Universidad Autónoma. Lima.

Castaño, G. (2017). Independencia de los estilos de aprendizaje de las variables cognitivas y afectivo motivacionales. Tesis para Doctorado. Universidad Complutense de Madrid.

Chalvin, M. J., (1995). Los dos cerebros en el aula, Madrid: TEA.

Chapilliquen, M. (2015). Competencias digitales en estudiantes con diferentes estilos de aprendizaje, del séptimo ciclo de educación secundaria. Tesis para Maestría. Pontificia Universidad Católica del Perú.

Cisterna, F (2007). Manual de metodología de la investigación cualitativa para educación y ciencias sociales. Revista Teoría. Universidad del Bío Bío. Concepción. Chile.

Comisión Económica para América Latina y el Caribe (CEPAL). Declaración de Incheón, 2015.

Cooper, D. (1990). Como mejorar la comprensión lectora. Madrid. ISBN

Cotton, J. (1989). Antecedentes históricos de la teoría del aprendizaje. Barcelona. MEC

Cortés, M., y Iglesias, M. (2004). Generalidades sobre Metodología de la Investigación. Campeche, Universidad Autónoma del Carmen. México: ISBN 968-6624-87-2.

De la Parra Paz, E. (2004). Herencia de vida para tus hijos. Crecimiento integral con técnicas PNL, Grijalbo, México, 
Delgado, J. (1997). Métodos y Técnicas cualitativas de investigación Social. Madrid.

Díaz, B. y Martins, A. (1986). Estrategias de Enseñanza-Aprendizaje. San José: IICA.

Díaz, F. y Hernández, G. (2002). Estrategias docentes para un aprendizaje significativo. Una visión constructivista. México: Mc Graw Hill.

Diaz, M. (2017).Estilos de aprendizaje y métodos pedagógicos en educación superior. Tesis Doctoral. Escuela Internacional de Doctorado. Madrid.

Feo, R. (2009). Estrategias Instruccionales para promover el aprendizaje estratégico en estudiantes del Instituto Pedagógico de Miranda José Manuel Siso Martínez. Trabajo de grado de Maestría no publicada, Instituto Pedagógico de Miranda José Manuel Siso Martínez, Miranda.

Fernández, C y Salinero, M. (2006). Las competencias en el marco de la convergencia europea: Un nuevo concepto para el diseño de programas educativos. Encounters on Education.

Feldman, D., Martorelli, G. \& Papalia, D. (2012). Desarrollo humano. México: Mc Graw Hill

Gago, F. (2004). La dirección pedagógica de los institutos de educación secundaria. Un estudio sobre el liderazgo educacional. En Ministerio de Ciencia y Cultura, Premios nacionales de investigación educativa 2004. Madrid: CIDE $\mathrm{N}^{\circ}$ 170, colección Investigación, 395-422.

Gibbs, G. (2012). El análisis de los datos cualitativos en investigación cualitativa. Madrid: Morata.

Gómez, P. (2005). El aprendizaje experiencial, Universidad de Buenos Aires, facultad de Psicología.

Gómez, S. (2012). Metodología de la Investigación. Estado de México: Red Tercer Milenio S.C.

Hernández, R., Fernández., C., Baptista, P. (2014). Metodología de la investigación. (6 ed.). México: McGraw. Hill Interamericana.

Honey, P. (2007). Los estilos de aprendizaje procedimientos de diagnóstico y mejora. Bilbao: Mensajeros.

Hilgard, (1979). Teorías del aprendizaje, México: Trillas.

Krause, M. (1995). La investigación cualitativa: un campo de posibilidades y desafíos. Revista Temas de Educación, (7), 19-36. Disponible en: https://goo.gl/zUifVo

Leliwa, S y Scangarello, I. (2011). Psicología y educación. Córdova: Brujas. 
López, A. (2015). Relación entre estilos de aprendizaje y la comprensión de lectura en estudiantes de Maestría. Tesis de Maestría. Universidad Nacional Enrique Guzmán y Valle. Lima.

Manrique, O. (2013). El material didáctico para la construcción de aprendizajes significativos. Revista Colombiana de Ciencias Sociales, vol. 4, núm. 1, pp. 101-108 Fundación Universitaria, Colombia. Recuperado https://www.redalyc.org/pdf/4978/497856284008.pdf

Marco del Buen Desempeño Docente (MBDD, 2012). Un buen maestro cambia tu vida. Lima, pp. 1-56.

Mayz, C. (2009). Como desarrollar, de una manera comprensiva, el análisis cualitativo de los datos Universidad de Carabobo. Venezuela. Educere, 13(44), 55 - 66.

Mejía N. (2004). Sobre la Investigación Cualitativa. Nuevos Conceptos y Campos de Desarrollo. Investigaciones sociales. 8(13). 277-299. UNMSN.

Ministerio de Educación del Perú (Minedu, 2007). Proyecto educativo nacional al 2021: la educación que queremos para el Perú. Recuperado de http://www.minedu.gob.pe/DeInteres/xtras/PEN-2021.pdf

Ministerio de Educación del Perú (Minedu, 2012). Marco del Buen Desempeño Docente: para mejorar tu práctica como maestro y guiar el aprendizaje de tus estudiantes. Depósito Legal en la Biblioteca Nacional del Perú: № 2014-04604.

Ministerio de Educación del Perú (Minedu, 2016). Currículo Nacional de la Educación Básica. Lima, Perú.

Ministerio de Educación del Perú (Minedu, 2016). Programación Curricular de Educación Secundaria. Recuperado de: www.minedu.gob.pe/curriculo/pdf/programa-curricular-educacion-secundaria.pdf

Ministerio de Educación del Perú (Minedu, 2017). Una mirada a la profesión docente en el Perú: futuros docentes en servicio y formadores de docentes. Depósito Legal en la Biblioteca Nacional del Perú: № 2017-16050.

Miras, M. (1993). Un punto de partida para el aprendizaje de nuevos contenidos los conocimientos previos. El constructivismo en el aula. Barcelona.

Monroy, F. (2018). Revisión de las habilidades y estrategias de enseñanza en función de los estilos de aprendizaje que presentan los alumnos de magisterio de Madrid. Tesis de Maestría. Universidad pública de Badajoz, España.

Moore. (2001). Habilidades de enseñanza en el aula. Boston: Mc Graw- Hill. 
Mora, F., (2013). Neuroeducación solo se puede aprender aquello que se ama. Madrid Alianza Editorial.

O’Cconnor, J., Seymur, J. (1993). Introducción a la PNL, Ed. Urano, México.

Okuda, M. y Gómez, C. (2005). Métodos en investigación cualitativa: triangulación. Revista Colombiana de Psiquiatría, 34(1), 118-124.

Pérez Gómez, A. (1989). Análisis didácticos de las teorías de aprendizaje. Málaga: Spicum

Rettis, H. (2015). Estilos de aprendizaje y rendimiento académico de la asignatura de estadística de los estudiantes del III ciclo de la EAPA, Facultad de Ciencias Administrativas. Tesis de Maestría. Universidad Nacional Mayor de San Marcos. Lima.

Ruiz, J. (2010). Importancia de la investigación Revista Científica. 10(2), 125-126. Universidad del Zulia, Maracaibo, Venezuela.

Sobrino, M. (2017). Relación entre estilos de aprendizaje y hábitos de estudios en los estudiantes de la asignatura Metodología de Trabajo Universitario. Tesis de Maestría. Universidad Privada Telesup. Lima.

Taylor, M. (1998). Educación y capacitación basada en competencias un panorama de la experiencia del Reino Unido. México. Montevideo: Cinterfor. 262 p. i.

Tobón, S. (2001). Aprender a emprender un enfoque curricular. La ceja: Funorie.

Tobón, S. (2010). Formación integral y competencias. Pensamiento complejo, currículo, didáctica y evaluación. Madrid. Morata.

Tobón, S., y Fernández, J. (2003). La cartografía conceptual. Islas baleares. España memorias del IV congreso internacional virtual de educación.

Ullari, M. (2016). Influencia de los estilos de aprendizaje en el rendimiento académico del idioma inglés de los estudiantes del Centro de Idiomas de la Facultad de Ciencias de la Educación. Tesis de Maestría. Universidad Nacional de Chimborazo. Rio Bamba.

Verlee, L. (1995). Aprender con todo el cerebro, Madrid: Martínez Roca.

Vinagre, A. (2017).La influencia de los estilos de aprendizaje en la asignatura de Dibujo Técnico. Tesis de Maestría. Instituto de ciencias de la Educación Universidad Politécnica de Madrid.

Woolfolk, A. (1996). Psicología educativa. México: Prentice hall 
ANEXOS 
ANEXO $\mathbf{N}^{\circ} 1$

MATRIZ DE CATEGORIZACION

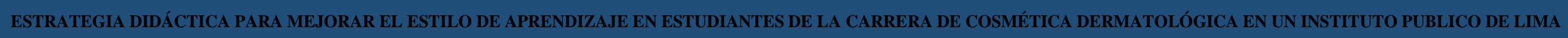
AUTOR: LLACTAHUAMAN CHAVELON Nalda






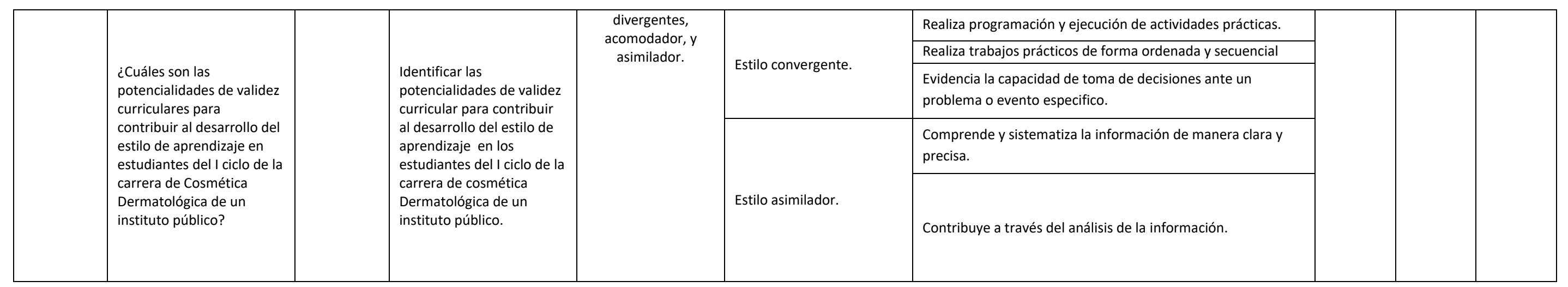


Datos informativos:

Entrevistador:

Lugar y Fecha:

Duración:

OBJETIVO: Proponer una estrategia didáctica que contribuya a desarrollar mejor un estilo de aprendizaje en los estudiantes del I Ciclo de la Carrera de Cosmética Dermatológica de un instituto privado de Lima.

Preguntas:

1. ¿Emplea usted técnicas pedagógicas para mantener la atención durante el desarrollo de la sesión de clases mejorando el proceso de enseñanza aprendizaje?

2. ¿Usted diseña materiales pedagógicos para cada sesión de clases para mantener el interés del estudiante?

3. ¿Pone usted en práctica la sistematización del procedimiento de un trabajo o permite el libre desenvolvimiento del estudiante?

4. ¿Realiza actividades en donde se recoja los aprendizajes previos antes de iniciar el desarrollo de la sesión de clases que corresponde?

5. ¿Usted tiene en consideración estrategias para la comprensión lectura y recojo de información, indicaría algunas de ellas?

6. ¿Usted toma en cuenta siempre la importancia de los conocimientos previos para el análisis de la nueva información?

7. ¿Usted hace uso de técnicas pedagógicas que cuenten con ayudas visuales y esquemas para facilitar el análisis de la información durante el proceso de enseñanza aprendizaje?

8. ¿La institución cuenta con un laboratorio e infraestructura, equipamiento y materiales para el desarrollo de las actividades prácticas?

9. ¿Incentiva usted el desarrollo de trabajos grupales en todas las sesiones de clases teniendo en cuenta las capacidades de cada alumno?

10. ¿Toma en cuenta lo que saben los estudiantes a través de los aprendizajes previos sobre el tema, antes de ejecutar la práctica que corresponde a la sesión de clase?

11. ¿De qué manera usted promueve el aprendizaje basado en problemas, explique brevemente y cuál es el objetivo de dicha estrategia didáctica?

12. ¿Considera usted diversos escenarios como espacios naturales u otros, para mejorar el proceso de enseñanza aprendizaje en el análisis de la información, en la sesión de clases? 


\title{
ANEXO No 3: CUESTIONARIO A LOS ESTUDIANTES
}

\section{Autora: Nalda Llactahuaman Chavelon}

\author{
Datos Informativos \\ Nombre y Apellido \\ Institución Educativa \\ Grado / Sección
}

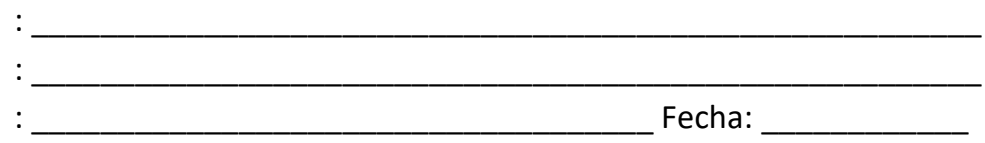

\section{Objetivo:}

Determinar las estrategias que utiliza el docente de dermatología en el desarrollo de sus sesiones de enseñanzaaprendizaje.

\begin{abstract}
Estimado estudiante, la información que nos proveas en el siguiente cuestionario nos ayudará a mejorar el proceso de enseñanza aprendizaje, por lo que te pedimos que tus respuestas sean lo más sinceras posibles.
\end{abstract} Marca solo una de las alternativas de acuerdo a la tabla adjunta. Tienes 30 minutos.

\begin{tabular}{|c|c|c|c|c|}
\hline NUNCA & CASI NUNCA & A VECES & CASI SIEMPRE & SIEMPRE \\
\hline 1 & 2 & 3 & 4 & 5 \\
\hline
\end{tabular}

\begin{tabular}{|l|l|l|l|l|l|l|}
\hline \multirow{2}{*}{ INDICADORES } & \multicolumn{4}{|c|}{ PUNTAJE } \\
\cline { 2 - 6 } & & 1 & 2 & 3 & 4 & 5 \\
\hline
\end{tabular}

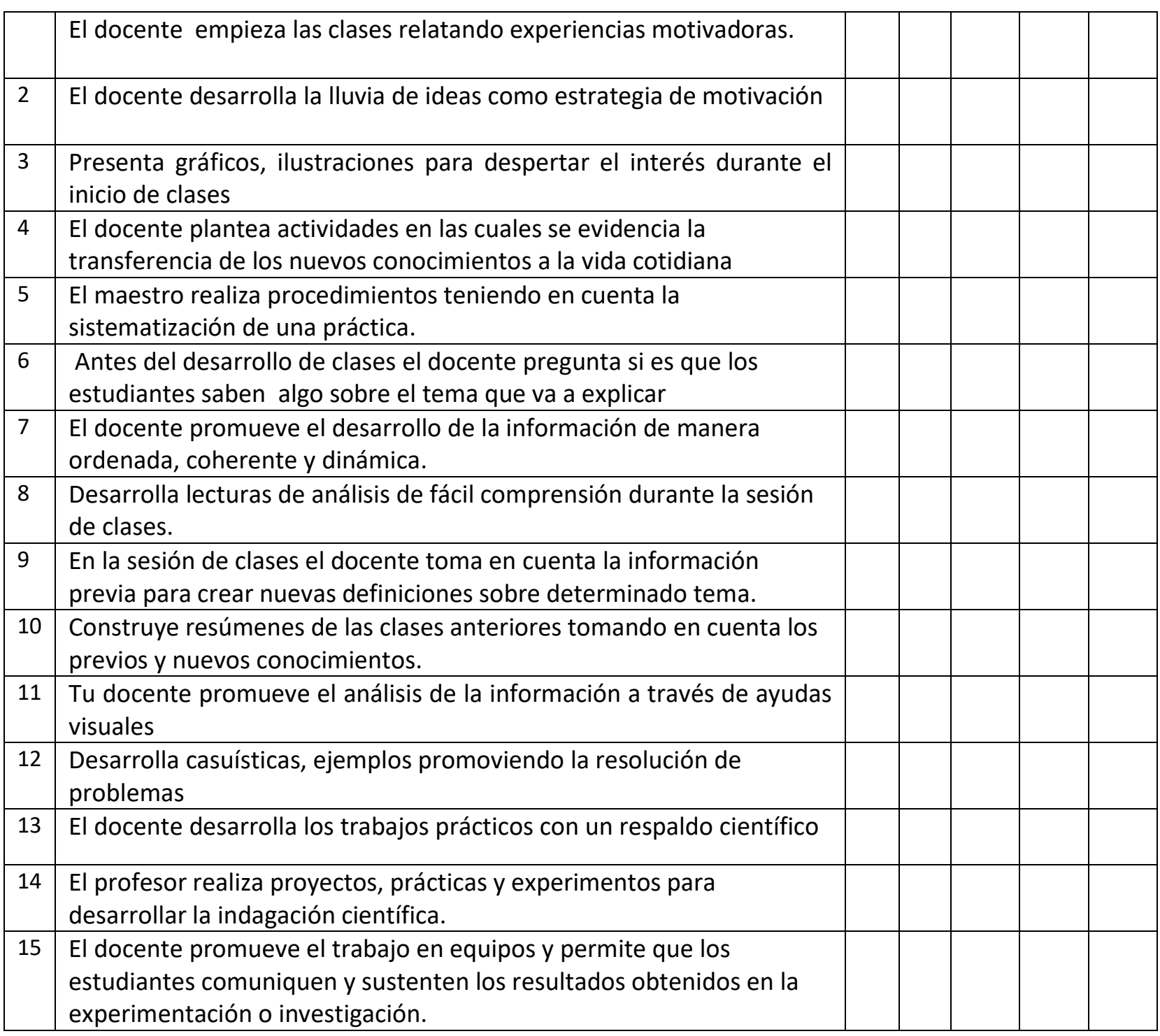




\begin{tabular}{|c|l|l|l|l|l|}
\hline 16 & $\begin{array}{l}\text { Tu docente promueve la ejecución de prácticas en equipo durante la } \\
\text { sesión de clases. }\end{array}$ & & & \\
\hline 17 & $\begin{array}{l}\text { En la sesión de clase el docente ordena el desarrollo de los trabajos } \\
\text { prácticos }\end{array}$ & & & & \\
\hline 18 & $\begin{array}{l}\text { El docente desarrolla problemas para promover tu toma de } \\
\text { decisiones en la sesión de clases. }\end{array}$ & & & \\
\hline 19 & $\begin{array}{l}\text { El profesor realiza análisis de la información en párrafos de lecturas } \\
\text { seleccionadas en la sesión de clases. }\end{array}$ & & & \\
\hline 20 & $\begin{array}{l}\text { El docente es claro y ordenado en el desarrollo de la información en } \\
\text { las sesiones de clase, durante el proceso de enseñanza aprendizaje. }\end{array}$ & & & & \\
\hline
\end{tabular}

MUCHAS GRACIAS POR TU COLABORACION 
ANEXO No 4: GUIA DE OBSERVACION DE CLASE

Autora: Nalda Llactahuaman Chavelon

\section{DATOS GENERALES}

\begin{tabular}{|l|l|l|l|}
\hline Docente: & Curso : & \\
\hline Fecha: & Hora de Inicio : & \\
\hline $\begin{array}{l}\text { Nombre del investigador } \\
\text { (observador): }\end{array}$ & Hora de Cierre: & \\
\hline Tema de la sesión de clase: & & \\
\hline
\end{tabular}

El documento que se presenta a continuación, tiene por finalidad servir de instrumento de observación durante la sesión de clase sobre aspectos relacionados con el estilo de aprendizaje de cada uno de los estudiantes de la asignatura. La observación se llevará a cabo en un periodo de 02 horas pedagógicas de 45 minutos cada una. Este documento permitirá obtener valoraciones y descripciones cualitativas de las situaciones que se presenten durante la clase y que están relacionadas con el estilo de aprendizaje de cada uno de los estudiantes.

\begin{tabular}{|c|c|c|c|c|c|}
\hline Categorías & $\begin{array}{l}\text { Sub categoría } \\
\text { (SC) }\end{array}$ & INDICADORES & SI & $\begin{array}{l}\text { A } \\
\text { VECE } \\
S\end{array}$ & NO \\
\hline \multirow{10}{*}{$\begin{array}{l}\text { Estrategia } \\
\text { didáctica }\end{array}$} & \multirow{3}{*}{$\begin{array}{l}\text { Creación de } \\
\text { espacio para } \\
\text { favorecer la } \\
\text { atención de los } \\
\text { estudiantes }\end{array}$} & $\begin{array}{l}\text { 1.1 Los estudiantes mantienen la atención y motivación en } \\
\text { todo momento durante la sesión de aprendizaje. }\end{array}$ & & & \\
\hline & & $\begin{array}{l}\text { 1.2 Los estudiantes intervienen con preguntas e ideas de } \\
\text { interés relacionadas con el tema durante el desarrollo de la } \\
\text { sesión de clases. }\end{array}$ & & & \\
\hline & & $\begin{array}{l}\text { 1.3 Los estudiantes realizan esquemas, ilustraciones que les } \\
\text { permite mantener la atención durante el proceso de } \\
\text { enseñanza aprendizaje. }\end{array}$ & & & \\
\hline & \multirow{2}{*}{$\begin{array}{l}\text { Espacios } \\
\text { académicos } \\
\text { para motivar la } \\
\text { personalización } \\
\text { de la } \\
\text { información }\end{array}$} & $\begin{array}{l}\text { 1.4. El material de apoyo para el estudiante es adecuado } \\
\text { porque permite abordar información que tiene relación con } \\
\text { las experiencias cotidianas del estudiante. }\end{array}$ & & & \\
\hline & & $\begin{array}{l}\text { 1.5. Al responder las preguntas del docente, los estudiantes } \\
\text { demuestran su comprensión de la secuencia de los pasos } \\
\text { desarrollados del trabajo práctico durante la sesión de } \\
\text { enseñanza aprendizaje. }\end{array}$ & & & \\
\hline & \multirow{3}{*}{$\begin{array}{l}\text { Espacio } \\
\text { pedagógico en } \\
\text { la sesión de } \\
\text { clases para } \\
\text { alcanzar la } \\
\text { adquisición de la } \\
\text { información }\end{array}$} & $\begin{array}{l}\text { 1.6. Los estudiantes desarrollan una comunicación activa y } \\
\text { dinámica donde el docente recoge los aprendizajes previos } \\
\text { durante toda la sesión de enseñanza aprendizaje. }\end{array}$ & & & \\
\hline & & $\begin{array}{l}\text { 1.7. Los estudiantes muestran su capacidad de obtener } \\
\text { conclusiones de la información referente al tema estudiado } \\
\text { en la sesión de clases. }\end{array}$ & & & \\
\hline & & $\begin{array}{l}\text { 1.8. A partir de los materiales y espacios utilizados en el } \\
\text { análisis de la información, los estudiantes muestran } \\
\text { capacidad de comprensión y análisis durante el proceso de } \\
\text { enseñanza. }\end{array}$ & & & \\
\hline & \multirow[t]{2}{*}{$\begin{array}{l}\text { Construcción } \\
\text { lógica del } \\
\text { conocimiento. }\end{array}$} & $\begin{array}{l}\text { 1.9. Los estudiantes muestran su capacidad de construir } \\
\text { nuevas definiciones a partir de lluvias de ideas y de } \\
\text { información obtenida anteriormente en las sesiones de clase }\end{array}$ & & & \\
\hline & & $\begin{array}{l}\text { 1.10. El material de lectura entregado ayuda a que el } \\
\text { estudiante muestre su capacidad de construcción y análisis } \\
\text { de información en la sesión de aprendizaje. }\end{array}$ & & & \\
\hline
\end{tabular}




\begin{tabular}{|c|c|c|c|c|c|}
\hline & $\begin{array}{l}\text { Sub categoría } \\
\text { (SC) }\end{array}$ & INDICADORES & $\mathrm{SI}$ & NO & $\begin{array}{c}\text { A } \\
\text { VECES }\end{array}$ \\
\hline \multirow{10}{*}{$\begin{array}{l}\text { Estilos de } \\
\text { aprendiz } \\
\text { aje }\end{array}$} & \multirow[b]{2}{*}{$\begin{array}{l}\text { Estilo teórico- } \\
\text { divergente. }\end{array}$} & $\begin{array}{l}\text { 2.1. El docente brinda la información necesaria para su análisis } \\
\text { y comprensión a través de ayudas visuales para la mejora del } \\
\text { aprendizaje. }\end{array}$ & & & \\
\hline & & $\begin{array}{l}\text { 2.2. Durante la sesión de aprendizaje, se evidencia la } \\
\text { capacidad de resolución de problemas ante la presentación de } \\
\text { casuísticas con problemáticas del contexto que ayudan al } \\
\text { aprendizaje. }\end{array}$ & & & \\
\hline & \multirow{3}{*}{$\begin{array}{l}\text { Estilo } \\
\text { pragmático- } \\
\text { acomodador. }\end{array}$} & $\begin{array}{l}\text { 2.3. La sesión de clase evidencia una sistematización del } \\
\text { proceso de aprendizaje, fundamentado en su teoría así como } \\
\text { en el desarrollo de la práctica. }\end{array}$ & & & \\
\hline & & $\begin{array}{l}\text { 2.4. El docente detecta las capacidades, ritmos y estilos de los } \\
\text { estudiantes para tomarlos en cuenta al realizar un proyecto o } \\
\text { practica en el proceso de enseñanza aprendizaje. }\end{array}$ & & & \\
\hline & & $\begin{array}{l}\text { 2.5 Durante la sesión de aprendizaje, se evidencia una } \\
\text { estructura ordenada en los trabajos en equipo donde se } \\
\text { evidencia la capacidad del estudiante para liderar. }\end{array}$ & & & \\
\hline & \multirow{3}{*}{$\begin{array}{l}\text { Estilo } \\
\text { convergente- } \\
\text { activo }\end{array}$} & $\begin{array}{l}\text { 2.6. En la sesión de aprendizaje se observa la aplicación } \\
\text { ordenada de acciones del proceso del procedimiento práctico } \\
\text { durante la sesión de clases. }\end{array}$ & & & \\
\hline & & $\begin{array}{l}\text { 2.7. Durante la sesión de aprendizaje se indican los resultados } \\
\text { esperados del proceso práctico, así como del resultado final. }\end{array}$ & & & \\
\hline & & $\begin{array}{l}\text { 2.8. El docente brinda la información necesaria para contribuir } \\
\text { a la capacidad de toma de decisiones durante el proceso de } \\
\text { aprendizaje. }\end{array}$ & & & \\
\hline & \multirow{2}{*}{$\begin{array}{l}\text { Estilo } \\
\text { asimilador- } \\
\text { reflexivo. }\end{array}$} & $\begin{array}{l}\text { 2.9. Los estudiantes muestran su capacidad de analizar y } \\
\text { obtener conclusiones referentes a la información estudiada } \\
\text { en la sesión de enseñanza aprendizaje. }\end{array}$ & & & \\
\hline & & $\begin{array}{l}\text { 2.10. Durante la sesión de aprendizaje el docente emplea el } \\
\text { uso sistematizado de técnicas de aprendizaje del marco } \\
\text { conceptual específico a las actividades de aprendizaje. }\end{array}$ & & & \\
\hline
\end{tabular}


ANEXO N5: VALIDACIÓN POR JUICIO DE EXPERTOS DE INSTRUMENTOS DE RECOGIDA DE INFORMACIÓN

\section{Autora: Nalda Llactahuaman Chavelon}

OPNOON DE APUCABUDAD DE LA ENTREVSTA.

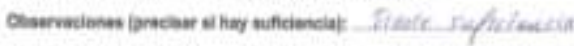

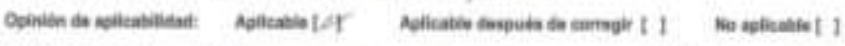

\begin{tabular}{|c|c|c|c|}
\hline 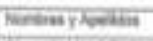 & 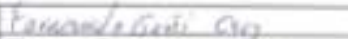 & कWN & 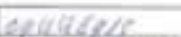 \\
\hline Deveminimitas & 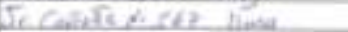 & 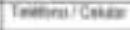 & $9 x+y<0100$ \\
\hline 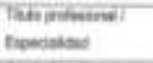 & 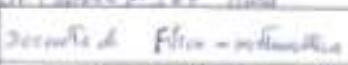 & \multirow[t]{2}{*}{ Pan } & \\
\hline Gabo Readins & 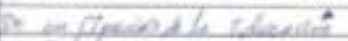 & & \\
\hline Hendosorianias & Arcivilan & Wueytas & 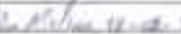 \\
\hline
\end{tabular}

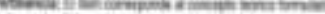

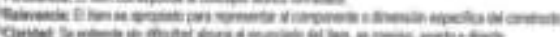

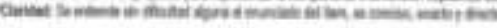

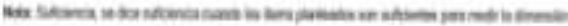

OPINDON DE APUACABILIDAD DE LA OBSERVACION:

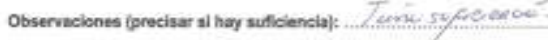

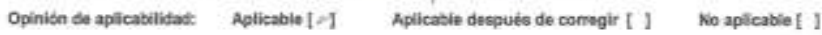

\begin{tabular}{|c|c|c|c|}
\hline Norities y Apebsos & hernondo town ling & CWIK & 094 \\
\hline 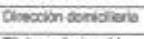 & II Canute $N^{2}$ SD2 hima & Tothon/ Center & 710 \\
\hline 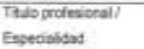 & Doont de Fisuz-14atustice & Fime & \\
\hline Gosep Acasentico & 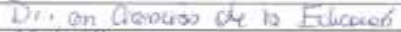 & & \\
\hline Netodskper iariation & Ménctilogo- & Luever yectie & 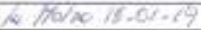 \\
\hline
\end{tabular}

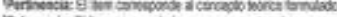

(a)

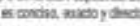

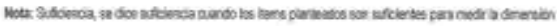

nombre del especialista: Jeswés Herge Mrantus de Oca $S$ GRADO CIENTIFICO OACADÉMICO: DOCTOY FIRMA:

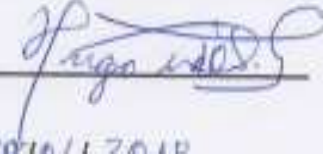

rerua. $001 \mathrm{~L} / \mathrm{in} / \mathrm{L}$ 


\section{ANEXO N 5: VALIDACIÓN DE LA PROPUESTA.}

Evaluación y aprobación de la modelación de la propuesta por especialistas

Estimado profesor:

Dra. Miriam Velásquez

Le solicitamos su amable disposición para colaborar en el proceso de validación metodológica de modelación de la propuesta en la investigación aplicada educacional cuyo título es Estrategia didáctica para mejorar el estilo de aprendizaje en los estudiantes de la carrera de Cosmética Dermatológica de un instituto superior tecnológico público de Lima presentada en la Maestría en Educación con Mención en gestión en la educación de la Universidad San Ignacio de Loyola. El docente asesor de la tesis es el magíster Hernán Gerardo Flores Valdiviezo.

Por esta razón, se adjuntan las fichas de valoración interna y externa con los ítems para que usted nos pueda manifestar sus apreciaciones en cada una de ellas. Ajuntamos los siguientes documentos:

Introducción

Marco metodológico

Propuesta

Matriz de categorización

Agradecemos sus importantes aportes para este proceso de culminación de investigación científica.

Saludos cordiales,

Nalda Llactahuaman Chavelon, autor de la investigación.

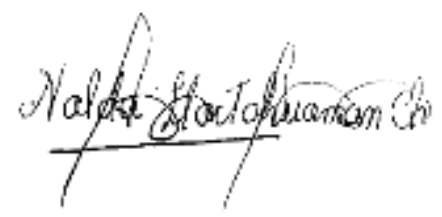

Fecha: 27/ 06/ 2020 
Ficha de validación de la propuesta metodológica

Datos generales.

Apellidos y nombres de especialista:

Grado de estudios alcanzado:

Resultado científico en valoración: Estrategia didáctica para mejorar el estilo de aprendizaje en los estudiantes de la carrera de Cosmética Dermatológica de instituto superior tecnológico público de Lima.

Autor del resultado científico: Nalda Llactahuaman Chavelon

Aspectos a observar

\section{Validación interna}

\begin{tabular}{|c|c|c|c|c|c|c|c|c|}
\hline \multirow{3}{*}{ indicadores } & \multirow{2}{*}{\multicolumn{5}{|c|}{$\begin{array}{l}\text { Escala de } \\
\text { valoración }\end{array}$}} & \multicolumn{3}{|l|}{ Aspectos } \\
\hline & & & & & & \multirow{2}{*}{ Positivos } & \multirow{2}{*}{ Negativos } & \multirow{2}{*}{ Sugerencias } \\
\hline & 1 & 2 & 3 & 4 & 5 & & & \\
\hline $\begin{array}{l}\text { Factibilidad de aplicación del resultado que se } \\
\text { presenta. }\end{array}$ & & & & & $\underline{x}$ & & & \\
\hline $\begin{array}{l}\text { Claridad de la propuesta para ser aplicado por } \\
\text { otros }\end{array}$ & & & & $\underline{x}$ & & & & \\
\hline $\begin{array}{l}\text { Posibilidad de la propuesta de extensión a } \\
\text { otros contextos semejantes }\end{array}$ & & & & & $\underline{x}$ & & & \\
\hline $\begin{array}{l}\text { Correspondencia con las necesidades sociales e } \\
\text { individuales actuales }\end{array}$ & & & & $\underline{x}$ & & & & \\
\hline $\begin{array}{l}\text { Congruencia entre el resultado propuesto y el } \\
\text { objetivo fijado. }\end{array}$ & & & & $\underline{x}$ & & & & \\
\hline $\begin{array}{l}\text { Novedad en el uso de conceptos y } \\
\text { procedimientos de la propuesta. }\end{array}$ & & & $\underline{X}$ & & & & & \\
\hline $\begin{array}{l}\text { La modelación contiene propósitos basados en } \\
\text { los fundamentos educativos, curriculares y } \\
\text { pedagógicos, detallado, preciso y efectivo }\end{array}$ & & & & $x$ & & & & \\
\hline $\begin{array}{l}\text { La propuesta está contextualizada a la realidad } \\
\text { en estudio. }\end{array}$ & & & & & $\underline{x}$ & & & \\
\hline $\begin{array}{l}\text { Presenta objetivos claros, coherentes y posibles } \\
\text { de alcanzar. }\end{array}$ & & & & $\underline{x}$ & & & & \\
\hline $\begin{array}{l}\text { Contiene un plan de acción de lo general a lo } \\
\text { particular. }\end{array}$ & & & & $\underline{x}$ & & & & \\
\hline
\end{tabular}


Ficha de validación externa (forma)

\begin{tabular}{|c|c|c|c|c|c|c|c|c|}
\hline \multicolumn{2}{|l|}{ Indicadores } & \multicolumn{3}{|c|}{$\begin{array}{l}\text { Escala de } \\
\text { valoración }\end{array}$} & & \multicolumn{3}{|l|}{ Aspectos } \\
\hline & & \begin{tabular}{l|l}
1 \\
\end{tabular} & \begin{tabular}{l|l}
2 & 3
\end{tabular} & 4 & 5 & \multirow{2}{*}{ Positivos } & \multirow{2}{*}{$\underset{\mathrm{s}}{\text { Negativo }}$} & \\
\hline Claridad & $\begin{array}{l}\text { Es formulado con lenguaje } \\
\text { apropiado }\end{array}$ & & & & $\underline{x}$ & & & \\
\hline Objetividad & $\begin{array}{l}\text { Está expresado en } \\
\text { conductas observables }\end{array}$ & & & & $\underline{X}$ & & & \\
\hline Actualidad & $\begin{array}{l}\text { Adecuado al avance de la } \\
\text { ciencia pedagógica }\end{array}$ & & & $\underline{x}$ & & & & \\
\hline Organización & $\begin{array}{l}\text { Existe una organización } \\
\text { lógica }\end{array}$ & & & & $\underline{x}$ & & & \\
\hline Suficiencia & $\begin{array}{l}\text { Comprende los aspectos de } \\
\text { cantidad y calidad }\end{array}$ & & & $\underline{x}$ & & & & \\
\hline $\begin{array}{l}\text { Intencionalida } \\
\text { d }\end{array}$ & $\begin{array}{l}\text { Adecuado para valorar los } \\
\text { aspectos de las categorías }\end{array}$ & & & $\underline{X}$ & & & & \\
\hline Consistencia & $\begin{array}{l}\text { Basado en aspectos teóricos } \\
\text { científicos de la educación }\end{array}$ & & & $\underline{\underline{X}}$ & & & & \\
\hline Coherencia & $\begin{array}{l}\text { Entre el propósito, diseño y } \\
\text { la implementación de la } \\
\text { propuesta }\end{array}$ & & & & $\underline{x}$ & & & \\
\hline Metodología & $\begin{array}{l}\text { La estrategia responde al } \\
\text { propósito de la } \\
\text { investigación }\end{array}$ & & & $\underline{\underline{X}}$ & & & & \\
\hline Pertinencia & $\begin{array}{l}\text { Es útil y adecuado para la } \\
\text { investigación }\end{array}$ & & & $\underline{x}$ & & & & \\
\hline
\end{tabular}

Aportes o sugerencias para el perfeccionamiento del resultado científico:

Opinión de aplicabilidad:

\section{Resultados}

Promedio de valoración $=\frac{\text { Valoración interna }+ \text { valoración externa }}{2}$

Resultado de valoración: 
Escala de valoración

\begin{tabular}{lrl}
\hline Escala & \multicolumn{1}{l}{$\begin{array}{l}\text { Rango } \\
\text { frecuencia }\end{array}$} & \multicolumn{1}{l}{$\begin{array}{l}\text { Rango } \\
\text { porcentaje }\end{array}$} \\
\hline Deficiente & {$[10-17]$} & {$[20 \%-35 \%]$} \\
Bajo & {$[18-25]$} & {$[36 \%-51 \%]$} \\
Regular & {$[26-33]$} & {$[52 \%-67 \%]$} \\
Bien & {$[34-41]$} & {$[68 \%-83 \%]$} \\
Muy bien & {$[42-50]$} & {$[84 \%-100 \%]$} \\
\hline
\end{tabular}

\section{Opinión de aplicabilidad:}
a) Deficiente ( )
b) Bajo ( )
c) Regular ( )
d) Bien (X )
e) Muy Bien ( )

\begin{tabular}{|l|l|l|l|}
\hline Nombres y Apellidos & \multicolumn{4}{|l|}{ MIRIRIAM E. VELÁZQUEZ TEJEDA } \\
\hline DNI N & 00858024 & Teléfono / Celular & 7465044 \\
\hline Dirección domiciliaria & LOS GIRASOLES 140 & LICENCIADA EN EDUCACIÓN & \\
\hline $\begin{array}{l}\text { Título profesional / } \\
\text { Especialidad }\end{array}$ & MAG. EN PSICOLOGÍA EDUCATIVA Y DRA. EN EDUCACION \\
\hline Grado Académico & DOCENTE INVESTIGADORA EN LA USIL & & Temático \\
\hline $\begin{array}{l}\text { Ocupación y año de } \\
\text { experiencia }\end{array}$ & Metodólogo & & Experiencia: 30 .años \\
\hline \begin{tabular}{l} 
Metodólogo/temático \\
\hline
\end{tabular}
\end{tabular}

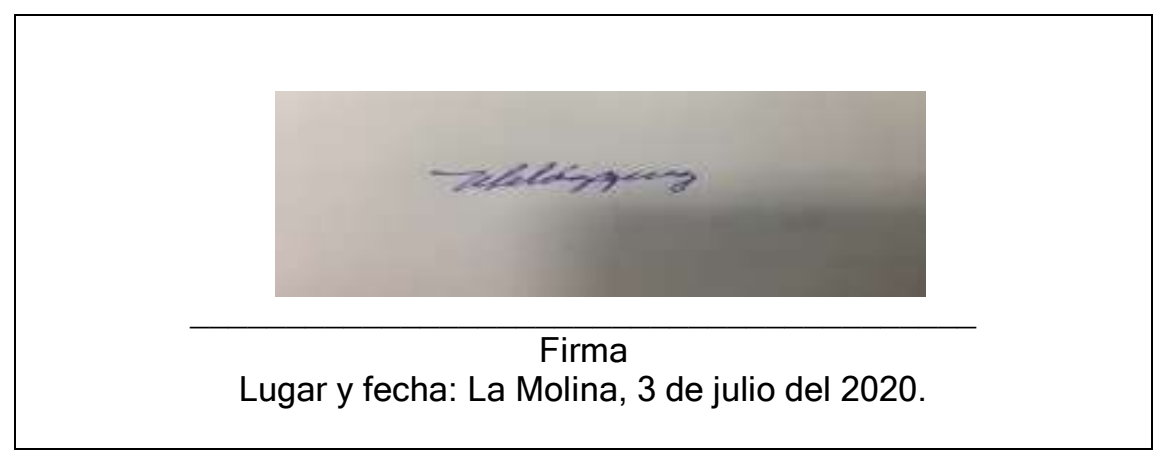




\section{Evaluación y aprobación de la modelación de la propuesta por especialistas}

\section{Estimado profesor:}

Dr. Félix Goñi Cruz

Le solicitamos su amable disposición para colaborar en el proceso de validación metodológica de modelación de la propuesta en la investigación aplicada educacional cuyo título es Estrategia didáctica para mejorar el estilo de aprendizaje en los estudiantes de la carrera de Cosmética Dermatológica de un instituto superior tecnológico público de Lima presentada en la Maestría en Educación con Mención en gestión en la educación de la Universidad San Ignacio de Loyola. El docente asesor de la tesis es el magíster Hernán Gerardo Flores Valdiviezo.

Por esta razón, se adjuntan las fichas de valoración interna y externa con los ítems para que usted nos pueda manifestar sus apreciaciones en cada una de ellas. Ajuntamos los siguientes documentos:

Introducción

Marco metodológico

Propuesta

Matriz de categorización

Agradecemos sus importantes aportes para este proceso de culminación de investigación científica.

Saludos cordiales,

Nalda Llactahuaman Chavelon, autor de la investigación.

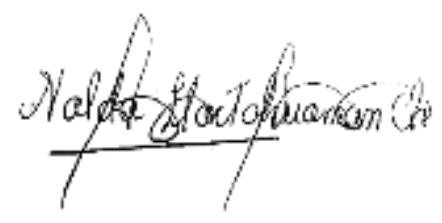

Fecha: $27 / 06 / 2020$ 


\section{Datos generales.}

Apellidos y nombres de especialista:

Grado de estudios alcanzado:

Resultado científico en valoración: Estrategia didáctica para mejorar el estilo de aprendizaje en los estudiantes de la carrera de Cosmética Dermatológica de instituto superior tecnológico público de Lima.

Autor del resultado científico: Nalda Llactahuaman Chavelon Aspectos a observar

\section{Validación interna}

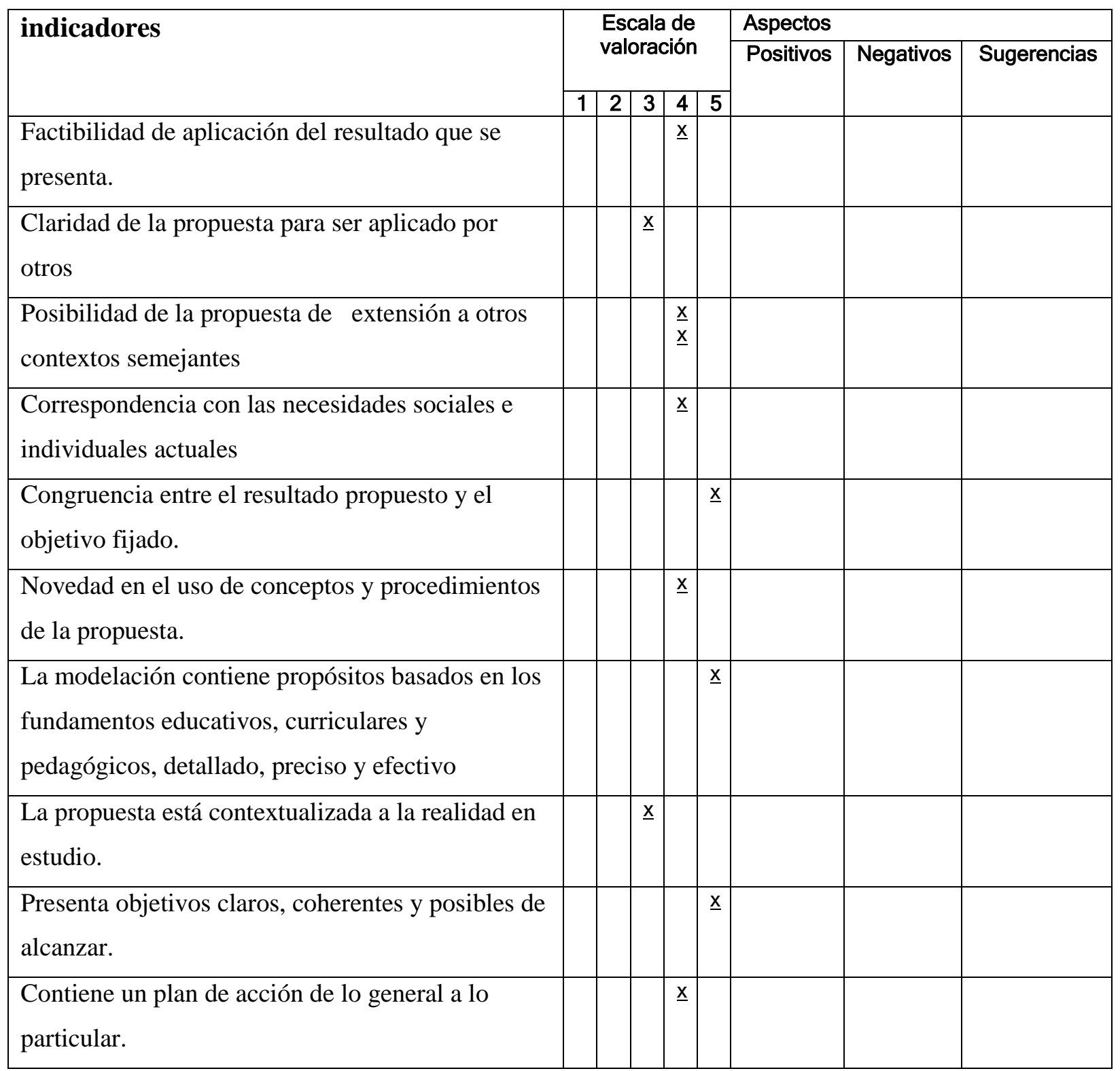


Ficha de validación externa (forma)

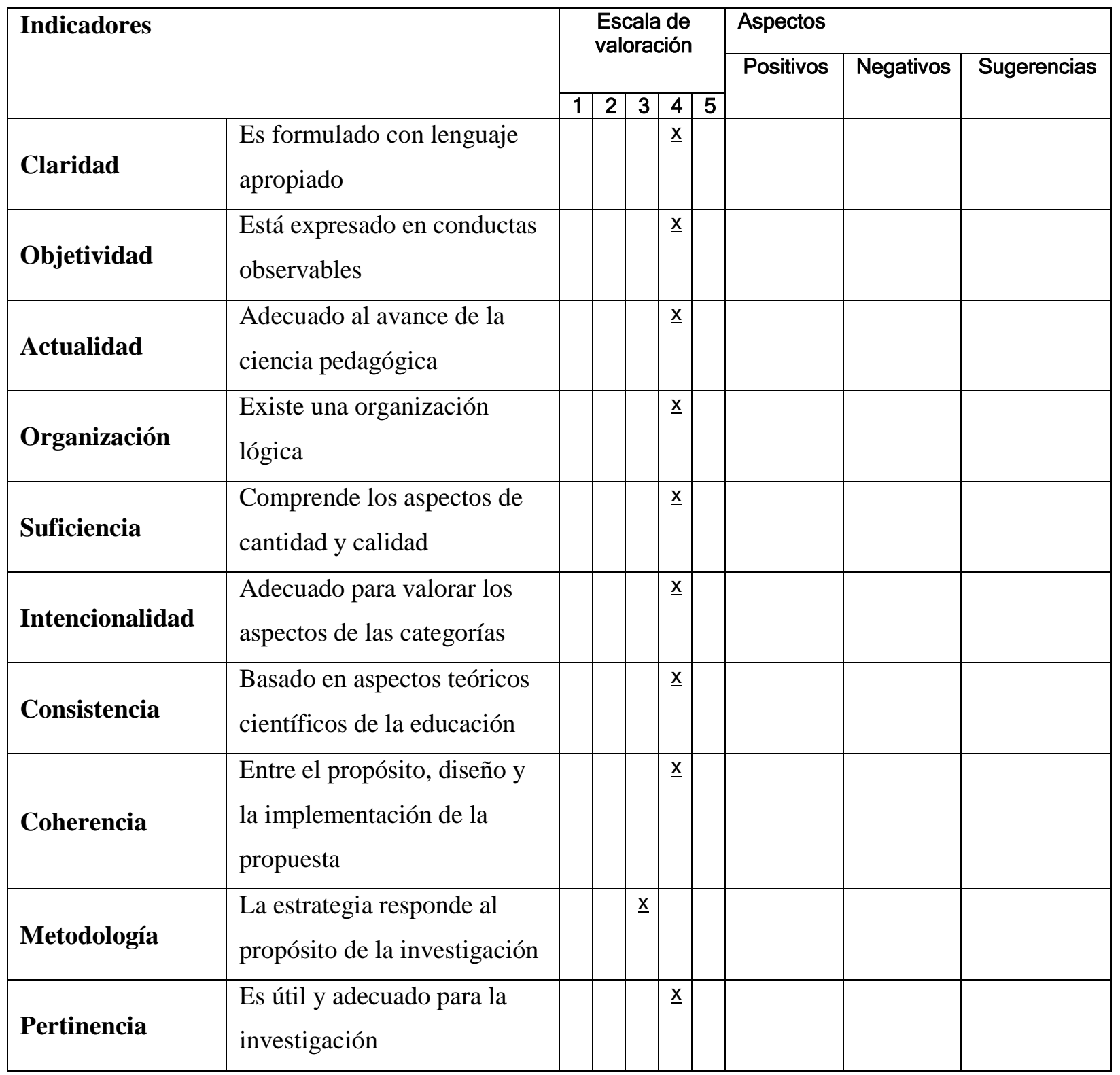

Aportes o sugerencias para el perfeccionamiento del resultado científico:

Opinión de aplicabilidad:

\section{Resultados}

Promedio de valoración $=\frac{\text { Valoración interna+valoración externa }}{2}$

Resultado de valoración: 
Escala de valoración

\begin{tabular}{lcc}
\hline Escala & Rango frecuencia & Rango porcentaje \\
\hline Deficiente & {$[10-17]$} & {$[20 \%-35 \%]$} \\
Bajo & {$[18-25]$} & {$[36 \%-51 \%]$} \\
Regular & {$[26-33]$} & {$[52 \%-67 \%]$} \\
Bien & {$[34-41]$} & {$[68 \%-83 \%]$} \\
Muy bien & {$[42-50]$} & {$[84 \%-100 \%]$} \\
\hline
\end{tabular}

\section{Opinión de aplicabilidad:}
a) Deficiente ( )
b) Baja ( )
c) Regular ( )
d) Buena ( )
e) Muy Buena ( )

\begin{tabular}{|l|l|l|l|}
\hline Nombres y Apellidos & GOÑI CRUZ FERNANDO & DNI N & 09446915 \\
\hline $\begin{array}{l}\text { Dirección } \\
\text { domiciliaria }\end{array}$ & JR. CAÑETE 567 LIMA & Teléfono / Celular & 985412510 \\
\hline $\begin{array}{l}\text { Título profesional / } \\
\text { Especialidad }\end{array}$ & BACHILLER EN FISICA-MATEMÁTICA & \\
\hline Grado Académico & DR. EN CIENCIAS DE LA EDUCACIÓN \\
\hline $\begin{array}{l}\text { Ocupación y año de } \\
\text { experiencia }\end{array}$ & DOCENTE / 20 AÑOS DE EXPERIENCIA \\
\hline Metodólogo/temático & METODÓLOGO \\
\hline
\end{tabular}

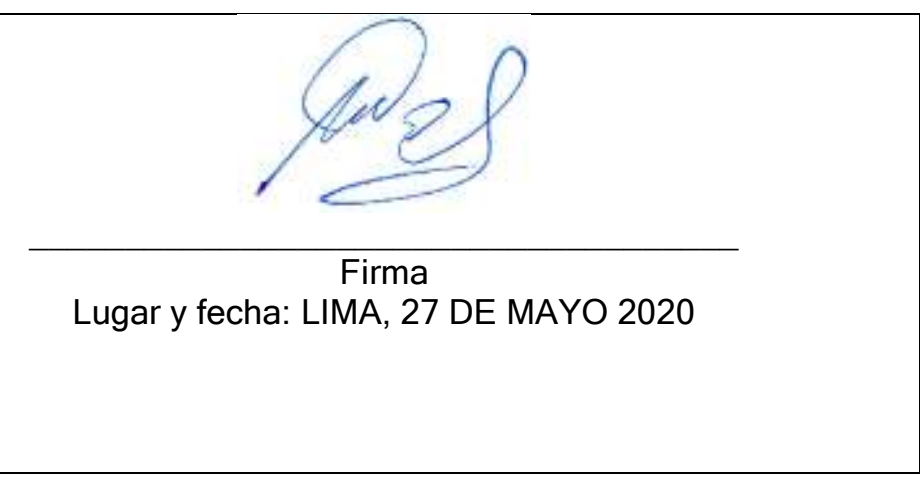




\section{Ficha de validación de la propuesta metodológica}

\section{Datos generales.}

Apellidos y nombres de especialista: Muñoz Salazar José Manuel

Grado de estudios alcanzado: Doctor en Ciencias de la Educación

Resultado científico en valoración: Estrategia didáctica para mejorar el estilo de aprendizaje en los estudiantes de la carrera de Cosmética Dermatológica de un Instituto Superior Tecnológico Público de Lima

Autor del resultado científico: Bachiller Nalda Llactahuaman Chavelon

Aspectos a observar

Validacion interna

\begin{tabular}{|c|c|c|c|c|c|c|}
\hline \multirow[t]{2}{*}{ indicadores } & \multicolumn{3}{|c|}{$\begin{array}{l}\text { Escala de } \\
\text { valoración }\end{array}$} & \multicolumn{3}{|l|}{ Aspectos } \\
\hline & \begin{tabular}{l|l}
1 & 2 \\
\end{tabular} & \begin{tabular}{|l|l|}
3 & 4
\end{tabular} & 5 & Positivos & Negativos & Sugerencias \\
\hline $\begin{array}{l}\text { Factibilidad de aplicación del resultado } \\
\text { que se presenta. }\end{array}$ & & $\mathrm{X}$ & & & & \\
\hline $\begin{array}{l}\text { Claridad de la propuesta para ser } \\
\text { aplicado por otros }\end{array}$ & & $X$ & & & & \\
\hline $\begin{array}{l}\text { Posibilidad de la propuesta de extensión a } \\
\text { otros contextos semejantes }\end{array}$ & & $X$ & & & & \\
\hline $\begin{array}{l}\text { Correspondencia con las necesidades } \\
\text { sociales e individuales actuales }\end{array}$ & & & $X$ & & & \\
\hline $\begin{array}{l}\text { Congruencia entre el resultado propuesto } \\
\text { y el objetivo fijado. }\end{array}$ & & & $X$ & & & \\
\hline $\begin{array}{l}\text { Novedad en el uso de conceptos y } \\
\text { procedimientos de la propuesta. }\end{array}$ & & $\mathrm{X}$ & & & & \\
\hline $\begin{array}{l}\text { La modelación contiene propósitos basados } \\
\text { en los fundamentos educativos, curriculares y } \\
\text { pedagógicos, detallado, preciso y efectivo }\end{array}$ & & & $X$ & & & \\
\hline $\begin{array}{l}\text { La propuesta está contextualizada a la } \\
\text { realidad en estudio. }\end{array}$ & & $\mathrm{X}$ & & & & \\
\hline $\begin{array}{l}\text { Presenta objetivos claros, coherentes y } \\
\text { posibles de alcanzar. }\end{array}$ & & $\mathrm{X}$ & & & & \\
\hline $\begin{array}{l}\text { Contiene un plan de acción de lo general } \\
\text { a lo particular. }\end{array}$ & & & $X$ & & & \\
\hline
\end{tabular}


Ficha de validación externa (forma)

\begin{tabular}{|c|c|c|c|c|c|c|c|}
\hline \multirow{2}{*}{\multicolumn{2}{|c|}{ Indicadores }} & \multirow{2}{*}{\multicolumn{3}{|c|}{$\begin{array}{l}\text { Escala de } \\
\text { valoración }\end{array}$}} & \multicolumn{3}{|l|}{ Aspectos } \\
\hline & & & & & \multirow{3}{*}{ Positivos } & \multirow{3}{*}{ Negativos } & \multirow{3}{*}{ Sugerencias } \\
\hline & & \begin{tabular}{l|l}
1 & 2 \\
\end{tabular} & 3 & 4 & & & \\
\hline Claridad & $\begin{array}{l}\text { Es formulado con } \\
\text { lenguaje apropiado }\end{array}$ & & & $x$ & & & \\
\hline Objetividad & $\begin{array}{l}\text { Está expresado en } \\
\text { conductas } \\
\text { observables }\end{array}$ & & & $x$ & & & \\
\hline Actualidad & $\begin{array}{l}\text { Adecuado al avance de } \\
\text { la ciencia pedagógica }\end{array}$ & & & & $X$ & & \\
\hline Organización & $\begin{array}{l}\text { Existe una } \\
\text { organización lógica }\end{array}$ & & & $x$ & & & \\
\hline Suficiencia & $\begin{array}{l}\text { Comprende los aspectos } \\
\text { de cantidad y calidad }\end{array}$ & & & & $X$ & & \\
\hline Intencionalidad & $\begin{array}{l}\text { Adecuado para valorar } \\
\text { los aspectos de las } \\
\text { categorías }\end{array}$ & & & $x$ & & & \\
\hline Consistencia & $\begin{array}{l}\text { Basado en aspectos } \\
\text { teóricos científicos de la } \\
\text { educación }\end{array}$ & & & & $X$ & & \\
\hline Coherencia & $\begin{array}{l}\text { Entre el propósito, } \\
\text { diseño y la } \\
\text { implementación de la } \\
\text { propuesta }\end{array}$ & & & $x$ & & & \\
\hline Metodología & $\begin{array}{l}\text { La estrategia responde al } \\
\text { propósito de la } \\
\text { investigación }\end{array}$ & & & $x$ & & & \\
\hline Pertinencia & $\begin{array}{l}\text { Es útil y adecuado para } \\
\text { la investigación }\end{array}$ & & & & $X$ & & \\
\hline
\end{tabular}

\section{Aportes o sugerencias para el perfeccionamiento del resultado científico:}

\section{Opinión de aplicabilidad.}

La propuesta de modelamiento es aplicable

\section{Resultados}

Promedio de valoración $=\frac{\text { Valoración interna+valoración externa }}{2}$

Resultado de valoración: $\frac{44+44}{2}=44$ 
Escala de valoración

\begin{tabular}{lcc}
\hline Escala & Rango frecuencia & Rango porcentaje \\
\hline Deficiente & {$[10-17]$} & {$[20 \%-35 \%]$} \\
Bajo & {$[18-25]$} & {$[36 \%-51 \%]$} \\
Regular & {$[26-33]$} & {$[52 \%-67 \%]$} \\
Bien & {$[34-41]$} & {$[68 \%-83 \%]$} \\
Muy bien & {$[42-50]$} & {$[84 \%-100 \%]$} \\
\hline
\end{tabular}

\section{Opinión de aplicabilidad:}
a) Deficiente
b) Bajo
c) Regular ( ) d) Bien
) Muy bien (X)

\begin{tabular}{|l|l|c|c|}
\hline Nombres y Apellidos & \multicolumn{1}{|c|}{ José Manuel Muñoz Salazar } & DNI N & 09536793 \\
\hline Dirección domiciliaria & \multicolumn{2}{|l|}{} \\
\hline $\begin{array}{l}\text { Título profesional / } \\
\text { Especialidad }\end{array}$ & Ingeniero Electrónico / Celular & \\
\hline Grado Académico & Doctor en Ciencias de la Educación \\
\hline $\begin{array}{l}\text { Ocupación y año de } \\
\text { experiencia }\end{array}$ & Docente 35 años de experiencia \\
\hline Metodólogo/temático & Metodólogo \\
\hline
\end{tabular}

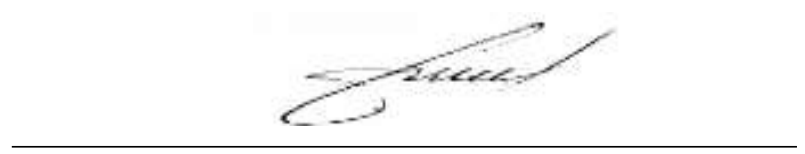

Firma

Lugar y fecha: La Molina, 02 de julio

del 2020 